\title{
THE MANAGEMENT OF POST-CONSUMER PHARMACEUTICAL WASTE: A COMPARISON BETWEEN BRITISH COLUMBIA AND ONTARIO PROGRAMS
}

\author{
by \\ Lisa Kingsmore \\ Bachelor of Science in Chemistry, Winthrop University, 2009 \\ A thesis \\ presented to Ryerson University \\ in partial fulfillment of the \\ requirements for the degree of \\ Master of Applied Science \\ in the Program of \\ Environmental Applied Science and Management
}

Toronto, Ontario, Canada, 2013

CLisa Kingsmore 2013 


\section{Author's Declaration}

I hereby declare that I am the sole author of this thesis. This is a true copy of the thesis, including any required final revisions, as accepted by my examiners.

I authorize Ryerson University to lend this thesis to other institutions or individuals for the purpose of scholarly research.

I further authorize Ryerson University to reproduce this thesis by photocopying or by other means, in total or in part, at the request of other institutions or individuals for the purpose of scholarly research.

I understand that my thesis may be made electronically available to the public. 


\title{
THE MANAGEMENT OF POST-CONSUMER PHARMACEUTICAL WASTE: A COMPARISON BETWEEN BRITISH COLUMBIA AND ONTARIO PROGRAMS
}

\author{
Lisa Kingsmore, \\ Master of Applied Science, 2013 \\ Environmental Applied Science and Management \\ Ryerson University
}

\begin{abstract}
The presence of pharmaceutical waste in the environment is an emerging concern. The challenges of achieving high levels of scientific certainty concerning its impacts has motivated jurisdictions to adopt medications return programs (MRPs) to safely manage the public's postconsumer pharmaceuticals (i.e. unused/expired drugs). There are several variables for governments to consider when implementing MRPs, particularly when based on extended producer responsibility (EPR). This comparative policy analysis examined regulatory MRPs in British Columbia and Ontario as cases to compare and evaluate. It developed 12 criteria for an optimal MRP consistent with EPR practices, including key performance measures, and applied them to evaluate the British Columbia and Ontario programs. It then explored Ontario's revised MRP, launched in 2013, to determine if the positive and negative indicators from British Columbia's long-standing program have been incorporated, and analyzed if policy lessondrawing or policy convergence occurred in practice.
\end{abstract}




\section{Acknowledgements}

I would like to thank my co-supervisors, Dr. Alex Wellington and Dr. Ron Pushchak, for their continued guidance, encouragement and support over the past two years. They both provided invaluable advice, and I am grateful to have had the opportunity to work under their supervision. I would also like to thank my examination committee members, Dr. Carolyn Johns and Dr. Kernaghan Webb, for taking the time to participate in my committee.

This research was supported by the Social Sciences and Humanities Research Council (SSHRC), Ontario Graduate Scholarship (OGS), and National Collegiate Athletic Association (NCAA) Postgraduate Scholarship. 


\section{Table of Contents}

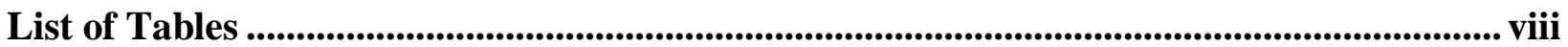

List of Figures.................................................................................................................................... ix

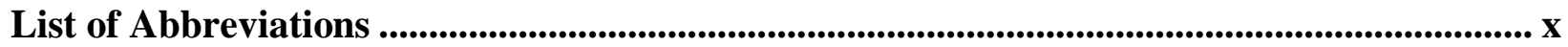

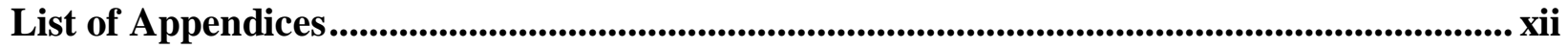

Chapter 1: Introduction ................................................................................................................................. 1

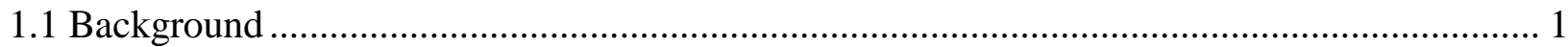

1.2 Gaps in Current Knowledge ....................................................................................... 3

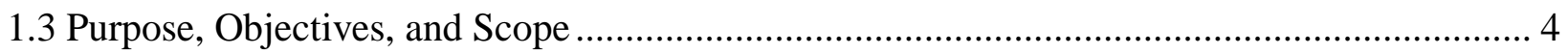

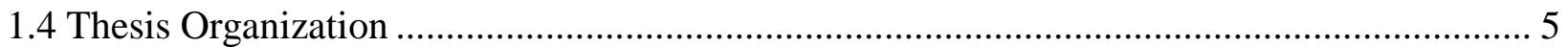

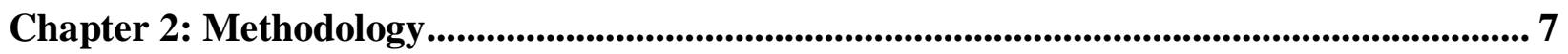

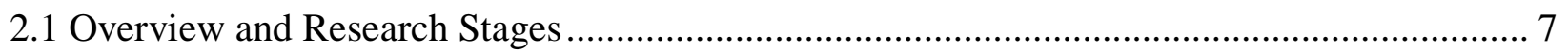

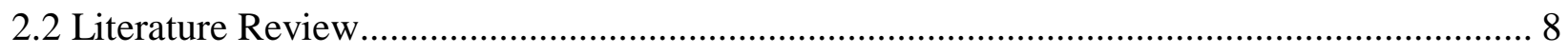

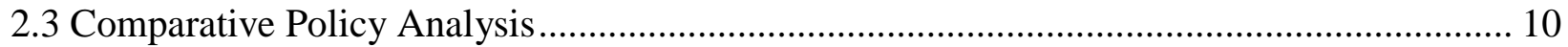

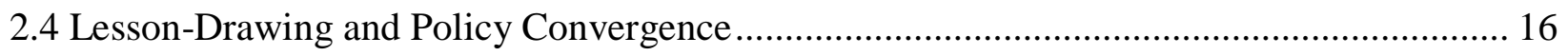

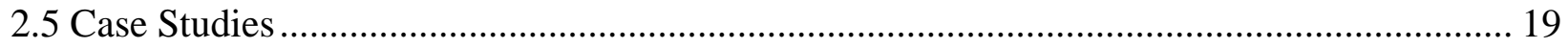

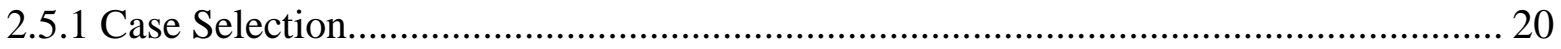

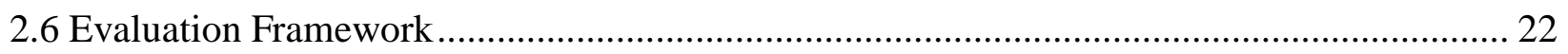

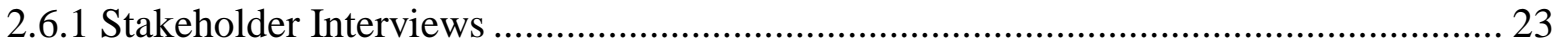

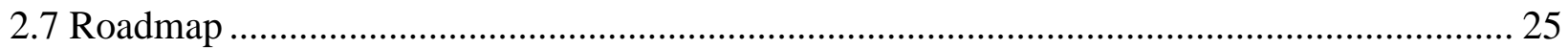

Chapter 3: Step 1 - Literature Review on Pharmaceuticals in the Environment ................. 26

3.1 History of Detecting Pharmaceuticals in the Environment............................................. 26

3.2 Concerns with Pharmaceuticals in the Environment .................................................... 28

3.3 Sources and Pathways into the Environment.............................................................. 31

3.4 Management Strategies in a Comparative Context ........................................................ 36

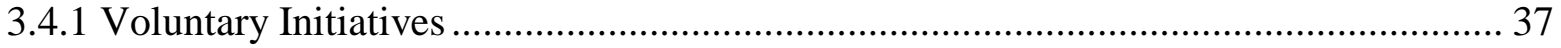

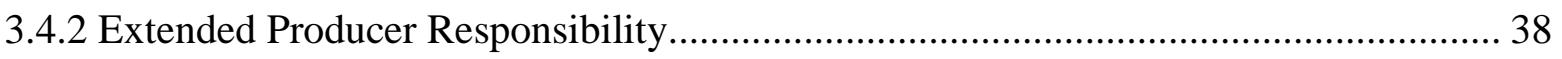

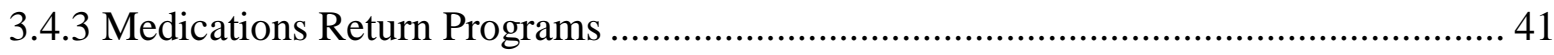

3.4.4 Criteria for an Optimal Medications Return Program Based on EPR ....................... 43

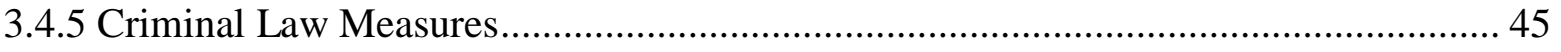

3.4.6 Environmental Risk Assessment Policies............................................................. 46 
3.5 Examples of Management Strategies ............................................................................. 48

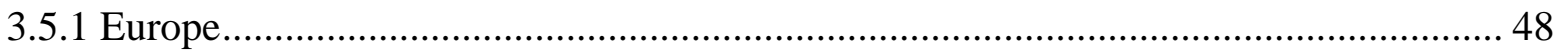

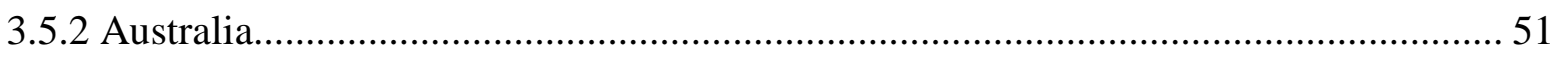

3.5.3 United States .................................................................................................. 52

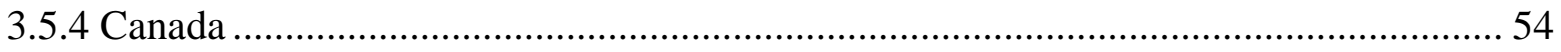

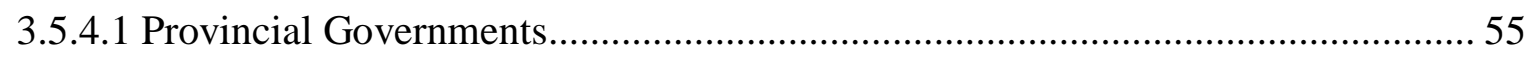

3.5.4.2 Municipal Governments............................................................................ 58

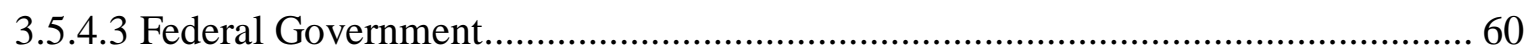

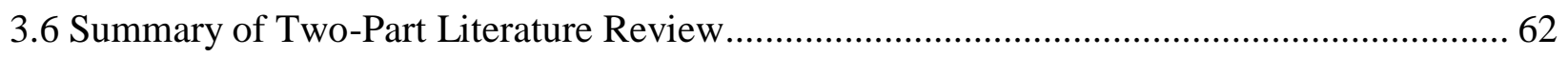

Chapter 4: Setting the Context for Analyzing British Columbia and Ontario ....................... 64

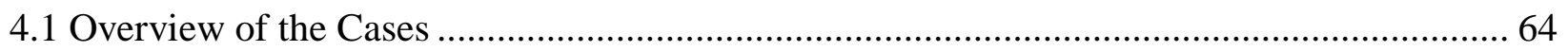

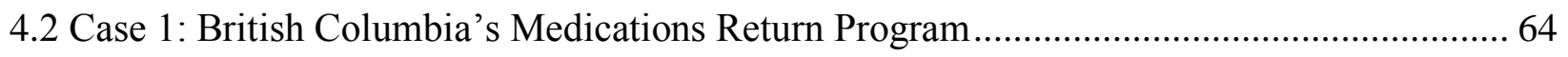

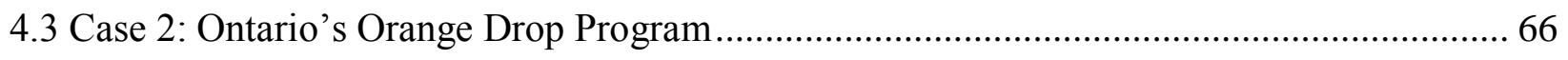

4.4 Case 3: Ontario's New Medications Return Program................................................................. 70

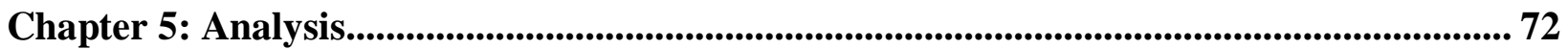

5.1 Step 2: Comparative Policy Analysis - BC's Medications Return Program vs. Ontario's

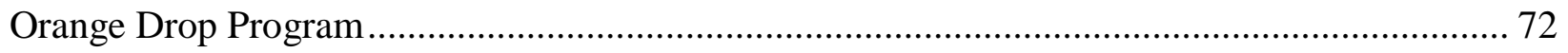

5.1.1 Stakeholder Roles and Responsibilities.............................................................. 72

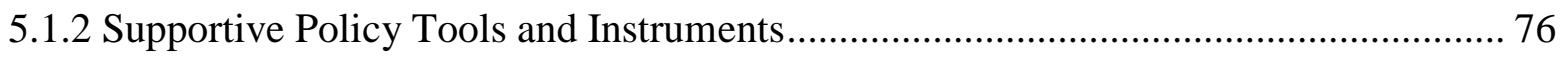

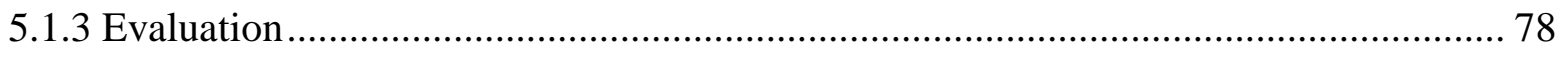

5.1.3.1 Achieving Policy Goals ................................................................................. 78

5.1.3.2 Stakeholder Perceptions.................................................................................. 83

5.1.3.3 Meeting Criteria for an Optimal Return Program ................................................ 87

5.2 Step 3: Lesson Drawing \& Policy Convergence........................................................................ 96

5.3 Step 4: Comparative Policy Analysis - Ontario's Orange Drop Program vs. Ontario's

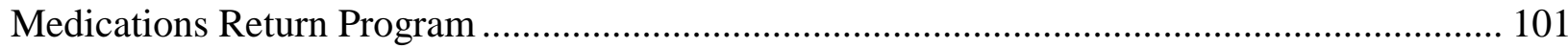

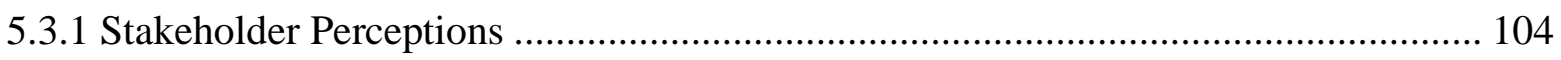

5.4 Step 5: Lesson-Drawing \& Policy Convergence ………………………………….............. 107

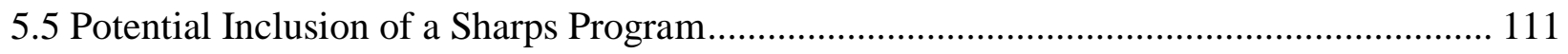

5.6 Summary of Lesson-Drawing \& Policy Convergence............................................................ 113 
Chapter 6: Conclusion .................................................................................................................................... 115

Chapter 7: Policy Recommendations and Directions for Future Research .......................... 118

Appendices ...................................................................................................................................................... 123

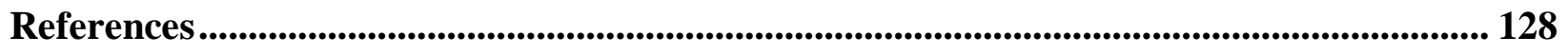




\section{List of Tables}

Table 1. Stakeholder Groups Interviewed in British Columbia and Ontario..............................24

Table 2. PhACs Detected in Finished Drinking Water Worldwide .........................................27

Table 3. Removal Efficiency of PhACs from Conventional \& Advanced Wastewater

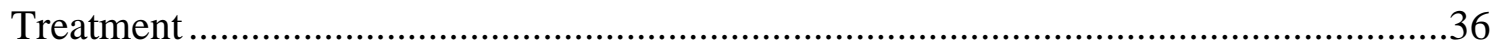

Table 4. Benefits and Disbenefits of Voluntary EPR Programs ...............................................40

Table 5. Benefits and Disbenefits of Regulatory EPR Programs ...........................................40

Table 6. Potential Economic, Environmental and Health Benefits of MRPs .............................43

Table 7. Criteria for an Optimal Medications Return Program Based on EPR ..........................44

Table 8. Risk Assessment vs. the Precautionary Approach .....................................................4

Table 9. Number of Pharmaceuticals Sold and Returned through European Return Programs ...49

Table 10. Collection Systems in Canada for Unused/Expired Drugs ........................................57

Table 11. Stakeholders' Responsibilities in BC's Medications Return Program .......................74

Table 12. Stakeholders' Responsibilities for Managing Pharmaceutical Waste in Ontario's

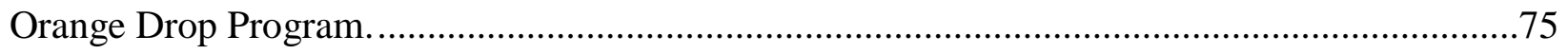

Table 13. Supportive Policy Tools for BC's and Ontario's Respective Return Program.............78

Table 14. Promotion \& Education in 20 Pharmacies Participating in BC's Medications Return

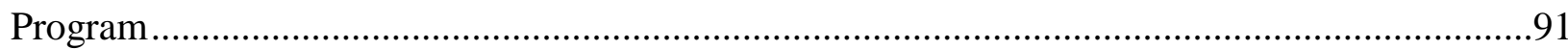

Table 15. Evaluation of BC's MRP and Ontario's Orange Drop Against Criteria for an Optimal

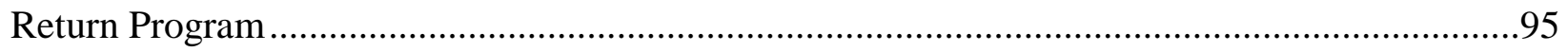

Table 16. Positive Indicators Present in Ontario’s new Medications Return Program ..............109

Table 17. Negative Indicators Avoided in Ontario's new Medications Return Program ...........109

Table 18. Advantages and Disadvantages of Regulating Sharps under an EPR Framework ......113 


\section{List of Figures}

Figure 1. The Five Research Stages..............................................................................

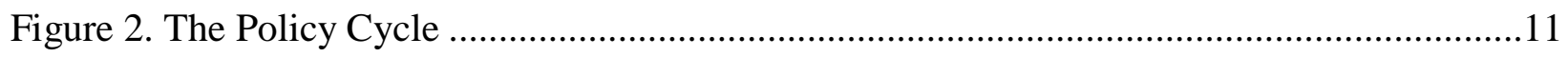

Figure 3. Stakeholders Involved in BC's Medications Return Program ...................................13

Figure 4. Stakeholders Involved in ON's Orange Drop Program (For Managing Pharmaceutical

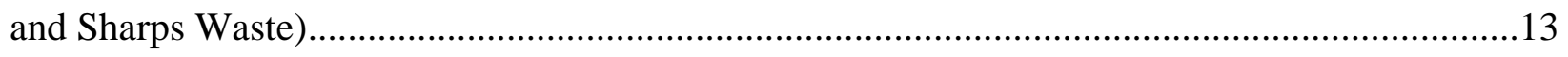

Figure 5. Stakeholders Involved in ON's Revised Medications Return Program .......................14

Figure 6. Most Frequently Detected Compounds in Untreated Source \& Finished Drinking

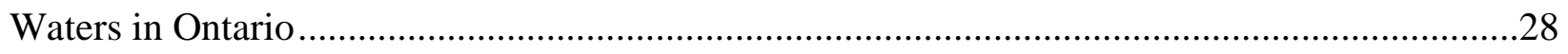

Figure 7. Sources and Pathways of PhACs into the Environment..............................................32

Figure 8. Comparing the Number of Prescriptions Filled in Canada in 1999 and 2011 ...............32

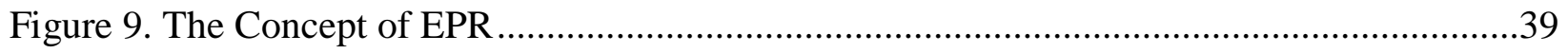

Figure 10. Management of Post-Consumer Pharmaceuticals \& Sharps in Ontario Since the 1990s 


\section{List of Abbreviations}

BC British Columbia

BC MOE British Columbia Ministry of Environment

CAP Canada-wide Action Plan

CCME Canadian Council of Ministers of the Environment

CEPA Canadian Environmental Protection Act

CMA Canadian Medical Association

CSR Corporate Social Responsibility

EA Environmental Assessment

ECO Environmental Commissioner of Ontario

EEA European Environment Agency

EIC Estimated Introduction Concentration

EMA Environmental Management Act

EMA European Medicines Agency

ENGO Environmental Non-Governmental Organization

EPA Environmental Protection Act

EPR Extended Producer Responsibility

ERA Environmental Risk Assessment

EU European Union

F\&DA Food and Drugs Act

HPSA Health Products Stewardship Association

IC\&I Industrial, Commercial or Institutional

IWMC Island Waste Management Corporation

MHSW Municipal Hazardous or Special Waste

MOE Ministry of the Environment

MRP Medications Return Program

NACPDM National Advisory Committee on Prescription Drug Misuse

NSNR New Substances Notification Regulations

OECD Organisation for Economic Co-operation \& Development

OMA Ontario Medical Association 
ON MOE Ontario Ministry of the Environment

OWMA Ontario Waste Management Association

P\&E Promotion and Education

PCPSA Post-Consumer Pharmaceutical Stewardship Association

PEC Predicted Environmental Concentration

PhACs Pharmacologically Active Compounds

PNEC Predicted No-Effect Concentration

RCO Recycling Council of Ontario

RUM Return Unwanted Medicines

RxA Alberta Pharmacists' Association

SO Stewardship Ontario

STP Sewage Treatment Plant

U.S. United States

U.S. DEA United States Drug Enforcement Administration

U.S. EPA United States Environmental Protection Agency

U.S. FDA United States Food and Drug Administration

WDA Waste Diversion Act

WDO Waste Diversion Ontario

WHO World Health Organization 


\section{List of Appendices}

Appendix A. Rexall's Poster and Brochure for Promoting Safe Drug Disposal .......................123

Appendix B. Brochure at View Street Pharmacy about BC's Medications Return Program......124

Appendix C. Brochure at Safeway Food \& Drug Regarding Proper Drug Disposal .................125

Appendix D. Poster at Shoppers Drug Mart Regarding Proper Drug Disposal.........................126

Appendix E. London Drugs’ Poster about Safe Sharps Disposal and Brochure about

Drug Safety 


\section{Chapter 1: Introduction}

\subsection{Background}

The increasing presence of pharmaceuticals and their metabolites, known in the literature as pharmacologically active compounds (PhACs), in the environment is an emerging international issue. Over the last two decades, several studies have detected PhACs in groundwater (Barnes et al., 2004; Fram \& Belitz, 2011; Sacher, Lange, Brauch, \& Blankenhorn, 2001), surface water (Hua, Bennett, Maio, Metcalfe, \& Letcher, 2006; Kolpin et al., 2002; Ternes, 1998), and soil (Edwards et al., 2009; Song, Ding, Chiou, \& Li, 2010; Topp et al., 2008). PhACs have also been detected in drinking water (Benotti et al., 2009; Ontario Ministry of the Environment [ON MOE], 2010a; Ternes et al., 2002).

The major concern of PhACs is their ability to act as endocrine disruptors and to decrease fertilization success in non-target species like fish (Environment Canada, 2012a). Scientists have not quantified the human health risks of $\mathrm{PhACs}$ but are concerned about the health impacts associated with exposure to a mixture of drugs in the environment (Canadian Medical Association [CMA] \& Collier, 2012). Human excretion of drugs has been recognized as the main route of entry into the environment; however, disposal practices also contribute (Health Canada, 2009; Ternes, 1998). Many consumers dispose of their unused drugs in the garbage or down the drain/toilet. Since sewage treatment plants (STPs) are not designed to treat all PhACs, these substances can pass through the treatment process and are then discharged into the environment (Health Canada, 2009; Ternes, 1998).

Several jurisdictions around the world have chosen to address this problem by providing the public with a medications return program (MRP), sometimes called disposal programs, collection programs or take-back schemes. These programs allow consumers to return their postconsumer pharmaceuticals ${ }^{1}$ to a pharmacy/collection depot for safe treatment and disposal, usually using incineration (Health Canada, 2009). Medications return programs tend to embrace the "polluter pays" or extended producer responsibility (EPR) concept. The Organisation for Economic Co-operation \& Development (OECD, 2001) has defined EPR as "an environmental policy approach in which a producer's responsibility, physical and/or financial, for a product is

\footnotetext{
${ }^{1}$ Post-consumer pharmaceuticals are unused or expired pharmaceuticals (prescription and nonprescription drugs) that are no longer deemed usable by the consumer.
} 
extended to the post-consumer stage of a product's life cycle" (p. 18). This widely used policy approach places responsibility on the producers, as opposed to governments and taxpayers, to fund the costs of diverting their product's waste from the environment. There can be distinct goals and motivations for EPR, including fiscal/financial, environmental, and public health or other social benefits.

In Canada, there are various provincial and local collection systems in place for the public's post-consumer drugs. Some systems are voluntary, as seen in Alberta and Saskatchewan, while others are regulated programs, as seen in Manitoba. Since 1999, the British Columbia Ministry of Environment (BC MOE) has monitored Canada's longest running, provincially regulated return program called the British Columbia (BC) Medications Return Program. This program allows consumers to return their unused drugs and natural health products to pharmacies for safe disposal. This program is funded by the drug and health product industries and supported by provincial regulation. On July 1, 2010, the Ontario Ministry of the Environment (ON MOE) attempted to implement a similar initiative for various hazardous waste materials, including drugs, called the Orange Drop Program; however, a mere nineteen days after implementation, the MOE suspended and ultimately ended the program.

Both provinces had similar policy goals which included the development and implementation of a return program to reduce the potential environmental and health impacts of PhACs, and to shift the financial responsibility to the drug producers through EPR. However, the programs resulted in different outcomes. BC's MRP has been operating for more than fourteen years, whereas Ontario's Orange Drop Program failed within weeks of implementation. There is a need for comparative policy analysis research to explore why this happened.

Although scientific uncertainties exist regarding the risks of PhACs in the environment, policymakers have implemented and continue to implement management frameworks to mitigate this problem. For instance, on October 1, 2012, more than two years after the Ontario MOE suspended the Orange Drop Program, a new regulation (O. Reg. 298/12) enacted under the Environmental Protection Act (EPA, 1990) came into force for managing post-consumer pharmaceuticals and sharps (needles, lancets and syringes). This regulation holds individual producers of drugs and sharps responsible for operating a collection system in Ontario.

There is a critical need for research to investigate and evaluate management frameworks used to reduce PhACs in the environment now, rather than waiting years for the science to 
evolve. The challenges of achieving high levels of scientific certainty concerning the potential impacts of PhACs helps to motivate a management approach which focuses on policy options for the disposal of unused drugs, and there are a number of variables for governments to consider when adopting such policy measures. There is sufficient knowledge, development, and experiences available for making policy comparisons, particularly within the Canadian context.

\subsection{Gaps in Current Knowledge}

There are some gaps in what is currently known regarding the effects of PhACs in the environment. Scientific studies have shown that drugs, such as synthetic estrogen used in birth control pills, can pass through STPs once excreted and have the potential to inhibit male fish sexual characteristics (Environment Canada, 2012a; Kidd et al., 2007; Ternes et al., 1999). However, science has not yet quantified the biological effects in fish posed by a mixture of drugs in wastewater effluent, sometimes referred to as a "cocktail" of compounds (Environment Canada, 2012a; Escher et al., 2005; Kümmerer, 2004). It is challenging to predict the behaviour of these pharmaceutical cocktails and conclusively determine the impacts on fish of substances that are present in STP effluent in parts-per-billion or even parts-per-trillion concentrations.

There are also uncertainties regarding the human health risks associated with PhACs. The concentrations of drugs in the environment that pose toxic effects on humans have not yet been extensively measured. A review of the literature by this author did not find any published studies establishing direct human health risks of exposure to trace levels of drugs in the environment. Since there are uncertainties regarding the risks and long term impacts, some may argue that there are no demonstrable objective risks.

These scientific uncertainties challenge policymaking as it forces decision makers to determine how much potential risk is acceptable and how much scientific information is sufficient to warrant action. Although there are gaps in the science, there is a sufficient amount of concern in the scientific literature and by policymakers to take precautionary measures to protect both the environment and human health. How governments apply (or do not apply) the Precautionary Principle ${ }^{2}$ as it relates to pharmaceuticals in the environment seems to play an

\footnotetext{
${ }^{2}$ One of the most widely used definitions of this principle was announced at the Wingspread Conference on the Precautionary Principle (1998): "When an activity raises threats of harm to human health or the environment, precautionary measures should be taken even if some cause and effect relationships are not fully established scientifically."
} 
important role in managing this complicated type of waste.

There are also gaps in the current knowledge from a policy perspective. Health Canada (2009) provided an overview of return programs for post-consumer pharmaceuticals in Canada and other countries, and summarized key aspects from each initiative. However, this report did not evaluate the programs, and it did not draw lessons through comparison of the different initiatives. Similarly, Imm (2010) conducted an evaluation of BC's Medications Return Program for managing unused/expired drugs. This study provided a detailed examination of BC's framework but there was little discussion or comparison with Ontario. Also, the Northwest Product Stewardship Council's (2009) study reviewed several waste diversion programs in Canada, including provincial programs for managing post-consumer pharmaceutical waste. This report analyzed waste management legislation and program models; however, as stated by the authors, the paper was "intended to be descriptive only, not to be an evaluation or to provide recommendations" (Northwest Product Stewardship Council, 2009, p. 1).

Overall, there is a lack of policy research that compares the different strategies that have been implemented by Canadian provinces to manage pharmaceuticals in the environment. Both $\mathrm{BC}$ and Ontario implemented waste management policies not only to reduce drugs in the environment, but also to shift the financial responsibility of collection and disposal from government to drug producers. Although the programs had similar policy goals, they have resulted in different outcomes. BC's Medications Return Program has been operating for more than fourteen years, whereas Ontario's initial Orange Drop Program failed within weeks of implementation. Thus, it is crucial to compare and evaluate the programs to determine whether adopting approaches from $\mathrm{BC}$ is worth pursuing in Ontario and other jurisdictions.

\subsection{Purpose, Objectives, and Scope}

The overall purpose of this research is to investigate, compare, and evaluate BC's and Ontario's program for managing post-consumer pharmaceutical waste. Within this central research goal, there are four key objectives/research questions:

1) Why did BC's Medications Return Program and Ontario's Orange Drop Program result in different outcomes? How effective are the programs - did the programs achieve the intended policy goals and objectives, and meet the criteria for an optimal MRP? (The evaluation framework is described further in Section 2.6). 
2) What positive and negative lessons can be drawn from BC's long-standing program based on its evaluation against the criteria for an optimal MRP?

3) How does Ontario's revised regulatory program for managing post-consumer pharmaceuticals compare with the previously implemented Orange Drop Program?

4) What positive and negative indicators can be identified in Ontario's revised program based on the lessons learned from BC's MRP? Is there evidence of policy convergence or policy lesson-drawing taking place by the Ontario policy actors?

Throughout this research, the terms "drugs," "pharmaceuticals," and "medications" are used interchangeably. When discussions are made about Ontario's Orange Drop Program, it is usually in reference to Phases 2 and 3 of the program that were launched on July 1, 2010 (which managed several hazardous waste materials including drugs and sharps). Although pharmaceuticals can be discharged into the environment from various sources and pathways, as described further in Chapter 3, this research focuses on the management of post-consumer pharmaceuticals - unused or expired drugs that are no longer deemed usable by the consumer. Key reasons as to why drugs go unused are due to a modification in treatment; consumer perception regarding the need for the drug; consumer perception regarding the effectiveness of the drug; safety associated with the drug (e.g. the drug expired); the consumer experienced unwanted side effects; or consumer death (Brushin, 2005).

MRPs have limitations since they focus on collecting and disposing of waste from individual, residential users. Pharmaceutical waste generated in hospitals, doctor's offices, dentist's offices, and other health care systems are often outside the scope of these programs. Return programs also have limitations since they collect and manage waste that has been returned by a consumer to a collection site, and thus do not include waste that has been metabolized after human consumption. However, since many medications go unused, return programs can prevent these substances from entering the environment.

\subsection{Thesis Organization}

This thesis consists of seven chapters. The methodology is set out in Chapter 2 which begins with an overview of the research stages. This chapter also reviews the literature on comparative policy analysis, policy lesson-drawing and policy convergence; identifies why the programs in $\mathrm{BC}$ and Ontario were chosen as cases for policy comparison; and reviews how the 
programs were evaluated. An extensive literature review of pharmaceuticals in the environment is conducted in Chapter 3 which analyzes the concerns with PhACs in the environment, the sources and pathways into the environment, and the management strategies used to mitigate the problem. Chapter 4 provides an overview of the medications return programs in British Columbia and Ontario to set the context prior to evaluation.

A comparative policy analysis is conducted in Chapter 5 in which the British Columbia and Ontario programs were used as cases to compare and evaluate. To evaluate the effectiveness of the programs, it was determined whether the MRPs met the overarching policy goals and objectives, and whether they achieved the criteria for an optimal MRP (as discussed in Section 2.6). This chapter also examines the positive and negative indicators identified in Ontario's revised MRP based on the lessons learned from BC, and assesses whether policy convergence or policy lesson-drawing has taken place in practice. A conclusion is made in Chapter 6 followed by policy recommendations for stakeholder groups, and opportunities for future research in Chapter 7. 


\section{Chapter 2: Methodology}

\subsection{Overview and Research Stages}

An extensive literature review was first conducted to explore the fundamental environmental problem: the increasing presence of PhACs in the environment. This is seen in Chapter 3 which thoroughly analyzes the scientific literature on drugs in the environment, and the management strategies used by jurisdictions to deal with this issue. It is clear that there are scientific uncertainties embedded within this environmental problem. Several questions have been raised: What are the cumulative effects of drugs in the environment? What are the long term risks of human exposure to a mixture of $\mathrm{PhACs}$ in the environment? Currently, these cannot be answered definitively using science. The scientific evidence, although very important, cannot solely be used to explain how to manage this problem. As described by the Apoteket AB, the National Corporation of Swedish Pharmacies (2006), "Waiting for the results of more research may not only take decades but the new knowledge may identify previously unknown sources of both uncertainty and ignorance, as awareness of what we do not know expands" (p. 129).

Considering the Precautionary Principle and recognizing that there is a gap in the science, this research approach looked to comparative policy analysis to compare and evaluate the effectiveness of medications return programs in selected cases, and to develop policy recommendations for improving and enhancing the effectiveness of these programs. As displayed in Figure 1, the approach for this research consisted of five steps, and policy recommendations were made at the end:

1) Two-Part Literature Review - Review of the scientific literature and the management strategies literature.

2) Comparative Policy Analysis - BC's MRP and Ontario's initial Orange Drop Program were investigated, compared and evaluated. The evaluation measured the effectiveness of these programs based on achieving the intended policy goals and objectives, and meeting the criteria for an optimal MRP (outlined in Section 2.6). This step addressed the first research objective as set out in Section 1.3.

3) Lesson-Drawing and Policy Convergence - Positive and negative lessons were drawn from BC's mature program based on its achievement of the criteria for an optimal MRP. This step related to the second research objective. 
4) Comparative Policy Analysis - Ontario's revised Medications Return Program (regulated under O. Reg. 298/12) was examined and compared with the previous Orange Drop Program. This addressed the third research objective.

5) Lesson-Drawing and Policy Convergence - The positive and negative indicators in Ontario's revised MRP were identified based on the lessons learned from BC's MRP. It was also determined whether policy convergence or policy lesson-drawing took place by the Ontario policy actors. This step investigated the fourth research objective.
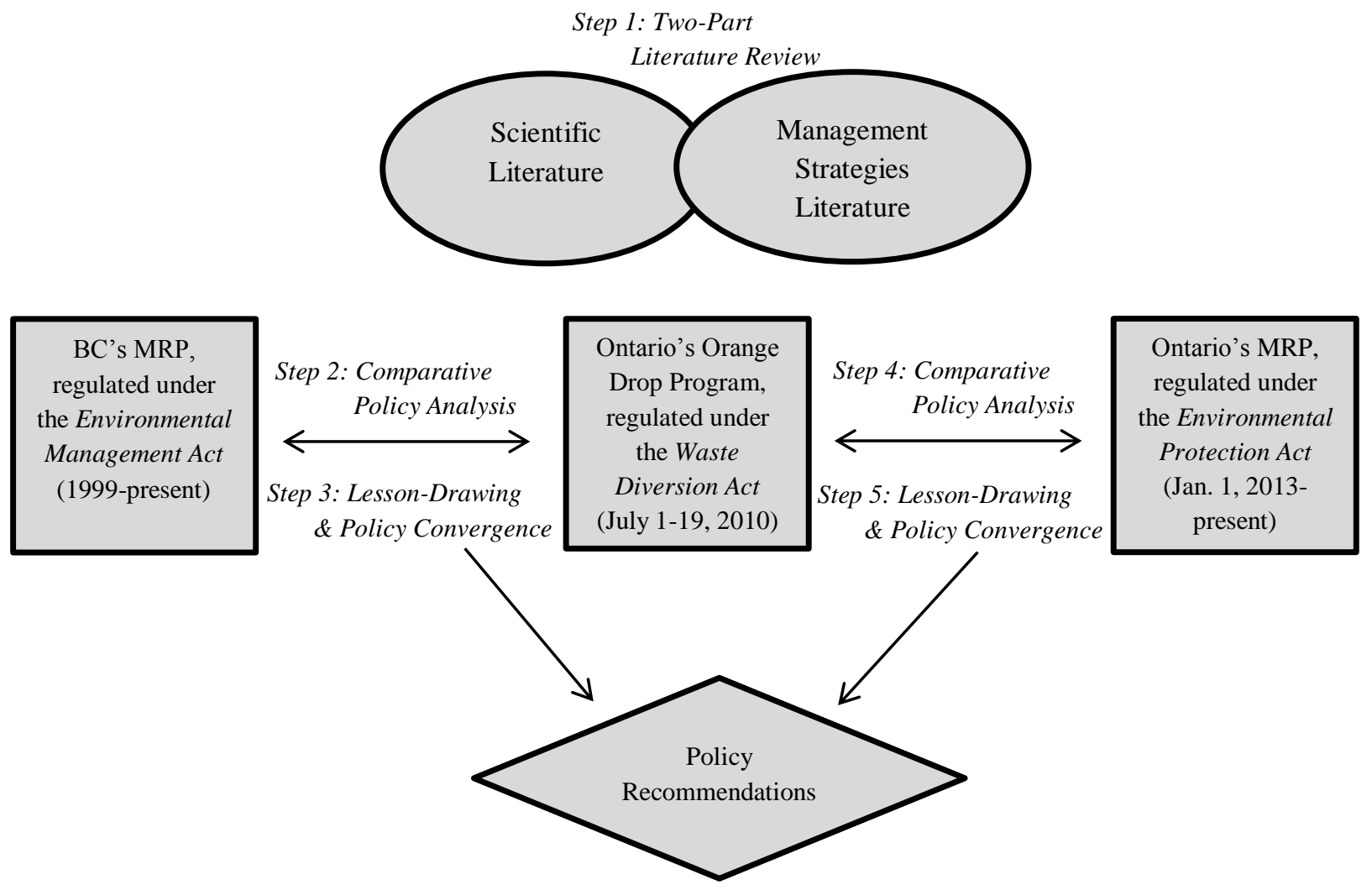

Figure 1. The Five Research Stages

\subsection{Literature Review}

The literature review for this thesis consisted of two parts: the scientific literature and the management strategies literature.

As seen in Sections 3.1 - 3.3, the scientific literature review analyzed the history of science detecting pharmaceuticals in the environment, the concerns and potential risks, and the sources and pathways of drugs into the environment. Although the main pathway of drugs entering the environment is through human consumption followed by excretion, the literature 
revealed that disposal practices of unused/expired drugs also contribute to the problem. The science has identified concerns with trace levels of PhACs in the environment, particularly for non-target species like aquatic life; however, the degree to which human health is directly impacted is unknown. Although there are scientific uncertainties associated with this waste, many jurisdictions have applied the Precautionary Principle by adopting strategies to reduce the potential harms associated with $\mathrm{PhACs}$.

This led to the second component of the literature review, as seen in Sections 3.4 - 3.6, in which a jurisdictional scan was conducted to investigate and compare the management strategies used by various jurisdictions to mitigate the problem. It was revealed that medications return programs are the most common management approach used by policymakers and they tend to embrace the concept of extended producer responsibility (either as regulated by government or as a voluntary initiative).

In Canada, policies and programs related to the environment and pharmaceutical waste management are most appropriately studied at the provincial level within an intergovernmental context. Waste management issues in Canada are mainly governed under provincial jurisdiction which has led to great variation in waste policies at the sub-national level. Dunn (1996a) claimed that Canada has long been a decentralized nation-state, and "[s]ince Canadian provinces have an unusually extensive array of powers for subnational governments, it is important what provincial cabinets do and how they do it" (p. 165). It is argued in the policy literature that Canadian provinces have more authority regarding environmental issues than American states $\mathrm{do}^{3}$. For instance, VanNijnatten and Boychuck (2006) have argued that "Canadian provincial governments are constitutionally more powerful and more independent than are American state governments in most areas of environmental policy-making and standard-setting” (p. 495). As summarized by Imbeau and Lachapelle (1996):

According to a widespread explanation, the weakness of centripetal forces in Canada results in the absence of a national identity shared by all Canadian provinces, thus contributing to the interprovincial variation in policy decisions. Provinces have created and developed over the years their own policies, values and symbols. (p. 405)

\footnotetext{
${ }^{3}$ Comparative research between the U.S. and Canada is a large topic that is beyond the scope of this present work. This topic was raised to emphasize the decentralized structure in Canada.
} 
Since pharmaceuticals are used to promote health and to treat illnesses, it is politically easier for governments to focus on disposal policies versus human consumption policies. Section 3.4.4 outlines the development of the criteria for an optimal MRP (which is used in Chapter 5 to evaluate the effectiveness of the programs in British Columbia and Ontario).

Overall, it was important to review both the scientific and management strategy literature to understand how governments have implemented policies and schemes to deal with the complexities and uncertainties associated with PhACs in the environment.

\subsection{Comparative Policy Analysis}

This section provides a review of the comparative policy literature to understand its benefits and limitations, and how it was applied in this study.

As described by Knoepfel, Larrue, Varone, \& Hill (2007), "All policies aim to resolve a public problem that is identified as such on the governmental agenda. Thus, they represent the response of the political-administrative system to a social reality that is deemed politically unacceptable" (p. 21). Policies can also aim to generate social benefits or to improve human welfare. As defined by Greenbaum and Wellington (2010), "A policy incorporates general goals and sets out acceptable procedures, techniques, strategies, or tools (often referred to in the policy literature as instruments) for moving forward" (p. 226-227).

The "policy cycle" is widely used in the literature to illustrate the phases of the decision and implementation processes in policymaking. As seen in Figure 2, the policymaking process is characterized as a continuous flow of decisions and procedures. It begins with the emergence and perception of a problem or the identification of a social benefit to be pursued, followed by agenda setting ${ }^{4}$. The policy goals are identified in phase 3 . A broad policy goal for most environmental issues is to protect the environment and human health in a cost-effective way. In phase 4 , actors of the political-administrative system are faced with the challenging task of formulating solutions and selecting the proper tools and instruments to resolve the problem.

Once the chosen policy instrument has been selected, implementation takes place. This consists of the application of selected solutions and the actions of political actors to address the problem (Knoepfel et al., 2007). As explained by Greenbaum and Wellington (2010),

\footnotetext{
${ }^{4}$ As defined by Knoepfel et al. (2007), "The agenda-setting phase corresponds to the consideration by the key actors of the political-administrative system of the numerous requests for action made by social groups or even the public services themselves" (p. 32).
} 
"Implementation involves a choice of policy instruments . . and a multitude of decisions regarding the detailed rules and standards that will give shape and effect to those instruments. Implementation [can be] carried out by means of regulations enacted under 'enabling' legislation" (p. 234). This phase involves the allocation of resources such as the staffing of a bureaucracy to develop, operate and enforce the policy option.

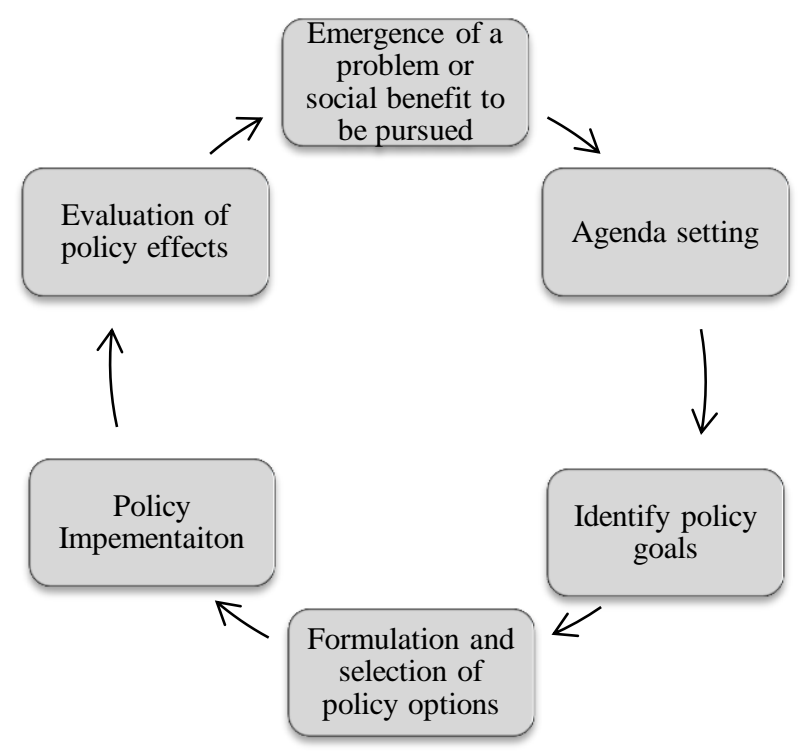

Figure 2. The Policy Cycle (Adapted from Knoepfel et al., 2007).

The central purpose of this research was to compare and evaluate return programs for managing post-consumer pharmaceuticals implemented by $\mathrm{BC}$ and Ontario. Hence, the implementation phase was the main stage in the policy cycle analyzed in this comparative study. Return programs not only create key environmental benefits (such as reducing PhACs in the environment), they also have the potential to generate significant social benefits (such as promoting the return of unused drugs versus accumulating this waste in the household). The benefits of return programs are analyzed further in Chapter 3.

Comparative studies are a well-established approach for studying comparative policy. As articulated by Dunn (1996b), “The benefits of comparative studies are well-known. They allow governments to recognize their relative position in the policy networks of the polity" (p. 9). Comparative studies gained popularity in the 1980s when government and industry developed a keen interest in reducing trade barriers by harmonizing regulations (Jasanoff, 2005). They were 
seen as a useful instrument for advancing well-recognized social objectives and providing helpful lessons to improve the effectiveness of administrative institutions (Jasanoff, 2005).

Comparative policy analysis involves an investigation of why and how policymakers implemented specific policies (Bennett, 1991; Cyr \& deLeon, 1975; Dolowitz \& Marsh, 1996; Dunn, 1996b; Howlett \& Lindquist, 2004; Radin \& Boase, 2000). Comparative policy analysis can provide insight regarding the public policy characteristics of a jurisdiction, such as political competition, cultural setting and governmental structures (Cyr \& deLeon, 1975). By analyzing and comparing experiences in different environments, this may allow policymakers to gain a new understanding of how to manage a problem. This can help policymakers pinpoint strengths and weaknesses with existing management approaches, and can increase their knowledge of their own system (Kamieniecki \& Sanasarian, 1990).

A common feature analyzed in comparative policy analysis is stakeholder identification. This involves outlining the individuals, groups or organizations that are affected by or have an interest in the proposed policy. As described by Knoepfel et al. (2007), policy is a "series of decisions or activities resulting from structured and recurrent interactions between different actors, both public and private, who are involved in various different ways in the emergence, identification and resolution of a problem defined politically as a public one" (p. 39). Stakeholders vary depending on the issue but common players include: governments, public sector agencies, private organizations, shareholders, interest groups, non-profit organizations, individuals, media, scientific experts, academics, and legal officials/courts.

Each stakeholder can have the potential to influence the way in which problems are framed and policies are developed. The political arena is competitive with several groups voicing their opinions and using financial, social or moral resources to sway the development of the policy in their favour (Greenbaum \& Wellington, 2010, p. 228). Although it is easier for policymakers to focus on the most active (and most resourceful) groups, if they ignore the less dynamic (and less resourceful) groups, then there is the potential of neglecting key elements in understanding the policy issue at hand.

Figures 3, 4 and 5 show the stakeholder groups involved in BC's Medications Return Program, Ontario's previously implemented Orange Drop Program, and Ontario's revised MRP launched on January 1, 2013, respectively. The roles and responsibilities of the stakeholders are analyzed in Chapter 5. 


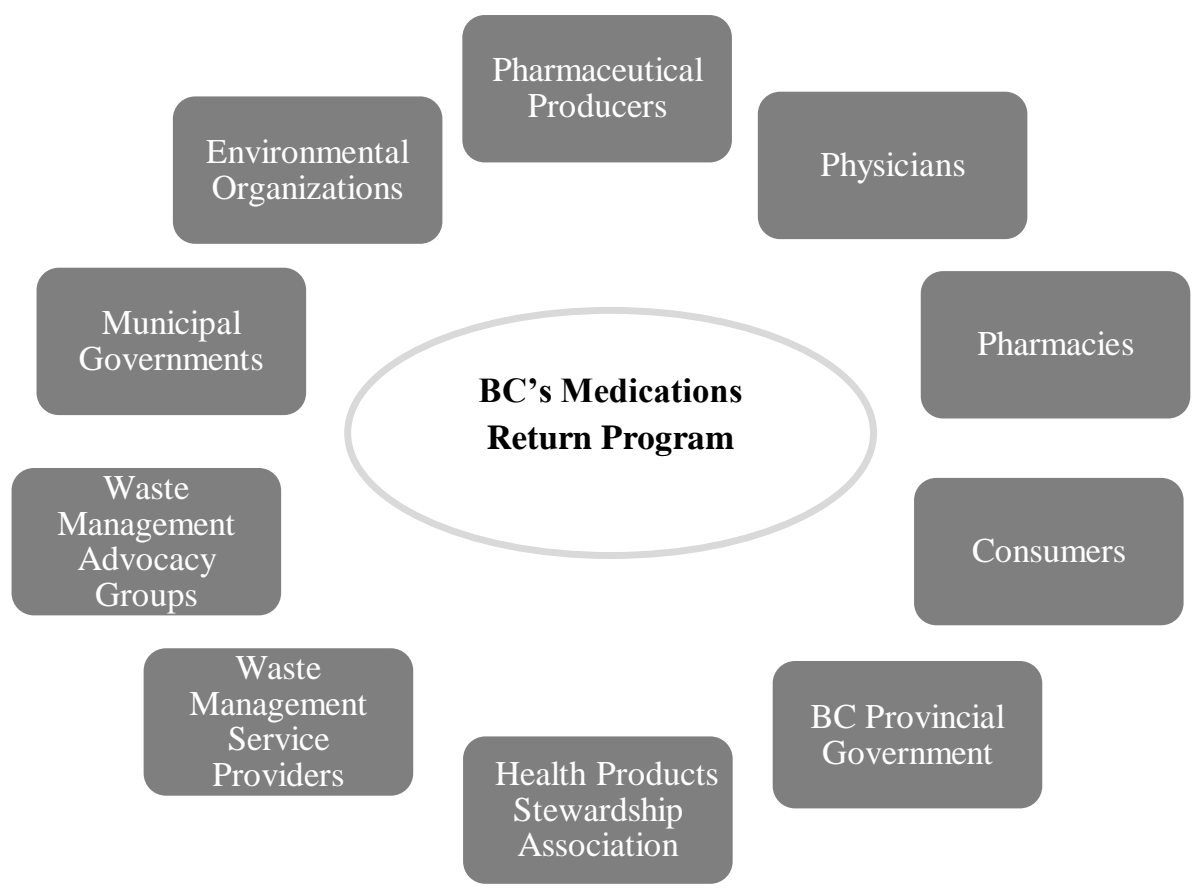

Figure 3. Stakeholders Involved in BC's Medications Return Program

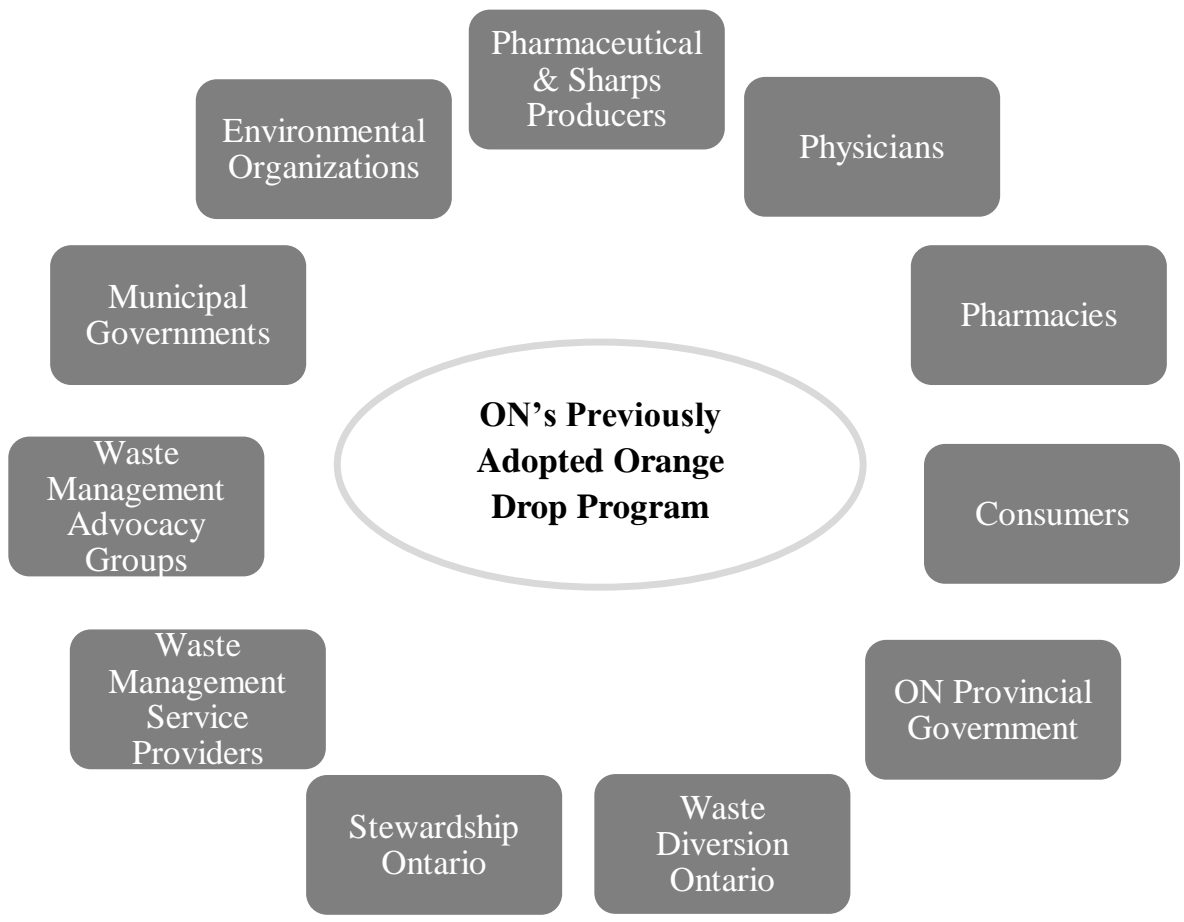

Figure 4. Stakeholders Involved in ON's Orange Drop Program (For Managing Pharmaceutical and Sharps Waste) 


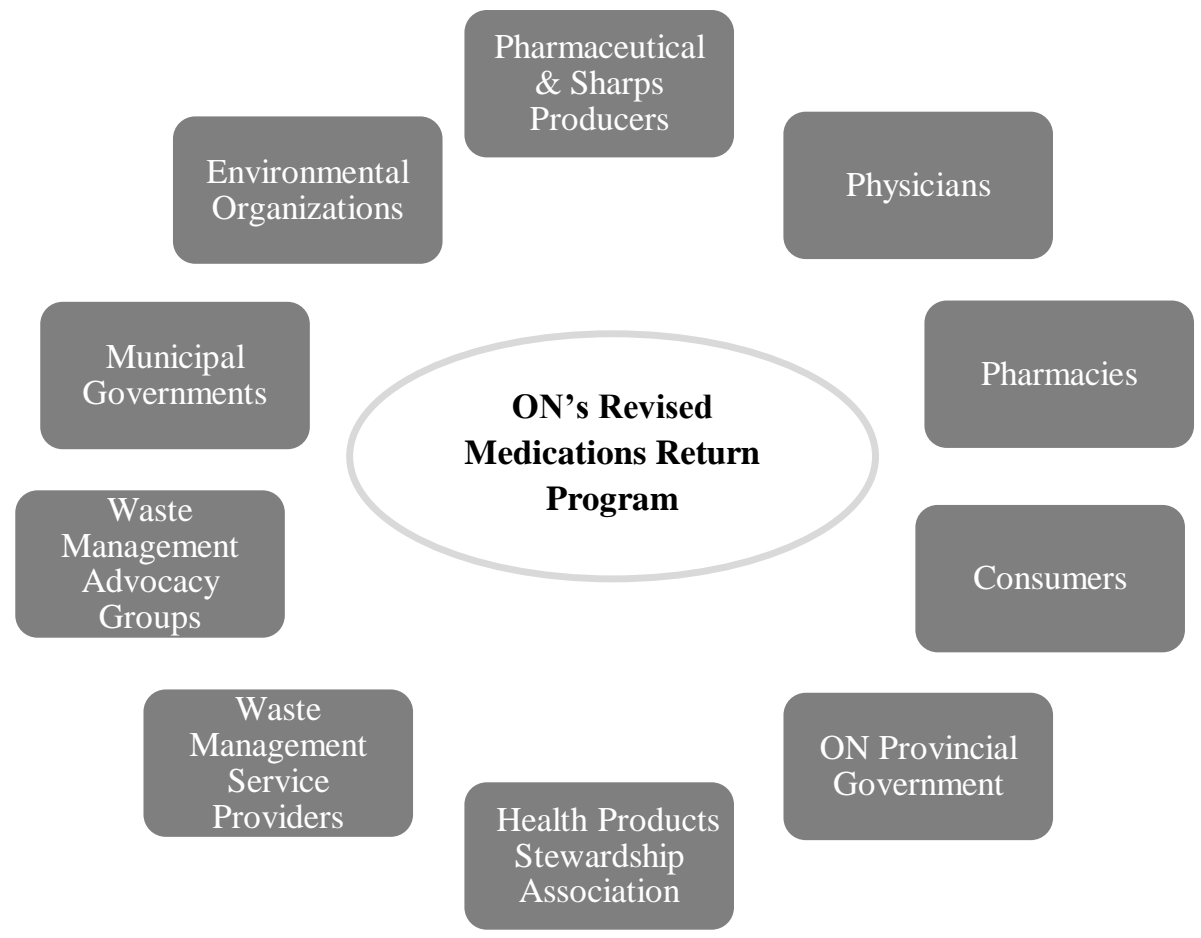

Figure 5. Stakeholders Involved in ON's Revised Medications Return Program

There are some challenges with comparative studies. This research can be difficult to conceptualize and implement. There is not a straightforward framework outlining research design, data collection and data analysis for comparative studies. Also, according to Cyr and deLeon (1975), when analyzing the variances between policies in different jurisdictions it can be difficult to determine whether the policy outcomes "are due to variations in the specificities of policies themselves, in the character of the problems they seek to mitigate, in the general cultural milieus in which they operate, or some combination of these" (p. 376). However, as argued by Kopstein and Lichbach (2005), "By comparing the range of possible political responses to global opportunities and constraints, we can begin to offer explanations for why countries develop as they do and evaluations about the trade-offs involved under different political orders" (p. 1-2).

Overall, comparative analysis is a commonly used research approach. The literature review has indicated that comparing the decisions and actions taken by different governments to respond to a common problem can help policymakers identify the strengths and weaknesses with their existing management approach. Important features in comparative analysis are analyzing stakeholders involved in the system and the measures used to respond to the problem. 
For this study, a comparative policy analysis was conducted to investigate and compare BC's Medications Return Program and Ontario's Orange Drop Program for managing pharmaceutical waste. The similarities and differences between their approaches were first analyzed to help understand how each program developed as they did, and then an evaluation framework (as outlined in Section 2.6) was applied to measure the effectiveness of the programs. The comparative analysis explored and compared the following elements:

1. Identification of policy goals and objectives (these are outlined in Chapter 4).

2. Stakeholder roles and responsibilities - analyzing the roles of the actors involved in developing, implementing and operating BC's MRP and Ontario's Orange Drop. As identified in the literature review, it is important to understand the responsibilities of the individuals, organizations, and authorities involved in designing and administering the programs. Some of the actors directly involved in the programs had responsibilities mandated by government through legislation/regulation, while others did not.

3. Supportive policy tools and instruments - investigating the policy tools put in place to support the programs. Both the $\mathrm{BC}$ and Ontario governments adopted measures to reinforce their programs. It was essential to analyze these measures since part of the evaluation framework (as seen in Section 2.6) looked at whether the programs and their supportive policy tools have met the overarching goals and objectives.

A comparative analysis was also conducted in Step 4 in this study. In this step, Ontario's terminated Orange Drop Program legislated under the Waste Diversion Act (WDA, 2002) was compared with Ontario's new Medications Return Program legislated under the Environmental Protection Act (1990). Ontario's recent regulation, O. Reg. 298/12 enacted under the EPA, sets out performance standards that pharmaceutical producers are required to meet for Ontario's new Medications Return Program. This comparative analysis investigated and compared this new program with the previous Orange Drop Program to identify similarities, differences and modifications between them. The key questions asked were: What makes this new program similar or different from the Orange Drop? Has anything even changed in Ontario?

Ontario’s new MRP recently launched on January 1, 2013 which means that it is still in its early implementation stage. As a result, the majority of the program's analysis was based on the new regulation. As argued by Rose (1993), "Planning to implement a new program is speculative, insofar as it involves 'If . . , then ...' hypotheses about how a program is expected 
to work" (p. 91). The requirements set out in O. Reg. 298/12 may seem effective (or ineffective) in theory; however, how the regulation will be translated into an operational program is too early to ascertain. Fortunately, since O. Reg. 298/12 set outs detailed environmental requirements for producers, there is a sufficient amount of information available for comparison.

\subsection{Lesson-Drawing and Policy Convergence}

A common research area of comparative policy analysis is to study why jurisdictions have adopted similar policies. Lesson-drawing and policy convergence are classifications used in the comparative policy literature to describe the causes of similarities in policy across jurisdictions. This section reviews these concepts and explains how they applied to this thesis.

According to Bennett (1991), similarities in policy between regions can signify a convergence of policy goals, content, instruments, outcomes, and/or styles. Bennett (1991) described policy convergence as "a process of 'becoming' rather than a condition of 'being' more alike” which involves "a pattern of development over time” (p. 219). Similarly, Knill (2005) defined policy convergence "as any increase in the similarity between one or more characteristics of a certain policy (e.g. policy objectives, policy instruments, policy settings) across a given set of political jurisdictions ... over a given period of time" (p. 768). Hence, policy convergence is often used to explain the result of a policy change over time, and it is characterized as a gradual movement towards similarity.

The literature has listed possible causes of policy convergence. Bennett (1991) argued that the causes are dynamic (as opposed to static qualities) and can be grouped into four processes: emulation, elite networking, harmonization and penetration. Stone (1999) suggested that the resemblance of policies across jurisdictions is mainly a result of structural forces in which policymaking elites take on a passive role, while Knill (2005) attributed two broad factors to explain policy convergence: causal mechanisms that trigger convergent policy changes, and facilitating factors which impact the effectiveness of these mechanisms.

Thus, the literature has identified that policymakers with similar problems could address them in similar ways without there being direct policy transfer. This suggests that there can be a convergence (i.e. resemblance or uniformity) of policy across regions over time, and it can take place independently of other jurisdictions. 
Lesson-drawing is another classification of policy change in the comparative policy literature. As stated by Rose (1993), a lesson is defined as "a program for action based on a program or programs undertaken in another city, state, or nation, or by the same organization in its own past” (p. 21). Lesson-drawing provides a framework for policy decision makers to evaluate existing programs elsewhere, and to determine whether adoption at home is worth pursuing, and if so, what modifications might be needed to ensure efficiency and effectiveness.

As supported by James and Lodge (2003), "In this sense, the 'lesson drawing' perspective deepens concepts of rational policy-making and enables policy-makers' behaviour to be compared to a benchmark of 'lesson drawing' behaviour" (p. 181). Thus, lesson-drawing offers guidance about how positive achievements in one jurisdiction can be used to improve policies in another area and how to avoid policies that do not work (Rose, 2005).

Lesson-drawing can be conducted across time or space. Investigating a program in a jurisdiction's own past has the potential to offer valuable lessons in how to improve the effectiveness of the program. As described by Rose (1993), "Ignorance of the past can affect policymaking, because those who do not learn lessons from mistakes of the past may be condemned to repeat them" (p. 78-79). Analyzing a program across space (another region) can also provide fruitful examples for lesson-drawing. Rose (1993) emphasized that "[e]ven though cities, states, or nations do not merge, common problems create common interests in public policy, and if agencies respond differently, the potential for lesson-drawing exists" (p. 96).

The use of lesson-drawing has become a well-recognized focus in studying comparative public policy (James \& Lodge, 2003). It has been used to study policies for protecting endangered species (Illical \& Harrison, 2007); government financial reporting (Brusca \& Montesinos, 2009); family policies (Gornick \& Meyers, 2001); cross-national transfer of policies (Wolman, 1992); modernizing local governance (McLaughlin, 2002); tourism education (Teixeira \& Baum, 2001); and the development of public services (James \& Lodge, 2003).

The literature, however, has identified weaknesses with lesson-drawing. The first relates to innovation. According to Rose (1993), lesson-drawing deviates away from innovative ideas to familiar programs that have been previously adopted. Similarly, Dolowitz and Marsh (1996) argued that when policymakers lesson-draw, this may reinforce the existing system since similar ideas are circulated amongst the jurisdictions, thus resulting in maintaining the status quo (p. $355)$. 
In addition, when policymakers draw positive and negative lessons from another program, it does not necessarily mean that applying/omitting these elements will automatically be effective in another jurisdiction. Rose (1993) argued, "The adoption of a new program is intended to remove dissatisfaction, but its very novelty creates uncertainties" (p. 91). Lessondrawing helps identify whether a program could be transferred to another jurisdiction but it cannot prescribe whether a program should be adopted (Rose, 1993).

Some of the central steps in lesson-drawing, as adapted from Rose (2005) are:

- Decide where to look for lessons. It makes sense to choose a jurisdiction that has similar goals, has a history of achieving its goals, and has the potential to provide valuable lessons.

- Determine positive lessons from the program analyzed in another jurisdiction (components that have been effective) and identify negative lessons (lessons that should be avoided). As stated by Rose (1991), "If it [the lesson] is negative, observers learn what not to do from watching the mistakes of others" (p. 4).

- Determine which positive lessons from the other jurisdiction could potentially be adopted, and of those which are most likely to be feasible.

Overall, both lesson-drawing and policy convergence are used in the comparative policy literature to refer to the causes of similarities in policy across jurisdictions. Lesson-drawing assumes that there is evidence that policy actors examined programs or policies in other jurisdictions and drew lessons from them. In contrast, policy convergence indicates that programs and policies can resemble each other over time without necessarily having direct evidence of policy actors drawing lessons.

As mentioned in the previous section, an evaluation framework was developed and applied in Step 2 of this thesis to determine whether the programs in British Columbia and Ontario achieved the criteria for an optimal medications return program (refer to Section 2.6). In Step 3, this author drew positive and negative lessons from BC's long-standing MRP based on its achievement of the evaluation criteria (i.e. elements that have been effective in meeting the criteria and elements that have hindered achieving the criteria), and it was determined which of these lessons could potentially be adopted in Ontario and would most likely be feasible.

In Step 5 of this thesis, it was investigated whether the positive and negative indicators learned from BC's program have been incorporated in Ontario's revised Medications Return 
Program. In other words, this step analyzed Ontario's revised MRP and identified whether the lessons learned from BC have been applied. As mentioned earlier, Ontario's new MRP was just recently implemented so it is difficult to draw concrete conclusions regarding its implementation and operation. However, positive and negative indicators of lesson-drawing can still be identified in the new regulation (O. Reg. 298/12).

Interview data was also explored in Step 5 of this thesis to identify whether there was an instance of Ontario policymakers lesson-drawing from British Columbia, or whether any similarities between BC's MRP and Ontario's revised MRP exist due to policy convergence (as discussed in Section 2.6).

\subsection{Case Studies}

This study involved a case analysis in which the BC and Ontario programs were used as cases to compare, evaluate and lesson-draw. A commonly used definition of a case study was articulated by Schramm (1971) in which he stated that "the essence of a case study, the central tendency among all types of case study, is that it tries to illuminate a decision or a set of decisions: why they were taken, how they were implemented, and with what result" (p. 6). Yin (2009) later defined a case study as "an empirical inquiry that investigates a contemporary phenomenon in depth and within its real-life context ..." (p. 18). In other words, the case study model involves a descriptive analysis of a case (a unit of analysis like a decision, program or process) within defined boundaries, as set by the author, in relation to its contextual conditions. This context-dependent knowledge generated from case studies, as argued by Flyvbjerg (2006), allows researchers to develop from "rule-based beginners to virtuoso experts" (p. 221).

Case studies typically focus on developmental factors. According to Flyvbjerg (2011), this means that a case evolves in time "often as a string of concrete and interrelated events that occur 'at such a time, in such a place' and that constitute the case when seen as a whole" (p. 301). Thus, cases can be useful for answering the questions: "What happened? How and why?" As supported by Crabbé and Leroy (2008, p. 59), case study research sets out to investigate:

- Which policy option should be chosen from a set of alternatives?

- Why does policy achieve its goals and objectives (or fail to)?

- By analyzing specific and well-chosen cases, can a causal relationship be identified between the policy intervention and the effect achieved? 
These questions were pertinent to this study which set out to address why Ontario's Orange Drop Program failed within weeks of implementation whereas BC's Medications Return Program has been operational for more than a decade. Overall, this research incorporated the case study model as it used medications return programs in $\mathrm{BC}$ and Ontario for the purposes of comparison, evaluation and lesson-drawing. Since there is a substantial amount of knowledge, experiences and policy development in these provinces, examining and learning from these two cases can help other jurisdictions understand the issues they would likely face when dealing with this complicated type of waste.

\subsubsection{Case Selection}

In Canada, environment is not assigned to one level of government. The Government of Canada Privy Council Office (2010) stated, “[Environment] is a diffuse area which may be addressed under various federal and provincial legislative powers depending on the nature or scope of the issue." As argued by VanderZwaag and Duncan (1992), "The constitution contains no enshrined rights to a healthy environment, nor does it dictate clear responsibility for effecting environmental protection or sustained management of resources" (p. 22).

Federal powers include environmental issues in the areas of Criminal Law, Sea Coast and Fisheries, and Interprovincial and International Transportation (Government of Canada Privy Council Office, 2010). Provincial powers include environmental initiatives in the areas of Property and Civil Rights and Municipalities (Government of Canada Privy Council Office, 2010). As explained by Dunsmuir (1991), "The provincial power, which is very extensive, comes from the fact that most environmental issues involve property and civil rights within the province" (section 1). The provinces delegate responsibilities to the municipalities to regulate local activities which affect the environment including zoning, sewage and garbage disposal.

As mentioned in Section 2.2, Canada has substantial variation of environmental and waste management policies at the sub-national level. For example, rather than enacting a federal law in Canada to establish nationwide air quality standards, the federal government developed national "objectives", and allowed provinces to set their own air quality standards (Rabe, 2002, p. 92). As stated by Rabe (2002), "This pattern of provincial deference is also evident in other areas of environmental policy, including water pollution and hazardous waste management, giving Canada one of the most decentralized environmental policy systems of any Western government" (p. 92). Thus, Canadian provinces are given extensive power to adopt their own 
strategies for protecting the environment.

In this light, BC and Ontario were selected as good comparators for this research since both provinces had similar policy objectives for addressing the presence of PhACs in the environment. Both provinces aimed to develop a regulated return program to not only reduce the potential environmental impacts of drugs in the environment, but to also shift the financial responsibility of drug collection and disposal from government to the drug producers. Although the programs had similar policy goals, they resulted in different outcomes. BC was the first province in Canada to implement a provincially regulated MRP which has been operating for more than fourteen years. As stated earlier, Ontario's Orange Drop Program failed within weeks of implementation. Thus, it was crucial to conduct a comparative policy analysis of BC and Ontario to investigate the similarities and differences between the regulated programs, and to draw lessons. As supported by Rose (1993), "The easiest place to search for lessons is within one's own country, for preconditions for lesson-drawing are easily met. There cannot be a total blockage on the transfer of programs ...." (p. 97).

It also made sense to compare waste policies with BC since they are recognized as a leader in waste reduction (VanNijnatten, 2002). A 2011 report card conducted by Extended Producer Responsibility Canada (2012a) graded the progress of Canadian jurisdictions in developing and implementing EPR legislation in compliance with the Canadian Council of Ministers of the Environment's (CCME's) 2009 Canada-wide Action Plan (CAP) for EPR. EPR Canada is a not-for-profit organization formed in 2011 to promote EPR policies, and its goal "is to foster continued growth and improvement of EPR policies, programs and practices in Canada" (EPR Canada, 2012a, p. 2). The CAP outlines elements that should be considered when developing producer-responsibility programs to strengthen the use of EPR and to promote the harmonization of programs across Canada. The CAP also sets out timelines for developing EPR laws for managing priority materials like pharmaceuticals. In the EPR report card, BC received the highest grade of A- while Ontario received a mediocre $\mathrm{C}+$.

EPR Canada Co-founder Geoff Love stated (EPR Canada, 2012b):

British Columbia clearly ranked well above the other governments. Its policies and programs designed to have producers pay $100 \%$ of the cost of managing many of their products and packaging after the consumer is finished with them are setting the bar high for other governments in Canada. (p. 1) 
Thus, comparing Ontario with BC, a recognized leader in adopting EPR programs, allowed for valuable program comparisons, evaluations, and lesson-drawing.

Lastly, BC and Ontario were also chosen for this research since they are relatively distant from each other. According to VanNijnatten (1999), many significant differences in environmental policymaking may exist between Canadian provinces, and those differences may be greater than those between other regions. VanNijnatten and Boychuck (2006) also stated, "Looking more closely at cross-border regions, in some specific cases policy differences between neighbouring states and provinces are less marked than differences between neighbouring states or between neighbouring provinces" (p. 488). This means that in some instances environmental policies in Canadian provinces and U.S. states that are in regions straddling the national border may resemble each other. Thus, it makes sense to look to BC, a Pacific coast province, as opposed to selecting a nearby province/state for a sufficiently different situation to provide more productive examples for policy lesson-drawing.

\subsection{Evaluation Framework}

The evaluation framework used to measure the effectiveness of Ontario's Orange Drop Program and BC's Medications Return Program consisted of two parts:

1. Whether the programs and their supportive policy tools have met the intended policy goals and objectives. Have the overarching policy goals been achieved? What are the stakeholders' perceptions of the programs and policy tools?

As discussed in Chapter 4, both programs had the same overarching policy goal and specific policy objective:

- Overarching policy goal - to reduce the potential environmental and health impacts associated with PhACs in a cost-effective manner.

- Specific policy objective - to provide a province-wide system for the public to return their unused drugs for safe disposal based on EPR: shifting $100 \%$ of the responsibility and costs for managing this waste from government (and taxpayers) to the producers.

2. Whether the programs have met a set of criteria for an optimal return program that are consistent with EPR practices. Do the programs meet the criteria for an optimal return program? The advantages and limitations of EPR and medications return programs have been widely documented in the literature such as government/agency documents, stewardship 
plans and reports, and academic journals. Thus, a comprehensive literature review was conducted to develop a set of benchmark criteria for an optimal medications return program (as seen in Section 3.4.4).

\section{Criteria for an Optimal Medications Return Program:}

- Clearly defined scope

- Results-based framework

- Accountability

- Internalizing program costs

- Effective monitoring and enforcement

- Open consultation process

- Key performance measures and targets:

○ Promotion and education

- Consumer awareness

- Accessibility

○ Product collection

- Proper end-of-life management

- Reporting and auditing requirements

\subsubsection{Stakeholder Interviews}

Most of the data required for evaluation was derived from document analysis e.g. stewardship reports, policy papers from governments and non-governmental groups, academic journals, and consulting reports. Interviews were also conducted with BC and Ontario representatives from provincial government, an environmental non-governmental organization (ENGO), a waste/recycling advocacy group, a consulting firm and an industry agency. They were semi-structured, open-ended interviews with stakeholders involved in or are knowledgeable of BC's or Ontario's program for managing unused/expired pharmaceuticals. Approval from Ryerson University's Research Ethics Board was attained before interviews commenced.

Table 1 shows the stakeholder groups interviewed. There were four interviews conducted in $\mathrm{BC}$, four interviews conducted in Ontario, and two interviews conducted with stakeholders involved in both BC and Ontario. Although only ten individuals were interviewed, 
it was important to obtain information from professional experts involved in the programs to gain an understanding of the roles and responsibilities of the stakeholders, implemented measures, and the actors' perceptions of the programs. The interviews provided the opportunity to gain insight into the programs to help measure their effectiveness. Also, with the new regulatory development taking place in Ontario, the interviews provided access to knowledge that otherwise may not have been obtained through document analysis. The stakeholders' opinions reflected different perspectives from individuals and did not represent the official views of the province or the organization that they represent.

Table 1. Stakeholder Groups Interviewed in British Columbia and Ontario

\begin{tabular}{|c|c|c|}
\hline BC Stakeholder Group & ON Stakeholder Group & $\begin{array}{c}\text { Both BC and ON } \\
\text { Stakeholder Group }\end{array}$ \\
\hline $\begin{array}{l}\text { Provincial government policy } \\
\text { officials } \\
-2 \text { individuals }\end{array}$ & $\begin{array}{l}\text { Provincial government policy } \\
\text { officials } \\
\text { - } 2 \text { individuals }\end{array}$ & $\begin{array}{l}\text { Consulting firm } \\
\text { - } 1 \text { individual }\end{array}$ \\
\hline $\begin{array}{l}\text { ENGO } \\
-1 \text { individual }\end{array}$ & $\begin{array}{l}\text { ENGO } \\
-1 \text { individual }\end{array}$ & $\begin{array}{l}\text { Industry agency } \\
-1 \text { individual }\end{array}$ \\
\hline $\begin{array}{l}\text { Waste/recycling advocacy group } \\
-1 \text { individual }\end{array}$ & $\begin{array}{l}\text { Waste/recycling advocacy group } \\
-1 \text { individual }\end{array}$ & \\
\hline
\end{tabular}

The questions asked to BC and Ontario stakeholders were slightly different since the programs were in different stages. BC's MRP has been fully operational since 1999 whereas Ontario's Orange Drop was suspended within weeks of implementation, and a new program in Ontario recently launched on January 1, 2013. Some questions addressed inquiries about program performance, program administration, and stakeholder roles and responsibilities, while others (as outlined below) were used to help evaluate the programs. Since BC's MRP is Canada's longest-running provincially regulated return program, it was critical to learn how the actors actually perceived the performance of the program and its supportive policy tool.

The questions asked to $\mathrm{BC}$ interviewees focused on determining the actors' perceptions of the program and policy tool:

- What are your views regarding the performance of BC's MRP, as it currently functions?

- What are your views regarding BC's Recycling Regulation?

The questions for Ontario actors focused on what lessons could be learned from Ontario's failed Orange Drop Program. Since the majority of interviews took place before January 1, 2013 
(when the new MRP launched), it did not make sense to ask the stakeholders' views regarding the performance of the revised program. The last question explored whether the Ontario provincial government reached out to other jurisdictions prior to launching its revised MRP to identify whether there was discernible evidence of Ontario policymakers lesson-drawing. The questions asked to Ontario actors were:

- Are there any lessons that can be learned from the Orange Drop that was terminated in 2010?

- What are your views regarding Ontario’s new Regulation (O. Reg. 298/12) for managing pharmaceutical and sharps waste?

- Are you aware if the Ontario provincial government examined Medications Return Programs in other jurisdictions, or consulted with other jurisdictions, before or during the development of O. Reg. 298/12?

\subsection{Roadmap}

Now that the methodology has been outlined, the next chapter analyzes the literature review of science detecting drugs in the environment, and the management strategies used to deal with this issue. In Chapter 4, a background of the cases for the comparative policy analysis and evaluation are analyzed. This includes British Columbia's Medications Return Program, Ontario's Orange Drop Program (suspended in 2010) and Ontario's new Medications Return Program (launched on January 1, 2013). Chapter 5 provides a thorough investigation, comparison and evaluation of these cases, and Chapter 6 provides a conclusion. In Chapter 7 , the thesis ends with policy recommendations for improving and enhancing the effectiveness of medications return programs, and directions for future research. 


\section{Chapter 3: Step 1 - Literature Review on Pharmaceuticals in the Environment}

\subsection{History of Detecting Pharmaceuticals in the Environment}

In the 1970s, scientists started to raise concerns regarding the ability of PhACs to act as environmental contaminants, and began detecting these substances in STP effluent (Garrison, Pope, \& Allen, 1976; Hignite \& Azarnoff, 1977; Tabak \& Bunch, 1970). Garrison et al. (1976) published the first study that identified drugs in STP effluent. The authors detected up to $2 \mu \mathrm{g} / \mathrm{L}$ of clofibric acid, an active metabolite in the cholesterol lowering drug clofibrate, in STP effluent in the U.S. In the 1980s, studies done outside the U.S. reported PhACs in STP effluent and surface waters, including the UK (Richardson \& Bowran, 1985; Watts, Crathorne, Fielding, \& Steel, 1984) and Canada (Rogers, Birtwell, Kruzynski, 1986).

In the 1990s, the issue of PhACs gained substantial interest due to an increasing number of papers reporting a growing presence of drugs in the environment. The technological advancements in analytical instrumentation during this time allowed scientists to detect $\mathrm{PhACs}$ in nanogram per litre concentrations (Heberer, Butz, \& Stan, 1995; Hirsch et al., 1998). By 1999, $68 \mathrm{PhACs}$ had been detected in waters worldwide (Jorgensen \& Halling-Sorensen, 2000); however, by 2006 the number of PhACs that were detected increased to 80 (Hua et al., 2006).

In the mid to late 2000s, there were more studies published reporting on the presence of PhACs in drinking water. Table 2 outlines several PhACs that have been detected in finished drinking waters. According to the Ontario MOE (2010a), more than 30 different pharmaceuticals or other contaminants of emerging concern have been measured in finished drinking waters worldwide. In 2010, the Ontario MOE released its report on the occurrence of pharmaceuticals in untreated source water and finished drinking water. Water samples from 17 municipal drinking water systems across Ontario were analyzed for 46 compounds, including pharmaceuticals, antibiotics, hormones, and bisphenol A (ON MOE, 2010a). Of the 46 compounds analyzed, 23 compounds were detected in source water and 22 were detected in finished drinking water. Figure 6 reveals the most frequently detected compounds in the study. 
Table 2. PhACs Detected in Finished Drinking Water Worldwide

\begin{tabular}{|c|c|c|c|}
\hline Compound & Description & Location & Reference(s) \\
\hline Acetaminophen & Analgesic & Canada & ON MOE, 2010a \\
\hline \multirow[t]{2}{*}{ Atenolol } & \multirow[t]{2}{*}{ Beta-blocker } & USA & Benotti et al., 2009 \\
\hline & & Spain & Huerta-Fontela, Galceran, \& Ventura, 2011 \\
\hline Bezafibrate & Lipid regulator & Canada & ON MOE, 2010a \\
\hline \multirow{2}{*}{ Carbamazepine } & \multirow{2}{*}{ Anticonvulsant } & USA & Benotti et al., 2009 \\
\hline & & Canada & ON MOE, 2010a \\
\hline \multirow[t]{3}{*}{ Clofibric acid } & \multirow[t]{3}{*}{ Lipid regulator } & Canada & ON MOE, 2010a \\
\hline & & Italy & Zuccato, Calamari, Natangelo, \& Fanelli, 2000 \\
\hline & & Germany & Heberer \& Stan, 1997 \\
\hline \multirow[t]{2}{*}{ Diazepam } & \multirow[t]{2}{*}{ Antianxiety } & USA & Benotti et al., 2009 \\
\hline & & Italy & Zuccato et al., 2000 \\
\hline \multirow[t]{2}{*}{ Diclofenac } & \multirow[t]{2}{*}{ Analgesic } & USA & Benotti et al., 2009 \\
\hline & & Canada & ON MOE, 2010a \\
\hline Enrofloxacin & Antibiotic & Canada & ON MOE, $2010 \mathrm{a}$ \\
\hline Erythromycin & Antibiotic & Canada & ON MOE, 2010a \\
\hline Equilin & Hormone & Canada & ON MOE, 2010a \\
\hline Fluoxetine & Antidepressant & USA & Benotti et al., 2009 \\
\hline \multirow{2}{*}{ Gemfibrozil } & \multirow{2}{*}{ Lipid regulator } & USA & Benotti et al., 2009 \\
\hline & & Canada & ON MOE, 2010a \\
\hline $\begin{array}{l}\text { Hydrochloroth- } \\
\text { iazide }\end{array}$ & Diuretic & Spain & Huerta-Fontela, Galceran, \& Ventura, 2011 \\
\hline \multirow{3}{*}{ Ibuprofen } & \multirow{3}{*}{ Analgesic } & Canada & ON MOE, 2010a \\
\hline & & USA & Loraine \& Pettigrove, 2006 \\
\hline & & Finland & Vieno, Tuhkanen, \& Kronberg, 2005 \\
\hline \multirow[t]{2}{*}{ Ketoprofen } & \multirow[t]{2}{*}{ Analgesic } & Canada & ON MOE, 2010a \\
\hline & & Finland & Vieno, Tuhkanen, \& Kronberg, 2005 \\
\hline Lincomycin & Antibiotic & Canada & ON MOE, 2010a \\
\hline Meclocyclin & Antibiotic & Canada & ON MOE, 2010a \\
\hline Meprobamate & Antianxiety & USA & Benotti et al., 2009 \\
\hline Monensin sodium & Antibiotic & Canada & ON MOE, 2010a \\
\hline Norfloxacin & Antibiotic & Canada & ON MOE, 2010a \\
\hline Phenazone & Analgesic & Germany & $\begin{array}{l}\text { Reddersen, Heberer, \& Dünnbier, 2002; } \\
\text { Zühlke, Dünnbier, \& Heberer, } 2004\end{array}$ \\
\hline \multirow[t]{2}{*}{ Phenytoin } & \multirow[t]{2}{*}{ Anticonvulsant } & USA & Benotti et al., 2009 \\
\hline & & Spain & Huerta-Fontela, Galceran, \& Ventura, 2011 \\
\hline Propyphenazone & Analgesic & Germany & $\begin{array}{l}\text { Reddersen, Heberer, \& Dünnbier, 2002; } \\
\text { Zühlke, Dünnbier, \& Heberer, } 2004\end{array}$ \\
\hline Roxithromycin & Antibiotic & Canada & ON MOE, 2010a \\
\hline Sotalol & Beta-blocker & Spain & Huerta-Fontela, Galceran, \& Ventura, 2011 \\
\hline $\begin{array}{l}\text { Sulfachloropyrid- } \\
\text { azine }\end{array}$ & Antibiotic & Canada & ON MOE, 2010a \\
\hline \multirow[t]{2}{*}{ Sulfamethoxazole } & \multirow[t]{2}{*}{ Antibiotic } & USA & Benotti et al., 2009 \\
\hline & & Canada & ON MOE, 2010a \\
\hline Tetracycline & Antibiotic & Canada & ON MOE, $2010 \mathrm{a}$ \\
\hline
\end{tabular}




\begin{tabular}{|l|l|l|l|}
\hline \multicolumn{1}{|c|}{ Compound } & \multicolumn{1}{|c|}{ Description } & Location & \multicolumn{1}{c|}{ Reference(s) } \\
\hline Triclosan & Antibacterial & USA & $\begin{array}{l}\text { Benotti et al., 2009; Loraine \& Pettigrove, } \\
2006\end{array}$ \\
\hline Trimethoprim & Antibiotic & Canada & ON MOE, 2010a \\
\hline Tylosin & Antibiotic & Canada & ON MOE, 2010a \\
\cline { 3 - 4 } & & Italy & Zuccato et al., 2000 \\
\hline
\end{tabular}

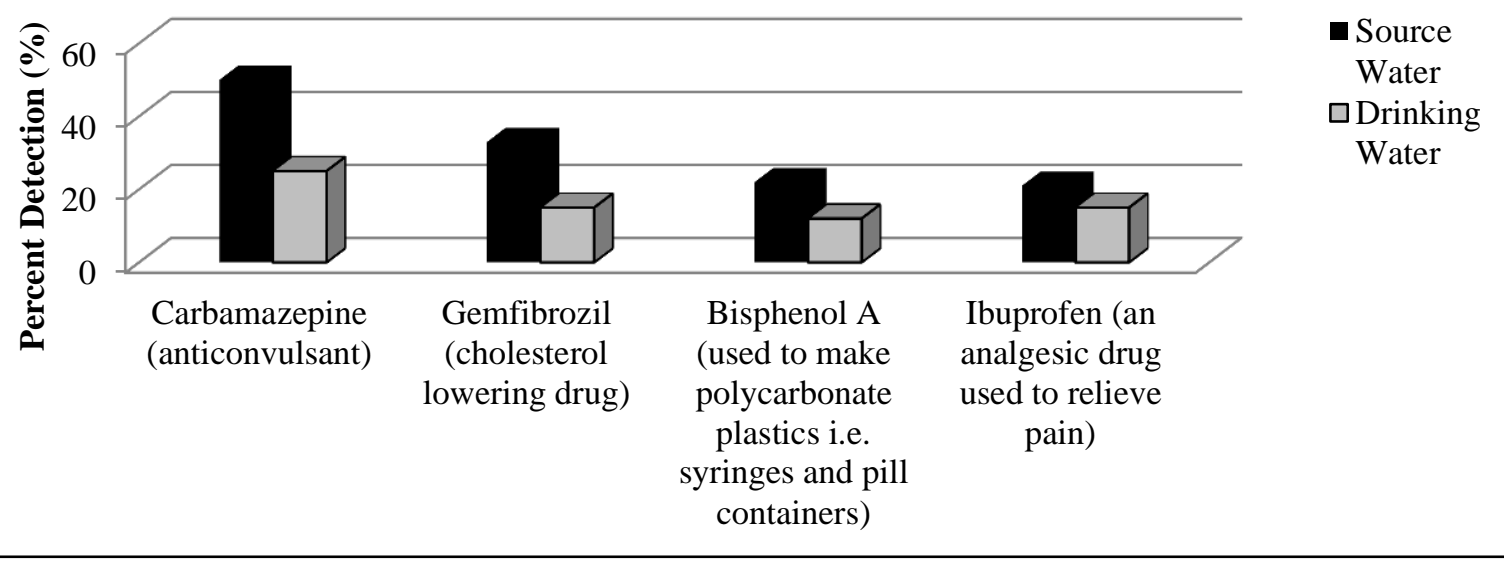

Figure 6. Most Frequently Detected Compounds in Untreated Source \& Finished Drinking Waters in Ontario (ON MOE, 2010a). Note: Bisphenol A is not a PhAC.

\subsection{Concerns with Pharmaceuticals in the Environment}

The greatest concern regarding $\mathrm{PhACs}$ is their potential effects on non-target aquatic species, such as fish. Drugs are specifically designed to interact with cellular receptors in low doses and to exert a biological effect. However, these compounds can also interact with nontarget receptors in other organisms when present in the environment. Enick and Moore (2007) identified four key reasons why PhACs are of major concern: these compounds are globally distributed and ubiquitous; they are designed to alter biological functions; they can exert a range of side effects in non-target species; and they can cause chronic toxicity at trace levels, $\mu \mathrm{g} / \mathrm{L}$ to ng/L. Also, according to the U.S. Environmental Protection Agency (U.S. EPA, 2010), the risks for aquatic species are of concern since they have continual exposures to higher concentrations of contaminants in untreated water, possible low dose effects, and multi-generational exposures.

If $\mathrm{PhACs}$ are continuously emitted into the environment, then some organisms may be exposed throughout their lifetime (Boxall et al., 2012). The U.S. EPA (2006) found that PhACs can be imparted to fish liver and tissue from wastewater. They analyzed fish from effluentdominated streams in Arizona, Florida, Illinois, New Mexico, Pennsylvania and Texas. The U.S. 
EPA (2006) detected seven pharmaceutical compounds in the fish liver or fillet tissues, and the most frequently detected drugs were diphenylhydramine (antihistamine), norfluoxetine (antidepressant), and sertraline (antidepressant). Another alarming study done by Kidd et al. (2007) found that chronic exposures of synthetic estrogen in trace concentrations can lead to the potential collapse of a fish population. Kidd et al. (2007) conducted a seven year, whole-lake analysis in northwestern Ontario, Canada, and discovered that chronic exposure of fathead minnow to low levels of synthetic estrogen results in feminization of males, altered oogenesis in females, and "a near extinction of this species from the lake" (p. 8897).

$\mathrm{PhACs}$ in the environment have caused hazardous and non-reversible effects on the reproduction and development systems in aquatic life. Scientists have attributed many of these effects, including the feminization of male fish, reduced fertility, and the masculinization of female fish, to endocrine disruptors (Environment Canada, 2012a; Harries et al., 1999; Purdom et al., 1994). The National Institute of Environmental Health Sciences (2010) defined endocrine disruptors as "naturally occurring compounds or man-made substances that may mimic or interfere with the function of hormones .... Endocrine disruptors may turn on, shut off, or modify signals that hormones carry, which may affect the normal functions of tissues and organs" (p. 1). Both natural and synthetic hormones can act as endocrine disruptors in the environment (Lai, Scrimshaw, \& Lester, 2002). A common synthetic hormone detected in the environment is ethinylestradiol (17 $\alpha$-ethinylestradiol). As described by the BC MOE (2009):

Ethinylestradiol is an orally bio-active estrogen used in almost all modern formulations of combined oral contraceptive pills and is one of the most commonly used medications. . . . It has a relatively high octanol-water partitioning coefficient $($ Kow $=3.67-4.2)$ which causes it to be persistent and preferentially attach to the organic matter in the aquatic environment. (p. 4)

Hinck, Blazer, Schmitt, Papoulias, \& Tillitt (2009) found widespread "intersex" smallmouth and largemouth bass in river basins throughout the United States. "Intersex" is a term used to describe an individual fish that exhibits both male and female characteristics (Hinck et al., 2009). The percentage of intersex fish per site was $8-91 \%$ for largemouth bass, with the highest (91\%) in the Pee Dee River, and 14-73\% for smallmouth bass, with the highest (73\%) in the Mississippi River (Hinck et al., 2009). The authors emphasized that the causes of intersex fish are unknown but may be linked to endocrine active compounds in the environment. 
In addition to endocrine disruptors, anxiolytics (drugs used to treat anxiety) are also of emerging concern to scientists. Benzodiazepines, the most commonly used anxiolytic, can resist photodegradation allowing them to persist in aquatic environments and be present in rivers and streams in concentrations as high as $0.4 \mu \mathrm{g} / \mathrm{L}$ (Brodin, Fick, Jonsson, \& Klaminder, 2013; Hummel, Löffler, Fink, Ternes, 2006). A recent study by Brodin et al. (2013) found that when fish were exposed to dilute concentrations of a benzodiazepine drug (oxazepam) they became more active, less social, and had a higher feeding rate. The results of this study are particularly worrisome as it demonstrates that $\mathrm{PhACs}$ have the ability to modify fish behaviour and potentially impact the composition and functioning of aquatic communities over time, indicating that they may have evolutionary and ecological implications (Brodin et al., 2013).

Long term health risks associated with human exposure to PhACs in the environment are unknown. As stated by the World Health Organization (WHO, 2011), "Concentrations of pharmaceuticals in drinking-water are generally more than 1000-fold below the MTD [minimum therapeutic dose] ... which suggests that appreciable risks to health arising from exposure to trace levels of pharmaceuticals in drinking-water are extremely unlikely" (p. X). It is difficult for scientists to quantify the human health risks posed by PhACs as there are several regional factors that must be considered. These include population demographics, level of drug use, cultural practices, dilution potential of receiving environments, wastewater and drinking water treatment infrastructure, urbanization and climate (Boxall et al., 2012).

Johnson et al. (2008) reported concerns regarding pregnant women exposed to drinking water containing trace levels of chemotherapy drugs, although the effects are not detectable. Even though PhACs have been detected in drinking water in only trace levels, there is a growing concern that drugs may have a cumulative effect in water. If antibiotics accumulate in the environment and are returned back into the human population, this could lead to antibiotic resistance (CMA \& Collier, 2012; Kristiansson et al., 2011). There is currently little knowledge available about how PhACs interact in selecting for antibiotic resistance (Boxall et al., 2012); however, the presence of resistant bacteria is growing (Ontario Medical Association, 2013). While antibiotic resistance has been linked to human medicine, it is debated whether veterinary medicine and agricultural practices contribute. The Ontario Medical Association (OMA, 2013) released a paper emphasizing that "[r]esistance to antibiotics is growing among a multitude of bacteria, with increasingly harmful effects on human health" (p. 1). The OMA 
(2013) stated that "infections with resistant bacteria are becoming more frequent, more difficult to treat, and more deadly. Patients are suffering longer with infections that often would have been quickly treated five or 10 years ago ...” (p. 4). The OMA (2013) provided recommendations, including Ontario banning the prophylactic or growth-promoting use of antibiotics in animal husbandry (production, breeding or caring of farm animals).

Another concern about exposure to $\mathrm{PhACs}$ is the health risks to more vulnerable individuals, including infants that drink contaminated tap water (CMA \& Collier, 2012). As summarized by Dr. Sébastien Sauvé from the Université de Montréal (CMA \& Collier, 2012):

If you were to drink two litres of water a day for 70 years, at the end of those 70 years, you would have taken $1 \%$ of the normal daily dose of someone taking that prescribed medication. For a variety of standard medications, the concentrations are exceedingly low... . The question we don't have the answer to is: What is the impact of chronic exposure to a very low exposure to a mixture of drugs? (p. 163)

Thus, although levels of drugs in the environment are low, the health risks of long-term exposure to these pharmaceutical cocktails are unknown but are of increasing concern.

\subsection{Sources and Pathways into the Environment}

Many studies have detected PhACs in groundwater (Barnes et al., 2004; Fram \& Belitz, 2011; Sacher et al., 2001), surface water (Hua et al., 2006; Kolpin et al., 2002; Ternes, 1998), soil (Edwards et al., 2009; Song et al., 2010; Topp et al., 2008), and drinking water (Benotti et al., 2009; Ontario MOE 2010; Ternes et al., 2002). When detected, the concentration of PhACs in surface water and groundwater tends to be less than $0.1 \mu \mathrm{g} / \mathrm{L}$, and the concentration in treated drinking water is usually less than $0.05 \mu \mathrm{g} / \mathrm{L}$ (WHO, 2012).

As seen in Figure 7, PhACs can enter the environment through various pathways depending on the use (veterinary or human use). Human consumption followed by excretion and discharge to surface water as STP effluent is the most common pathway (Health Canada, 2009; Ternes, 1998). This is not surprising since humans rely on drugs to improve health or even to survive. Canadians are filling more prescriptions than ever - about half of Canadian adults take at least one prescription drug and the number of prescriptions filled has increased by about $94 \%$ since 1999, as seen in Figure 8 (Canadian Generic Pharmaceutical Association, 2012; Health Council of Canada, 2010). In 2011, 527 million prescriptions were filled in Canada amounting to more than $\$ 22$ billion in sales (Canadian Generic Pharmaceutical Association, 2012). 


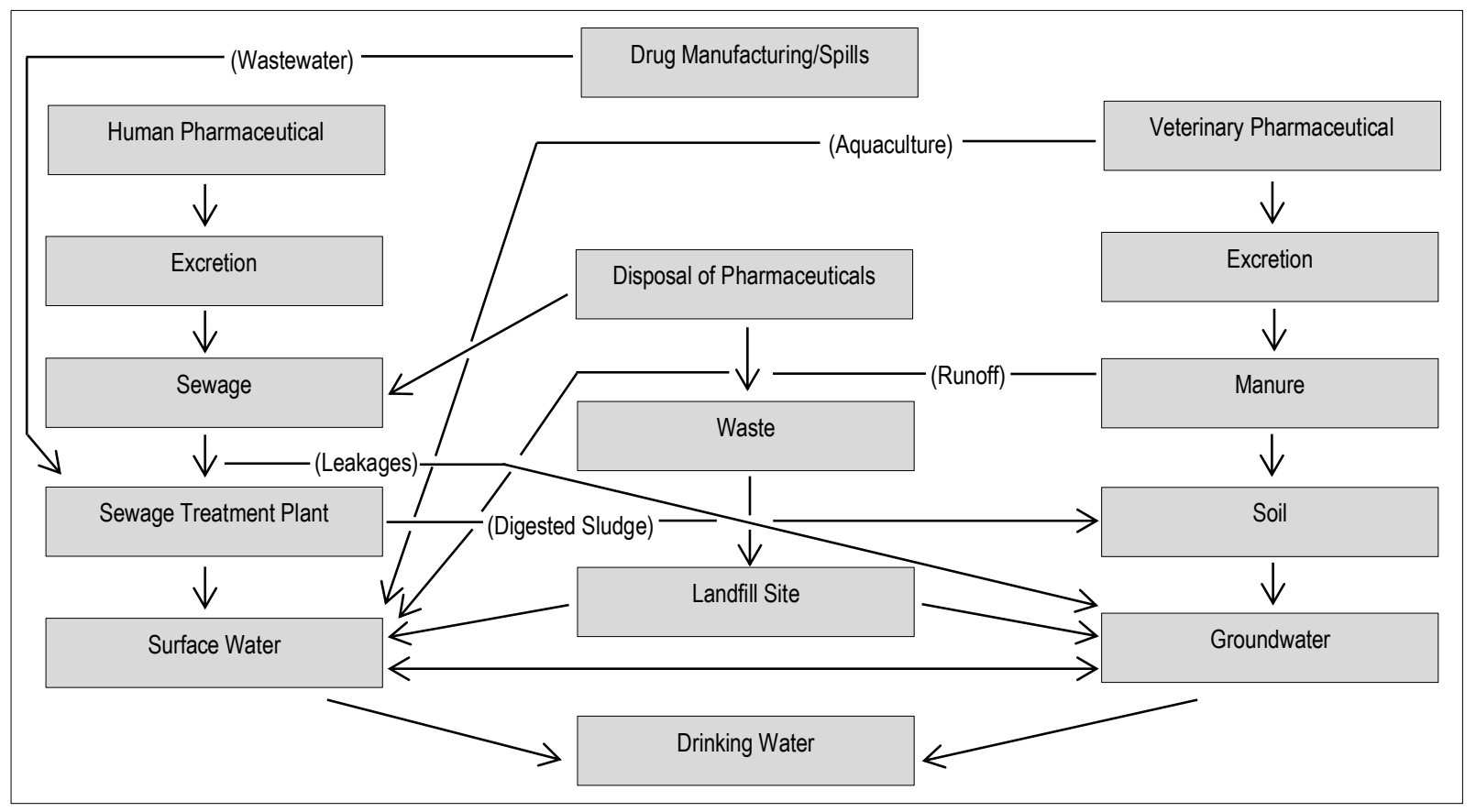

Figure 7. Sources and Pathways of PhACs into the Environment (Adapted from WHO, 2012)

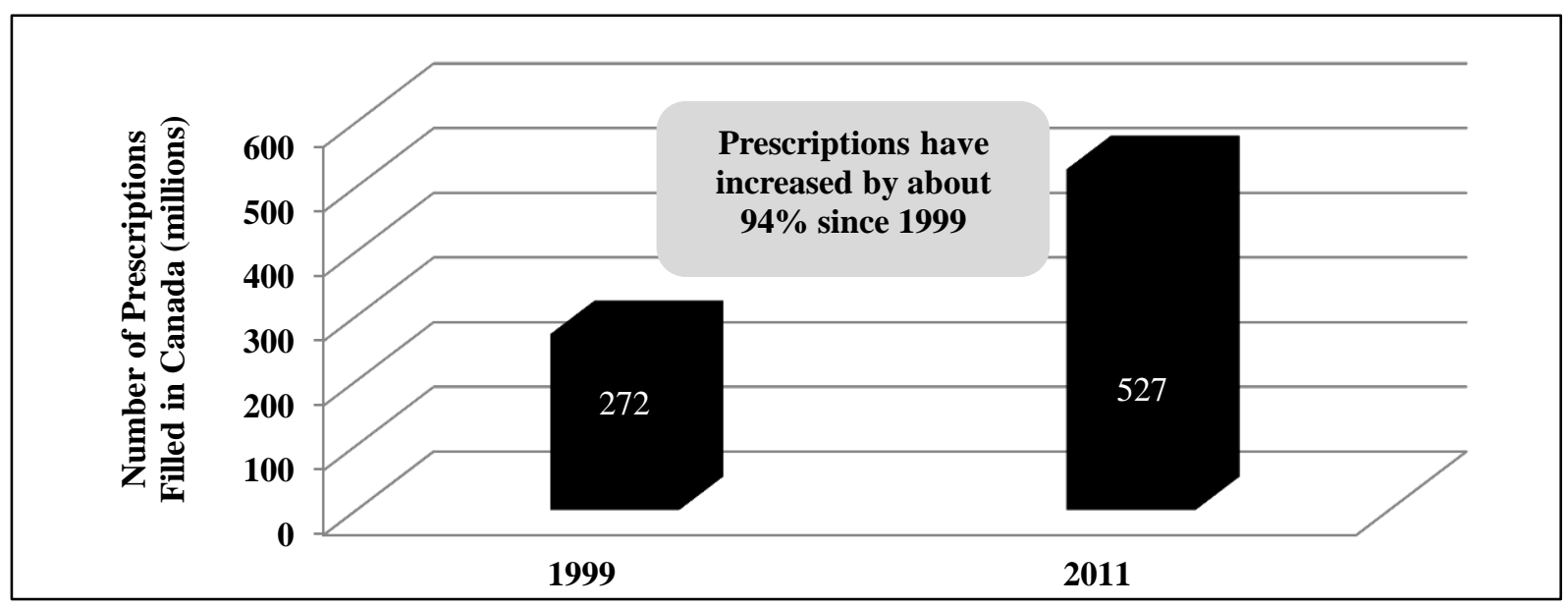

Figure 8. Comparing the Number of Prescriptions Filled in Canada in 1999 and 2011 (Canadian Generic Pharmaceutical Association, 2012; Health Council of Canada, 2010)

Once the pharmaceutical has been excreted in human urine or feces, the following pathways can take place in the STP process: the PhACs are mineralized by microorganisms, as seen with aspirin; the PhACs are persistent, polar and non-binding to solids and tend not to be removed by STPs, as seen with clofibrate; or the PhACs are less persistent and undergo partial degradation, as seen with penicillin (Sebastine \& Wakeman, 2003). Most secondary STPs can 
detect and remove some PhACs from wastewater effluent, such as meclofenamic acid, acetaminophen, and tolfenamic acid; however, other PhACs such as carbamazepine, synthetic estrogen, and lipid regulators like bezafibrate, gemfibrozil and clofibric acid are not effectively removed (Ternes, 1998). These PhACs can pass through the STP process, either degraded or unchanged, resulting in the discharge of contaminated wastewater effluent into the aquatic environment. The presence of PhACs in municipal wastewater and effluents has been acknowledged in the literature as a significant source of drugs in drinking water (WHO, 2011).

$\mathrm{PhACs}$ can also enter the environment through treated sewage sludge known as biosolids. Drugs that are lipophilic, indicating that they have a tendency to dissolve in lipids or fats, are not readily degradable in STPs resulting in a portion of the substance that is retained in sludge (Halling-Sørensen et al., 1998). When these biosolids are applied to agricultural fields as a source of crop nutrients and organic matter, a common farming technique, the PhACs can be discharged into the soils, and there is potential for the drugs to transport to water resources through tile drainage and surface runoff (Edwards et al., 2009; Topp et al., 2008). In Ontario, roughly $40 \%$ of the biosolids produced from domestic waste, approximately 16,000 dry tonnes, are applied to about 2,000 ha of agricultural land each year (Topp et al., 2008).

Veterinary drugs are also a source of environmental contamination. Animals receive veterinary drugs to treat diseases, increase growth rates (growth promoters), and improve feeding efficiency, and a significant amount of the parent compound will leave the animal unchanged through urine or feces (Environment Canada, 2008). Once the manure is applied to agricultural land as fertilizer, it can contaminate the soils and potentially enter surface waters and groundwaters through runoff and leaching (Dolliver \& Gupta, 2008; Environment Canada, 2008; Song et al., 2010; Ternes, 1998). Environment Canada (2008) has recognized the agricultural sector as a source of endocrine disruptors entering aquatic ecosystems through land application and subsequent runoff and leaching of biosolids and animal manure.

Although human excretion is recognized as the main route of entry of drugs into the environment, human disposal practices also contribute. Many consumers dispose of their unused/expired medications in the garbage or down the toilet. Statistics Canada (2007) found that almost a quarter of all Canadian households have unused/expired drugs - nearly $40 \%$ dispose of this waste in the garbage, down the drain/toilet or through burial. Similarly, Bound, Kitsou, \& Voulvoulis (2006) found that a third of South-East England consumers keep 
pharmaceuticals until they expire, and when the product must be discarded, the majority (63.2\%) dispose of the waste in the garbage, and $11.5 \%$ flush the waste down the sink/toilet. Another survey in Germany found that individuals dispose of most of their unused drugs down the drain amounting to 364 tons annually (Lubick, 2010). When drugs are flushed down the drain, many PhACs can pass through the STP process chemically changed or unchanged, as described earlier, and can subsequently be discharged into aquatic environments. When drugs are disposed directly in garbage, these active compounds can leach from landfills into groundwater supplies (Barnes et al., 2004; Holm, Ruegge, Bjerg, Christensen, 1995; Ternes, 1998).

Barnes et al. (2004) analyzed groundwater from monitoring wells located downgradient of a landfill in Oklahoma, and detected 22 organic contaminants including triclosan (up to 0.21 $\mu \mathrm{g} / \mathrm{L}$ ) and lincomycin (up to $0.10 \mu \mathrm{g} / \mathrm{L}$ ). Since the landfill had been closed for 15 years prior to collecting samples, this study indicated the potential for some contaminants to persist and be transported in groundwater (Barnes et al., 2004). Also, the Maine Department of Environmental Protection measured concentrations of drugs in landfill leachate (Behr, Stahler, \& Pistell, 2010). The three landfills chosen received large quantities of household waste, contained engineered liner systems, and received little or no sludge from STPs. They detected PhACs in the leachate in alarming levels, including up to $117,000 \mathrm{ng} / \mathrm{L}$ of acetaminophen and up to $14,800 \mathrm{ng} / \mathrm{L}$ of metformin (anti-diabetic drug) (Behr, Stahler, \& Pistell, 2010). As argued by Behr, Stahler, \& Pistell (2010), "Therefore, by selecting landfills that do not receive appreciable amounts of wastewater treatment plant sludge, one may conclude that any pharmaceuticals detected in the leachate result from their direct disposal via household waste ...” (p. 1).

It is difficult for scientists to determine the contribution of pharmaceutical waste in the environment from excretion versus the contribution of waste from human disposal. Both processes can lead to PhACs contaminating the environment. To gain a better understanding of the contributions, Ruhoy and Daughton (2007) analyzed coroner data on leftover drugs for measuring the quantities of medications accumulated by individuals. They found that the Clark County Coroner's Office in Nevada disposed of more than $102 \mathrm{~kg}$ of active pharmaceutical compounds mainly down the toilet ( $92 \%$ of the time) over 13 months. Ruhoy and Daughton (2007) extrapolated the data to estimate that about 17.9 tonnes of drugs from the deceased population alone are disposed into STPs by coroners annually. 
The widespread detection of PhACs in the aquatic environment has started to raise concerns regarding the effectiveness of STPs. There are two categories of wastewater treatment processes: conventional and advanced. Conventional treatment usually involves biological degradation using the activated sludge process, while advanced treatment consists of tertiary removal processes, including reverse osmosis and advanced oxidation (WHO, 2012). The efficacy of the treatment depends on the type of treatment process; the drug's chemical composition, reactivity and persistence; and how the substance responds to the treatment (WHO, 2012). Thus, the effectiveness in removing PhACs from wastewater differs greatly depending on the treatment type. Table 3 outlines removal efficiencies for wastewater treatment processes.

Water treatment facilities also play a key role in removing contaminants from drinking water. As studies continue to detect drugs in drinking water, there is a concern that these pharmaceutical cocktails may harm human health. Drinking water plants in Canada treat about 5,878 million cubic metres of raw water - surface water provides $88 \%$ and groundwater provides 10\% (Statistics Canada, 2009). As described by the WHO (2012):

None of the wide range of drinking-water treatment processes available have been designed specifically to remove pharmaceuticals that may be present in source waters. Nonetheless, removal of pharmaceuticals during drinking-water treatment is largely dependent on their physical and chemical properties, and treatment processes can therefore achieve some level of removal. (p. 18)

Conventional treatment, including coagulation, flocculation and sedimentation, tends to be inefficient in removing PhACs from raw drinking water (Ternes et al., 2002). More advanced and costly treatments, including ozonation, activated carbon, membrane filtration, and reverse osmosis can be effective in removing various $\mathrm{PhACs}$, and can even reach removal rates of more than 99\% (Kim, Cho, Kim, Vanderford, \& Snyder, 2007; Ternes et al., 2002). However, the current drinking water infrastructure has not been specifically designed to remove $\mathrm{PhACs}$. Statistics Canada (2009) found that the majority of treated water in Canada is processed ${ }^{5}$ using conventional treatment (47.5\%), followed by disinfection and other unfiltered systems (14.3\%), granular media filtration (12.7\%), and disinfection only (10.1\%).

\footnotetext{
${ }^{5}$ Based on total treated water volume in Canada. Conventional treatment includes disinfection, coagulation/flocculation, clarification, sedimentation and granular media filtration; disinfection and other unfiltered systems include disinfection and other processes; and granular media filtration includes disinfection and granular media filtration (Statistics Canada, 2009).
} 
Table 3. Removal Efficiency of PhACs from Conventional \& Advanced Wastewater Treatment (Adapted from WHO, 2012)

\begin{tabular}{|c|c|c|}
\hline Treatment Process & Removal Efficiency (\%) & Water Source \\
\hline \multicolumn{3}{|l|}{ Conventional Treatment: } \\
\hline Activated sludge & $7-100$ & Primary settled sewage \\
\hline Biological filtration & $6-71$ & Primary settled sewage \\
\hline Coagulation, filtration \& settling & $5-36$ & Not indicated \\
\hline Primary settling & $3-45$ & Not indicated \\
\hline Sand filtration & $0-99$ & Activated sludge effluent \\
\hline Treatment Process & Removal Efficiency (\%) & Water Source \\
\hline \multicolumn{3}{|l|}{ Advanced Treatment: } \\
\hline Biomembrane & $23-99$ & Treated effluent \\
\hline Dark \& light Fenton & $80-100$ & Not indicated \\
\hline Microfiltration \& reverse osmosis & $91-100$ & Secondary treated effluent \\
\hline Ozonation & $86-100$ & Secondary effluent \\
\hline Ozonation \& catalytic ozonation & $>9-100$ & Not indicated \\
\hline Ozonation/ultrasound \& sonocatalysis & $23-45$ & Not indicated \\
\hline Photolysis (UV/hydrogen peroxide) & $52-100$ & Not indicated \\
\hline Reverse osmosis & $62-97$ & Secondary treated effluent \\
\hline Ultrasound & $24-100$ & Not indicated \\
\hline UV irradiation & 29 & Not indicated \\
\hline $\mathrm{UV} / \mathrm{TiO}_{2}$ & $>95$ & Not indicated \\
\hline
\end{tabular}

Overall, this review of the scientific literature has revealed that the science has identified concerns with PhACs in the environment. However, there are several uncertainties, especially regarding the direct human health risks associated with these substances. As seen in the following sections, the second part of the literature review outlines and compares the management strategies utilized to deal with PhACs.

\subsection{Management Strategies in a Comparative Context}

This area of research reveals two complex dilemmas. The first relates to the design of drugs. If producers design and manufacture medications that can treat diseases or even prolong an individual's life but at the same time these ingredients cause environmental impacts and pose potential health risks, should human health or the environment be prioritized, or if both are to be pursued, how is the balancing to be achieved? The second dilemma involves the uncertainties of the behaviour and fate of drugs in the environment. It is known that low doses of medications, as prescribed by doctors, are not lethal to human health when first entering the body. After excretion, these substances undergo further dilution in STP effluent. What scientists do not 
know are the health impacts associated with exposure to a mixture of $\mathrm{PhACs}$ in the environment. Since it is unreasonable to prohibit individuals from taking drugs required for optimal health, governments must develop desirable actions for protecting both health and the environment.

As argued by Myers (2007), "Many environmental problems are difficult to evaluate because they are beset with scientific uncertainty. ... [W] hat is 'legitimate scientific caution' in the face of uncertainty?" Should policymakers take preventative measures and apply the Precautionary Principle even if cause and effect relationships have not been established scientifically? As seen in the following sections, policymakers have implemented different approaches to reduce $\mathrm{PhACs}$ in the environment.

\subsubsection{Voluntary Initiatives}

As the concerns associated with PhACs grow, some governments have required the drug industry through legislation to adopt a system to safely collect and dispose of the public's unused drugs. However, in several jurisdictions, the pharmaceutical industry has implemented voluntary initiatives to divert drugs from the environment. Webb (2007) defined voluntary environmental initiatives as "the full range of initiatives in which businesses undertake to reduce or minimize or eliminate an environmental impact or impacts, where the businesses are not legislatively required to undertake the initiative in question" (p. 3). Voluntary initiatives can embrace the concept of corporate social responsibility ${ }^{6}$ (CSR). According to the OECD (n.d.), under CSR " $[\mathrm{b}]$ usinesses are expected to obey the various laws which are applicable to them and, as a practical matter, often have to respond to societal expectations that are not written down as formal law."

Benefits of voluntary programs are that they embrace market and community energies to influence behaviour; they draw on non-governmental resources; and they can give firms more flexibility (compared to stringent regulations) to develop options for better performance (Environmental Commissioner of Ontario [ECO], 1996; Webb, 2004). Recognized weaknesses are that there is a lack of regulatory signals to mandate a change in performance, and there is the potential for firms not to participate ("free riders") while others invest and meet high standards (ECO, 1996; Webb, 2007).

\footnotetext{
${ }^{6}$ Foreign Affairs, Trade and Development Canada (2013) defined CSR as "voluntary activities undertaken by a company to operate in an economic, social and environmentally sustainable manner."
} 
Since pharmacies have a responsibility for providing safe and effective healthcare, several have adopted voluntary collection services for unused/expired drugs. As supported by the [Canadian] National Association of Pharmacy Regulatory Authorities (n.d.), "Although there appears to be little financial incentive ... for pharmacists to dispose of these materials appropriately, pharmacists who are known to practice in an environmentally responsible manner are seen as community-minded, and may benefit from enhanced consumer loyalty." These initiatives tend to be recognized as "good pharmacy practice" from governments and the public.

Examples of these initiatives are described in the following sections of this thesis. Some of them, like Alberta's ENVIRx Program and Nova Scotia's Medication Disposal Program are administered by their Pharmacists' Associations, while others like Shoppers Drug Mart's Sharps and Medication Disposal service are administered by retail pharmacies. Shoppers Drug Mart's initiative safely disposed of 159,000 kg of expired drugs and 115,000 kg of sharps returned by consumers in 2012 (Shoppers Drug Mart, 2012). A limitation of these strategies is that they assume voluntary compliance from consumers. If consumers choose not to participate or are not even aware of the service, then the initiative cannot even begin to effect change.

There have also been cases where the pharmaceutical producers have taken on the responsibility of managing their product's waste. This concept is analyzed in the next section.

\subsubsection{Extended Producer Responsibility}

Many jurisdictions have adopted extended producer responsibility as an approach to manage certain types of waste. EPR is a policy approach in which the producer of a product is held physically and/or financially liable for the post-consumer stage of that product's life cycle (OECD, 2001). Figure 9 outlines this concept. EPR can be regulated by government through formal legislation or it can be voluntary; however, the emphasis is placed on the producer taking responsibility for both the upstream phase (materials extraction and manufacturing) and downstream phase (post-consumer) of a product's lifecycle. Tables 4 and 5 summarize some benefits and disbenefits of voluntary and regulatory EPR programs, respectively.

Germany was one of the first countries to lead an EPR initiative with the German Packaging Ordinance in 1991 which made industry liable for handling its packaging waste (Hanisch, 2000). This initiative sparked North American interest in EPR in the mid-1990s. There are now various provincial and national EPR programs in Canada for products such as beverage containers, electronics and household hazardous waste (Environment Canada, 2012b). 
EPR is becoming an internationally widely used policy approach for managing waste as it can have environmental, financial, and public health or other social benefits. As supported by Scheijgrond (2011), EPR forces producers to identify environmental improvements and to influence changes in the upstream and downstream phases of a product's life. When producers are required to internalize the environmental costs of their product at the post-consumer stage, this provides an incentive to take environmental factors into account in the design and production of their product. EPR can stimulate innovation and pollution prevention activities like reducing materials and energy use; substituting toxic materials with non-toxic materials; increasing recyclable content; improving the efficiency of production processes; and extending the useful life of a product (McKerlie, Knight, \& Thorpe, 2006; OECD, 2001).

EPR programs can also provide a safe collection system for the public to return their waste which minimizes the product's potentially harmful environmental impacts from improper disposal. In order for EPR systems to work, the consumer must first voluntarily return their product. Thus, EPR is an approach that assumes voluntary compliance from consumers, and as described in Section 3.4.1, there are some weaknesses with this strategy.

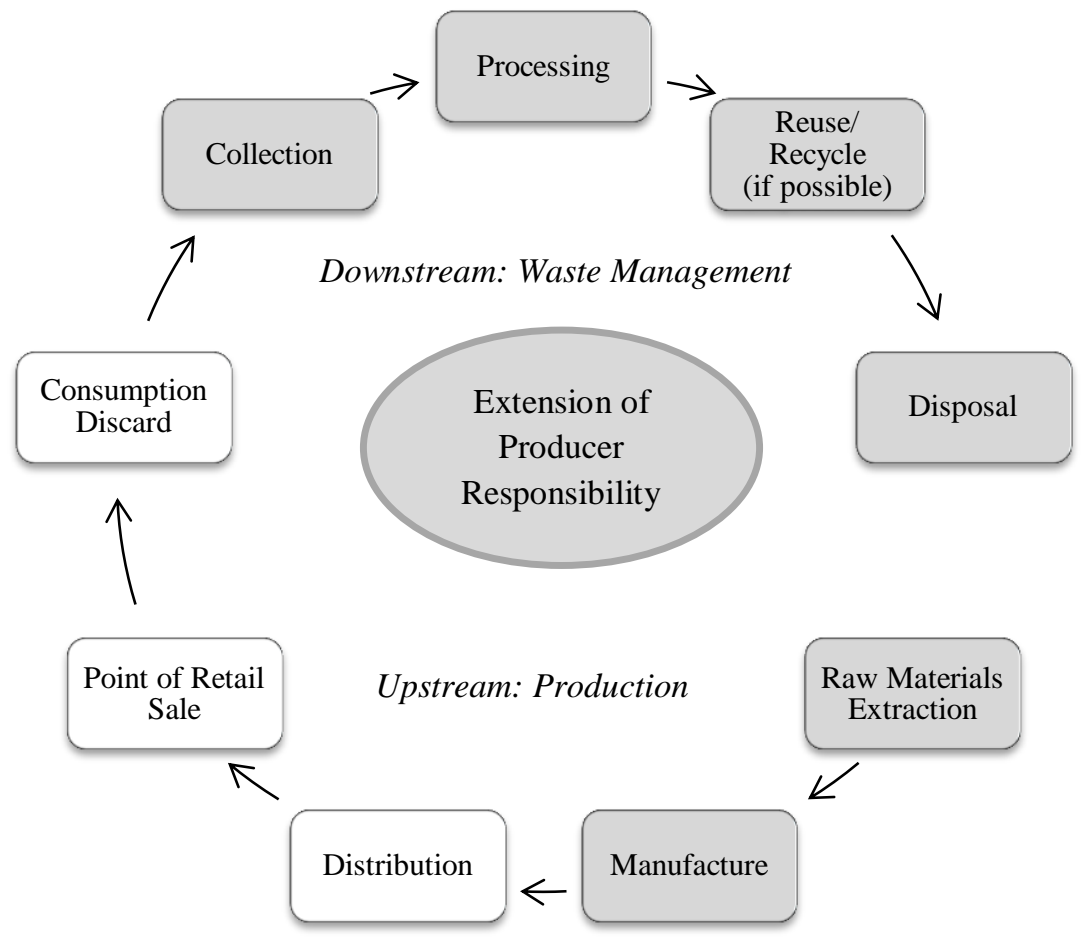

Figure 9. The Concept of EPR (Adapted from McKerlie, Knight, \& Thorpe, 2006). 
Table 4. Benefits and Disbenefits of Voluntary EPR Programs

\begin{tabular}{|c|c|c|}
\hline Stakeholder & Benefits & Disbenefits \\
\hline Governments & $\begin{array}{l}\text { - May reduce the need to enact } \\
\text { regulations which require } \\
\text { monitoring and enforcement } \\
\text { - May require less government } \\
\text { resources, staffing, and money }\end{array}$ & $\begin{array}{l}\text { - Standards are typically set by } \\
\text { industry (may be set low) } \\
\text { - } \quad \begin{array}{l}\text { Programs and performance reporting } \\
\text { may not be transparent to the public }\end{array} \\
\text { - } \quad \text { May require partial government } \\
\text { funding (and thus taxpayer dollars) }\end{array}$ \\
\hline $\begin{array}{l}\text { Producers of } \\
\text { Designated Products }\end{array}$ & $\begin{array}{l}\text { - Allow for self-regulation and } \\
\text { may reduce the need for } \\
\text { government to regulate } \\
\text { May constitute a due diligence } \\
\text { or reasonable care defence } \\
\text { - Reducing waste in the } \\
\text { environment is perceived as } \\
\text { positive from the public }\end{array}$ & $\begin{array}{l}\text { - Without regulations, this may create } \\
\text { unfair competition in the market as } \\
\text { some companies may not participate } \\
\text { or invest into the programs (free } \\
\text { riding) } \\
\text { - Usually require company funding } \\
\text { and resources }\end{array}$ \\
\hline
\end{tabular}

Table 5. Benefits and Disbenefits of Regulatory EPR Programs

\begin{tabular}{|l|l|l|}
\hline \multicolumn{1}{|c|}{ Stakeholder } & \multicolumn{1}{|c|}{ Benefits } & \multicolumn{1}{c|}{ Disbenefits } \\
\hline Governments & $\bullet \begin{array}{l}\text { Can shift waste management } \\
\text { costs away from governments } \\
\text { (and taxpayers) to producers } \\
\text { Governments can set stringent } \\
\text { standards and performance } \\
\text { measures }\end{array}$ & $\bullet \begin{array}{l}\text { Require monitoring and } \\
\text { enforcement costs from } \\
\text { governments }\end{array}$ \\
& $\bullet \begin{array}{l}\text { Programs can be made challenging to monitor } \\
\text { transparent to the public } \\
\text { hundreds of producers and hold } \\
\text { individual companies accountable }\end{array}$ \\
\hline $\begin{array}{l}\text { Producers of } \\
\text { Designated Products }\end{array}$ & $\bullet \begin{array}{l}\text { Regulated programs can } \\
\text { promote fair competition in the } \\
\text { market by requiring all } \\
\text { producers to participate } \\
\text { Reducing waste and protecting } \\
\text { the environment are perceived } \\
\text { as positive from the public }\end{array}$ & $\bullet \begin{array}{l}\text { Can be rigid and may not encourage } \\
\text { innovation or creativity } \\
\text { Monitored and enforced by } \\
\text { government } \\
\text { Require company funding and } \\
\text { resources }\end{array}$ \\
\hline
\end{tabular}

EPR can also have economic advantages. EPR programs that require producers to be financially liable for their product's post-consumer stage shift the financial responsibility of waste management from governments to producers. As argued by McKerlie, Knight, \& Thorpe (2006), an “. . . economy cannot grow in a sustainable way unless 'profitability' is decoupled from waste generation, and those profiting from the creation of waste are held accountable for the real costs associated with their products" (p. 618). Shifting the financial burden of collecting 
and disposing of waste to producers can alleviate the stress for governments that struggle to fund waste diversion initiatives. Also, as public pressure increases regarding landfill approvals, and with less space available for landfill sites, this "polluter pays" principle of EPR can be an attractive policy tool for governments.

EPR can also drive innovation and encourage efficiency in the marketplace (Ontario Waste Management Association [OWMA], 2013). When the responsibility and costs are placed on the producer, they will likely want to find the waste service provider that can manage the material at the lowest cost. This provides a strong incentive for waste diversion service providers to develop innovative technologies, processes and services that are of value to the producers and provide a competitive advantage in the marketplace (OWMA, 2013).

The term "stewardship" is often used interchangeably with EPR. Stewardship programs tend to be designed and operated by governments/government agencies, and the producers, if involved at all, are in a minority (EPR Canada, 2012a). Stewardship programs are usually funded by government or by fees imposed by government on producers or consumers. As described by EPR Canada (2012a), “Only programs where producers are solely and fully responsible for designing, operating and financing the diversion program and are accountable for the program's environmental performance are considered full EPR” (p. 3).

\subsubsection{Medications Return Programs}

Several jurisdictions have implemented medications return programs, also called collection programs, take-back schemes or disposal programs, to promote the safe disposal of drugs and to divert PhACs from the environment. Since drugs are intended to promote health and to treat illnesses, it seems easier and more feasible for governments to focus on disposal policies (through medications return programs) as opposed to human consumption policies.

The key objective of MRPs is to safely collect the public's post-consumer drugs at a collection location (e.g. a pharmacy/waste depot) for proper treatment and disposal, usually using incineration (Health Canada, 2009). MRPs tend to be initiated by governments, pharmaceutical associations and/or the drug industry. Some programs are regulated and enforced by government, as seen in many European Union (EU) states, while others are voluntary initiatives. Funding sources vary - some initiatives, such as those in Australia and Sweden, are mainly funded by governments, while other initiatives, as seen in Portugal and Spain, are funded by industry (Health Canada, 2009). Thus, return programs can be a form of 
EPR - holding producers financially/physically responsible for collecting, transporting and disposing of the waste their product generates.

Table 6 outlines some potential environmental, economic, and health benefits of medications return programs. Since MRPs can be based on the concept of EPR, many of the benefits discussed in Section 3.4.2 apply. For instance, programs that require producers to fund the collection, transportation and disposal of pharmaceutical waste shift the financial burden from governments (and taxpayers) to producers. These initiatives can also divert the public's waste from reaching aquatic environments and landfills. In addition to these economic and environmental benefits, return programs may also protect human health.

MRPs can provide a method for consumers to return unused drugs to a pharmacy as opposed to storing them at home where there may be an increased risk of drug abuse or addiction. About six out of ten teenagers claim that prescription drugs are easy to get from home (Partnership for a Drug-Free America, 2009). Canada is the world's second largest per capita consumer of prescription opioids such as morphine, codeine and oxycodone (National Advisory Committee on Prescription Drug Misuse [NACPDM], 2013). About one in six Ontario teens take prescription opioid pills for non-medical reasons (Fischer et al., 2013).

The harms associated with prescription drugs, including addiction, misuse and death, are becoming a major public health and safety concern (NACPDM, 2013). Some individuals taking prescribed drugs have health conditions for which the drugs are expected to effect a cure or treatment, or at least alleviate the symptoms. However, for others, the elements in the drugs are not beneficial to their health and may actually be potentially hazardous depending on the dose levels. Prescription drug misuse is becoming so prevalent in Canada, particularly in First Nation Communities, that the National Advisory Committee on Prescription Drug Misuse (NACPDM, 2013) published a national 10-year strategy to deal with the issue in Canada.

The harms associated with prescription drug misuse also place a financial burden on healthcare and public safety systems. The number of emergency hospital visits in the U.S. due to the misuse or abuse of drugs sharply increased by 115\% between 2004 and 2010 (Substance Abuse and Mental Health Services Administration, 2012). According to the NACPDM (2013) there are no data available on the costs of prescription drug misuse and harms in Canada; however, the yearly cost of non-medical use of prescription opioids in the U.S. is more than $\$ 50$ billion, with crime and lost productivity representing most of this cost. The NACPDM (2013) 
stated that there has "been a surge of criminal activity for diverting prescription drugs from legal, regulated supply routes to illegal markets" and that this "increases the pressures on Canada's enforcement measures and potentially compromises their effectiveness" (p. 11). Thus, MRPs provide an opportunity for consumers to properly dispose of their unused drugs as opposed to storing them at home which may potentially lead to the harms of drug misuse.

Overall, MRPs can generate not only key economic and environmental benefits but may also create public health and safety benefits. With prescription drug misuse becoming a widespread problem, this may explain why it has become more common to implement return schemes particularly across Canada and the U.S. The added public health and safety advantages, in addition to the environmental and economic benefits, makes an MRP an even more appealing management strategy since the public tends to place a high priority on their children's wellbeing.

Table 6. Potential Economic, Environmental and Health Benefits of MRPs

\begin{tabular}{|l|l|l|}
\hline \multicolumn{1}{|c|}{ Economic Benefits } & \multicolumn{1}{|c|}{ Environmental Benefits } & \multicolumn{1}{c|}{ Public Health Benefits } \\
\hline $\begin{array}{l}\text { - Can shift waste management } \\
\text { costs from governments to } \\
\text { producers through EPR }\end{array}$ & $\begin{array}{l}\text { Can allow for proper } \\
\text { collection, transportation and } \\
\text { disposal of medications }\end{array}$ & $\begin{array}{l}\text { Can promote the return of } \\
\text { drugs vs. storing them in the } \\
\text { house where there may be an } \\
\text { increased risk of drug abuse, } \\
\text { overdose, addiction, or death }\end{array}$ \\
$\begin{array}{l}\text { - Can alleviate pressure for } \\
\text { governments that struggle to } \\
\text { fund waste diversion initiatives }\end{array}$ & $\begin{array}{l}\text { - Can divert waste from } \\
\text { reaching aquatic environments } \\
\text { and landfills }\end{array}$ & $\begin{array}{l}\text { These harms associated } \\
\text { with prescription drugs can } \\
\text { place a burden on } \\
\text { communities, health care and } \\
\text { public safety systems }\end{array}$ \\
$\begin{array}{l}\text { - If producers fund the program, } \\
\text { there is less taxpayer money used } \\
\text { towards waste diversion/waste } \\
\text { management }\end{array}$ & $\begin{array}{l}\text {-If producers are forced to } \\
\text { pay for the program, this } \\
\text { provides an incentive to take } \\
\text { environmental factors into } \\
\text { account in the design and } \\
\text { production of their product }\end{array}$ & \\
\hline
\end{tabular}

\subsubsection{Criteria for an Optimal Medications Return Program Based on EPR}

Several jurisdictions have adopted EPR programs, including medications return programs. Hence, there is an extensive amount of knowledge, practices, experiences, and frameworks in place to learn from. The advantages and limitations of EPR and medications return programs have been widely documented in the literature such as government/agency documents, stewardship plans and reports, and academic journals. As a result, a comprehensive 
literature review was conducted to develop a set of benchmark criteria for an optimal medications return program when regulating extended producer responsibility. The criteria were used in Chapter 5 to measure the effectiveness of BC's Medications Return Program and Ontario's Orange Drop. Since BC and Ontario adopted regulatory MRPs based on the concept of extended producer responsibility, the chosen criteria focus on common elements identified in the EPR literature.

Table 7. Criteria for an Optimal Medications Return Program Based on EPR

\begin{tabular}{|c|c|}
\hline Criterion & Description \\
\hline $\begin{array}{l}\text { Clearly } \\
\text { Defined Scope }\end{array}$ & $\begin{array}{l}\text { - The program's objectives, product definitions, and roles and responsibilities of the } \\
\text { parties are clearly stated (BC MOE, 2012; CCME, 2009; OECD, 2001). }\end{array}$ \\
\hline $\begin{array}{l}\text { Results-based } \\
\text { Regulatory } \\
\text { Framework }\end{array}$ & $\begin{array}{l}\text { - The program focuses on setting measurable outcomes in regulations or legislation } \\
\text { and gives producers the flexibility to meet the outcomes (BC MOE, 2012; CCME, } \\
\text { 2009; ECO, 2012). }\end{array}$ \\
\hline Accountability & $\begin{array}{l}\text { - The producers are held accountable for financing and operating the program, and } \\
\text { for achieving performance measures (BC MOE, 2012; CCME, 2009; ECO, 2012; } \\
\text { Recycling Council of Ontario [RCO], 2012). }\end{array}$ \\
\hline $\begin{array}{l}\text { Internalizing } \\
\text { Program Costs }\end{array}$ & - $\quad$ Program costs are internalized as a factor of production (CCME, 2009). \\
\hline $\begin{array}{l}\text { Effective } \\
\text { Monitoring \& } \\
\text { Enforcement }\end{array}$ & $\begin{array}{l}\text { - The program has effective oversight to monitor the program and ensure a level } \\
\text { playing field is established (ECO, 2012; OECD, 2001). } \\
\text { The jurisdictional authority enforces the program and dedicates sufficient } \\
\text { resources to monitor compliance (CCME, 2009; ECO, 2012; RCO, 2012). }\end{array}$ \\
\hline $\begin{array}{l}\text { Open } \\
\text { Consultation } \\
\text { Process }\end{array}$ & $\begin{array}{l}\text { - There is an open consultation process during program development that allows } \\
\text { stakeholders to participate (BC MOE, 2012; CCME, 2009; OECD, 2001). }\end{array}$ \\
\hline $\begin{array}{l}\text { Performance } \\
\text { Measures and } \\
\text { Targets }\end{array}$ & $\begin{array}{l}\text { - Measurable key performance indicators of the program are established and } \\
\text { maintained (CCME, 2009; OECD, 2001). Expired drugs cannot be } \\
\text { reused/recycled like other products can (e.g. cell phones, laptops or computers). } \\
\text { Thus, the following measures are important for MRPs: } \\
\text { a) Promotion and Education (P\&E): } \\
\text { - There should be a requirement for producers to make investments in P\&E } \\
\text { strategies to maximize customer knowledge about the program and proper } \\
\text { disposal (CCME, 2009; RCO, 2012). This is most effective when there is a } \\
\text { provision that requires producers to partner with their distributors and retailers } \\
\text { to provide point of sale P\&E materials (RCO, 2012). These materials should } \\
\text { be available at the point of purchase (pharmacies) e.g. brochures, posters, and } \\
\text { medication leaflets/packages (Brushin, 2005; RCO, 2012; Vollmer, 2010). }\end{array}$ \\
\hline
\end{tabular}




\begin{tabular}{|c|c|}
\hline Criterion & Description \\
\hline $\begin{array}{l}\text { Performance } \\
\text { Measures and } \\
\text { Targets }\end{array}$ & $\begin{array}{l}\text { b) Consumer Awareness: } \\
\text { - This is the most important indicator because if consumers are not aware of } \\
\text { the program then disposal behaviour will likely not change (Brushin, 2005; } \\
\text { CCME, 2009; Vollmer, 2010; WHO, 2012). The producer should be } \\
\text { responsible for measuring the percentage of the population aware of the } \\
\text { program and have actually participated, and monitor how awareness changes } \\
\text { over time e.g. public surveys (BC MOE, 2012). } \\
\text { c) Accessibility: } \\
\text { - There should be accessible and convenient locations that are familiar, free } \\
\text { and frequent to consumers (CCME, 2009; RCO, 2012). } \\
\text { d) Product collection: } \\
\text { - Since drugs are a consumable product and are to be taken as prescribed by } \\
\text { physicians, then there should not be any waste. Hence, a stringent collection } \\
\text { target should not be set. However, collection data should be acquired to } \\
\text { understand program size and impact. }\end{array}$ \\
\hline $\begin{array}{l}\text { End-of-life } \\
\text { Management }\end{array}$ & $\begin{array}{l}\text { - Unused/expired pharmaceuticals should not be reused or recycled; they should be } \\
\text { safely destroyed by high temperature incineration (Vollmer, 2010; WHO, 1999). }\end{array}$ \\
\hline $\begin{array}{l}\text { Reporting and } \\
\text { Auditing } \\
\text { Requirements }\end{array}$ & $\begin{array}{l}\text { Publicly available reports (annual or bi-annual) are submitted to the authority } \\
\text { outlining progress towards meeting program objectives and targets (BC MOE, } \\
\text { 2012; CCME, 2009). } \\
\text { There are independent third-party audits on the operational performance of the } \\
\text { program such as audits on location of collection sites, total product collected, and } \\
\text { environmental service standards (BC MOE, 2012; CCME, 2009). }\end{array}$ \\
\hline
\end{tabular}

\subsubsection{Criminal Law Measures}

Criminal law deals with "public wrongs" - crimes that breach fundamental norms and values of society (Greenbaum \& Wellington, 2010, p. 49). Criminal law measures have been used by governments as a management strategy for promoting the proper disposal of drugs. Criminal law in Canada is a matter of federal jurisdiction and is mainly based on the Criminal Code of Canada; however, the Competition Act and the Controlled Drugs and Substances Act also have criminal provisions. The Controlled Drugs and Substances Act sets out eight schedules of drugs, offences and punishment for possessing, trafficking, importing, exporting and producing controlled substances ${ }^{7}$. This criminal law tool gives the federal government the power to administer initiatives that protect the public from the potential harms associated with the misuse of drugs. On May 11, 2013, Public Safety Canada and the Canadian Association of

${ }^{7}$ A "controlled substance" is a substance included in schedule I, II, III, IV or V in the Controlled Drugs and Substances Act, such as opium, codeine and oxycodone. 
Chiefs of Police launched the "National Prescription Drug Drop-Off Day" which allowed Canadians to return their unused/expired drugs to local police and community partners.

Federal criminal law measures have also been used in the U.S. to promote the proper disposal of drugs. The Secure and Responsible Drug Disposal Act of 2010 allows the U.S. Drug Enforcement Administration (U.S. DEA) along with state/local enforcement to facilitate "National Prescription Drug Take-Back Events" to safely collect the public's unused/expired drugs. Thus, criminal law can be used as a tool, as seen in both Canada and the U.S., to promote the safe disposal of drugs and to educate the public about the harms of prescription drug misuse.

\subsubsection{Environmental Risk Assessment Policies}

Some jurisdictions have environmental risk assessment (ERA) policies for drugs to determine the potential risks that these substances have on the environment. Kolluru (1996) defined risk assessment as the "process of estimating the probability of occurrence of an undesirable event and the magnitude of its consequences over a specified time period" (p. 4.44.5). This scientific tool uses risk analysis methods to decide if the risks are acceptable. Cooper and Vanderlinden (2009) described risk assessment as being science-based whereas decisions made during risk management take into account broader issues like economic impacts and social issues. Risk assessment usually involves four steps: data evaluation and hazard identification; toxicity or dose-response assessment; exposure assessment; and risk characterization.

According to Kolluru (1996), key advantages of risk assessment are that it provides a systematic framework for prioritizing problems; it uses situation-specific factors; and it can be resource effective. Limitations are that the risks are probabilistic while the methods are deterministic; there can be orders-of-magnitude variability in ecological assessments; and there are many assumptions made (Kolluru, 1996). For instance, it is challenging to quantify the behaviour of pharmaceutical cocktails interacting in the environment, especially since PhACs are detected in trace concentrations.

Risk assessment is often used in environmental policy approaches as a tool for addressing environmental risks. However, it has generated extensive controversy due to its science-based nature. Not only is science incorporated into the approach, it is usually used as a determining factor to classify risks. Although there have been reforms made to the traditional risk assessment tool, the overall "narrow, chemical-by-chemical approach remains" (Cooper \& Vanderlinden, 2009, p. 205). Risk assessment has been criticized for presuming environmental contaminants as 
"innocent until proven guilty" resulting in exposures continuing until "sufficient evidence has been gathered to refute this presumption of innocence" (Cooper \& Vanderlinden, 2009, p. 205).

Burton and Pushchak (1984) argued that one of the greatest difficulties faced with risk assessment is that it will not resolve the discrepancy between scientific and public perception of risk. The scientific community has generally accepted the objective definition "that risk equals the probability of an event times its consequence" whereas for the public, "risk is perceived (understood subjectively) rather than rationally calculated" (Burton \& Pushchak, 1984, p. 469).

Risk assessment differs from the precautionary approach, as seen in Table 8. Under the precautionary approach, action is taken if there is a concern about the risk even if there are scientific uncertainties. Extended producer responsibility can be considered a precautionary measure since action is taken to safely collect and dispose of the public's waste even when there are unknowns regarding the risks. By contrast, when using risk assessment, one waits for more information when there are uncertainties.

Table 8. Risk Assessment vs. the Precautionary Approach (Adapted from Cooper \& Vanderlinden, 2009, p. 209)

\begin{tabular}{|l|l|}
\hline \multicolumn{1}{|c|}{ Risk Assessment } & \multicolumn{1}{c|}{ Precautionary Approach } \\
\hline $\begin{array}{l}\text { If scientific uncertainty exists about risk, don't } \\
\text { act, wait for more information }\end{array}$ & $\begin{array}{l}\text { If concerned about risk, take action in the face of } \\
\text { scientific uncertainty }\end{array}$ \\
\hline $\begin{array}{l}\text { Focuses on avoiding Type I errors - those errors } \\
\text { that accept spurious associations as causal, known } \\
\text { as "false positives" (in other words, it is assumed } \\
\text { that one event causes another when it actually } \\
\text { does not) }\end{array}$ & $\begin{array}{l}\text { Focuses on avoiding Type II errors - those errors } \\
\text { that miss true causal associations, known as } \\
\text { "false negatives" (in other words, it is assumed } \\
\text { that two events are unrelated when actually, one } \\
\text { event causes the other) }\end{array}$ \\
\hline $\begin{array}{l}\text { Evaluates individual risk with little consideration } \\
\text { of the broader context (other similar risks or safer } \\
\text { alternatives) }\end{array}$ & $\begin{array}{l}\text { Broadens evaluation of risk to address additional } \\
\text { concerns, for example, temporal and spatial } \\
\text { considerations, combined risks from multiple } \\
\text { exposures, and an evaluation of safer alternatives }\end{array}$ \\
\hline $\begin{array}{l}\text { Reactive in nature, focuses on pollution control } \\
\text { and remediation }\end{array}$ & $\begin{array}{l}\text { Proactive in nature, focuses on design of safer } \\
\text { chemicals and products }\end{array}$ \\
\hline
\end{tabular}

According to Cooper and Vanderlinden (2009), risk assessment tends to evaluate risk with little consideration of the broader context whereas the precautionary approach addresses additional concerns and evaluates safer alternatives. This is seen with the extended producer responsibility strategy. Not only does EPR focus on waste diversion, it also addresses economic and health issues. EPR shifts the costs of waste management from taxpayers to producers, and 
has the potential to stimulate pollution prevention activities. Thus, it can be argued that EPR as a precautionary approach gives policymakers more opportunities to broaden their evaluation of the risk than can be offered with risk assessment (Cooper \& Vanderlinden, 2009).

\subsection{Examples of Management Strategies}

This section outlines examples of management strategies used by Europe, Australia, the U.S. and Canada to gain an understanding of the approaches used around the world to deal with PhACs in the environment. These jurisdictions are chosen since they have policy tools and instruments in place for managing this environmental problem.

\subsubsection{Europe}

General management strategies in Europe, in addition to well-developed examples in Sweden, Portugal and France, were examined.

In 2004, the EU adopted Directive 2004/27/EC which stated that "Member States shall ensure that appropriate collection systems are in place for medicinal products that are unused or have expired" (Article 127b). This Directive also mandates that the outer packaging (or immediate packaging) of medicinal products shall include "specific precautions relating to the disposal of unused medicinal products or waste derived from medicinal products, where appropriate, as well as reference to any appropriate collection system in place” (Article 54j).

The European Environment Agency (EEA) conducted a survey in 2008, consisting of 28 countries, to investigate the amount of waste collected through medications return programs (EEA, 2010). They found that pharmacies are the most common return site. As seen in Table 9, nations with the lowest collection rates were Croatia (0.19 g/capita annually) and Estonia (3.4 g/capita annually), while countries with the highest collection rates were Switzerland (237 g/capita annually) and France (231 g/capita annually) (Vollmer, 2010). According to Vollmer (2010), "They [collection rates] depend on the amount of pharmaceuticals distributed, variance in patients' compliance to use the prescribed pharmaceuticals for therapy and lack of knowledge of established return schemes or the environmental effects of pharmaceuticals flushed into the drain" (p. 176). Even though return programs have been widely established throughout Europe, the EEA (2010) still believed that a substantial volume of unused drugs are not collected. 
Table 9. Number of Pharmaceuticals Sold and Returned through European Return Programs (Vollmer, 2010)

\begin{tabular}{|l|l|l|}
\hline \multicolumn{1}{|c|}{ Country } & \multicolumn{1}{|c|}{$\begin{array}{c}\text { Number of Pharmaceutical } \\
\text { Packages Sold } \\
\text { (per capita annually) }\end{array}$} & $\begin{array}{c}\text { Unused/Expired } \\
\text { Pharmaceuticals Collected } \\
\text { (g per capita annually) }\end{array}$ \\
\hline Croatia & (Not indicated) & 0.19 \\
\hline Estonia & 19.46 & 3.4 \\
\hline Slovenia & 16.91 & 4.5 \\
\hline Lithuania & 27.12 & 10 \\
\hline Finland & 16.64 & 11 \\
\hline Iceland & (Not indicated) & 19 \\
\hline The Netherlands & 14.34 & 30 \\
\hline Czech Republic & 25.75 & 36 \\
\hline Liechtenstein & (Not indicated) & 39 \\
\hline Belgium & 21.83 & 46 \\
\hline Italy & 28.87 & 54 \\
\hline Denmark & 14.84 & 55 \\
\hline Spain & 26.99 & 57 \\
\hline Portugal & 25.12 & 58 \\
\hline Germany & 18.34 & 73 \\
\hline Styria & 22.71 (Austria) & 99 \\
\hline Sweden & 16.91 & 119 \\
\hline Ireland & 22.86 & 142 \\
\hline Luxembourg & 27.72 & 174 \\
\hline France & 51.79 & 231 \\
\hline Switzerland & 19.78 & 237 \\
\hline & & \\
\hline & & \\
\hline
\end{tabular}

Program costs and funding sources for return programs vary. All retail pharmacies in Sweden are owned by the Swedish state through a government-owned organization called Apoteket AB (Apoteket AB, 2012). Apoteket AB runs a take-back scheme by collecting unused drugs from the public as well as pharmaceutical waste from hospitals, healthcare centers and dental offices for incineration, costing them more than 1.4 million euros annually (Health Canada, 2009). By contrast, Portugal's national return program, called Valormed, only collects the public's unused drugs at pharmacies. Valormed is funded by the drug industry (pharmacies, pharmaceutical associations, manufacturers, distributors and importers), and companies pay an eco-fee of about 0.00504 euro per package released into the marketplace (Health Canada, 2009).

France's national return program, called Cyclamed, is managed by the pharmacies, drug industry and wholesalers, and costs over \$5.9 million to operate annually (Cyclamed, 2012). Law No. 2007-248 requires pharmacies to collect unused/expired drugs from consumers 
(Cyclamed, 2012). Cyclamed used to give drugs collected through the program that were still usable to humanitarian associations for redistribution in France and abroad. About 251 tonnes of drugs were redistributed in 2007 (Cyclamed, 2008). As of December 31, 2008, the redistribution scheme ended resulting in all waste being incinerated since then (Cyclamed, 2012).

The EU has also adopted a risk assessment policy for managing PhACs. Producers are required to conduct an environmental risk assessment when applying for marketing authorization for human medicinal products (Directive 2001/83/EC) and veterinary medicinal products (Directive 2001/82/EC). To gain authorization to place a medicinal product for human use in the market, the application must accompany an "[e]valuation of the potential environmental risks posed by the medicinal product. This impact shall be assessed and, on a case-by-case basis, specific arrangements to limit it shall be envisaged" (Directive 2001/83/EC, Article 8). The overall purpose of the ERA is to quantify the potential environmental risks of a drug.

The ERA consists of two phases. According to the European Medicines Agency (EMA, 2006), in phase one the drug's predicted environmental concentration (PEC) in surface water is determined using consumption data. If the PEC is less than $0.01 \mu \mathrm{g} / \mathrm{L}$ then the product is unlikely to pose an environmental risk, and if the PEC is equal to or greater than $0.01 \mu \mathrm{g} / \mathrm{L}$ then Phase II testing is required (EMA, 2006). Phase II consists of two tiers (A and B), and involves calculating the predicted no-effect concentration (PNEC) - the highest concentration of the substance for which adverse effects are not expected to occur on test species. In tier A, the $\mathrm{PEC/PNEC} \mathrm{ratio} \mathrm{is} \mathrm{determined} \mathrm{using} \mathrm{relevant} \mathrm{environmental} \mathrm{testing} \mathrm{("base} \mathrm{set} \mathrm{of} \mathrm{data")} \mathrm{(EMA,}$ 2006). If tier A indicates a potential environmental risk, then more testing is done to refine the PEC and PNEC values using an "extended data set on emission, fate and effects" (EMA, 2006).

The outcome of the ERA is that it identifies precautionary and safety measures for labelling, storing and disposing of drugs to reduce environmental exposure (EMA, 2006). However, as stated by Anette Küster from the Federal Environment Agency:

The marketing authorisation of a medicinal product for human use may not be refused because of environmental concerns. In contrast, for veterinary medicinal products the ERA is part of the risk-benefit analysis and hence the marketing authorisation may be refused due to environmental risk or risk mitigation measures have to be taken. (EEA, 2010, p. 18) 
The ERA Guideline recommends that all packaging of medicinal products (e.g. patient information leaflets) should include this statement: "Medicines should not be disposed of via wastewater or household waste. Ask your pharmacist how to dispose of medicines no longer required. These measures will help to protect the environment" (EMA, 2006 p. 10).

Perhaps the EU's reliance on the Precautionary Principle triggered the ERA policy for pharmaceuticals. The EU has incorporated this principle in the Treaty on the Functioning of the EU which states that environmental policies "shall be based on the precautionary principle and on the principles that preventive action should be taken, that environmental damage should as a priority be rectified at source and that the polluter should pay" (Article 191).

\subsubsection{Australia}

Since 1999, Australia has operated a national return program for the community's unused/expired drugs called the Return Unwanted Medicines (RUM) project. This program is facilitated by the National Return \& Disposal of Unwanted Medicines Limited organization. Consumers are encouraged to return their waste to pharmacies (at no additional cost), while pharmaceutical wholesalers provide financial support through a nominal fee for the collection and transportation of waste to and from pharmacies (The National Return \& Disposal of Unwanted Medicines Limited, 2011). Similar to the EU, the waste is incinerated.

The RUM project is primarily funded by the Federal government; however, some drug manufacturers have provided sponsorship support. In 2009, the Federal Budget approved over $\$ 9$ million for the RUM project over four years (The National Return \& Disposal of Unwanted Medicines Limited, 2011). In 2000-2001, about 235,000 kg of unused drugs was collected, while later in 2011-2012, 576,000 kg was collected (The National Return \& Disposal of Unwanted Medicines Limited, n.d.). As stated by the RUM Project Manager, Simon Appel, "We have ongoing difficulty in accessing increased funding, which flows from increasing collections. Neither can we afford a consumer awareness campaign, which means our 'success' is due to individual pharmacies encouraging consumers" (personal communication from inquiry message, March 28, 2013).

A RUM survey conducted by Brushin (2005) found that about $68.4 \%$ of drugs returned through RUM are solid (tablets and lozenges), roughly $11.8 \%$ are liquid (drops and solutions); and 5\% are semi-solid (creams and ointments). The most common drugs returned are for treating the cardiovascular system (roughly 20\%), nervous system (about 20\%) and alimentary 
tract and metabolism (about 15\%) (Brushin, 2005). The five most common reasons for returning drugs are due to: the drug's efficacy e.g. the drug expired (32.9\%); death of the consumer (27.1\%); a modification in treatment (13.1\%); the consumer's perception regarding the need for the drug (9.2\%); and the consumer experienced unwanted effects (8.5\%) (Brushin, 2005).

\subsubsection{United States}

The U.S. does not have a national medications return program. Take-back schemes take place across communities at the local government level. As argued by the Product Stewardship Institute in the U.S., "Although drug collection and disposal programs are growing fast, most U.S. communities do not offer programs to properly dispose of waste medications" (2012a).

The Secure and Responsible Drug Disposal Act of 2010, which amended the Controlled Substances Act, allows the U.S. Drug Enforcement Administration "to develop permanent, ongoing, and responsible methods for disposal" (U.S. DEA, 2013). This criminal law measure, as described earlier, allows the U.S. DEA to facilitate "National Prescription Drug Take-Back Events" to safely collect the public's unused drugs. The previous five Take-Back Events collected more than 1,409 tons of medications (U.S. DEA, 2013).

Before the Secure and Responsible Drug Disposal Act was enacted, Federal law did not permit take-back programs to accept controlled substances unless they received special approval from the U.S. DEA and arranged for full-time law enforcement officers to receive the controlled substances directly from the consumer (Secure and Responsible Drug Disposal Act of 2010, s. 2). Hence, many of the return initiatives would take place at Police Departments. For instance, the New Jersey Division of Consumer Affairs, through their "Project Medicine Drop" program, placed secure drop boxes in police departments for the public to return their unused/expired drugs throughout the year (New Jersey Division of Consumer Affairs, 2013).

On December 21, 2012, the U.S. DEA released a Notice of Proposed Rulemaking for Disposal of Controlled Substances (U.S. DEA, 2013). The proposed regulations would permit authorized collectors, such as drug manufacturers or pharmacies, to operate permanent collection sites and mail-back programs, and would still allow law enforcement agencies to operate takeback events and other collection programs. However, until these regulations become permanent, the U.S. DEA will continue to operate National Take-Back Events (U.S. DEA, 2013).

The Food and Drug Administration (U.S. FDA, 2013a) published a disposal protocol on their website for Americans to follow if their community does not have a return program. They 
advise consumers to mix the drugs with an unpalatable substance like kitty litter; place the mixture in a container; and then dispose of it in the trash. The U.S. FDA (2013a) also published a list of drugs recommended for disposal by flushing, including Percocet and Oxycontin.

The state of Maine tested a pilot program in 2007 called the "The Safe Medicine Disposal for ME" which allowed consumers to mail their unused/expired drugs through the U.S. Postal Service to the Maine Drug Enforcement Agency for safe disposal. Maine received program funding from the U.S. EPA (Kaye, Crittenden, \& Gressitt, 2010). About 2,300 lbs of drugs were collected representing a $42 \%$ envelope utilization and return rate (Kaye, Crittenden, \& Gressitt, 2010). More than 380,000 pills were cataloged through the drug inventory process, and the estimated average wholesale price of drugs collected was \$572,772.35 USD (Kaye, Crittenden, \& Gressitt, 2010). This program allowed citizens to participate in a simple "do it yourself" system; however, funding was an issue. The EPA grant came to an end in 2012, and the program ultimately ended due to lack of funding (J. Crittenden, personal communication from inquiry message, April 8, 2013).

In 2011, a bill called the Pharmaceutical Stewardship Act of 2011 was introduced to Congress which would require drug producers to collect and dispose of unused drugs through a stewardship program (Product Stewardship Institute, 2012b). This would have been based on EPR; however, the bill died. Not long after, Alameda County in California enacted the nation's first law (the Safe Drug Disposal Ordinance) in 2012 requiring drug companies to pay for the collection and disposal of unused drugs. The County of Alameda California (2012) stated, "Of the annual $\$ 186$ million in profits generated by drug companies in Alameda County, officials say the projected cost of a . . producer-funded program would be about 1 cent for every $\$ 33$ of pharmaceuticals sold in the County."

Overall, the issue of $\mathrm{PhACs}$ in the environment is a recognized problem in the U.S, and the recent implementation of the Secure and Responsible Drug Disposal Act allows more opportunities to safely collect the public's unused drugs. However, federal and state governments have been hesitant to adopt EPR approaches.

The U.S. also has an environmental assessment (EA) process for drugs. The U.S. FDA is mandated under the National Environmental Policy Act (1970) to consider the environmental impacts of approving drugs in the application process (U.S. FDA, 1998). 
As described by the U.S. FDA:

FDA's regulations ... specify that environmental assessments (EAs) must be submitted as part of certain new drug applications (NDAs), abbreviated applications, applications for marketing approval of a biologic product, supplements to such applications, investigational new drug applications (INDs) and for various other actions . . . unless the action qualifies for categorical exclusion. (1998, p. 1)

An EA is required if the estimated introduction concentration (EIC) of the substance in the aquatic environment is greater or equal to $1 \mu \mathrm{g} / \mathrm{L}$ (U.S. FDA, 1998). The U.S. FDA recommends a tiered approach to fate and effects testing which begins with tier one: acute ecotoxicity testing on a test organism; followed by tier two: acute ecotoxicity testing on a base set of aquatic/terrestrial organisms; and then tier three: chronic toxicity testing on aquatic/terrestrial organisms (U.S. FDA, 1998). Chronic testing is only required if the acute testing indicates a risk or if the substance could bioaccumulate. In 2005, it was estimated that 50 new drugs were placed on the U.S. market, and less than a quarter of them had an EIC above the $1 \mu \mathrm{g} / \mathrm{L}$ trigger concentration requiring Tier A risk assessment testing (Hemminger, 2005). According to the U.S. FDA (2011), drugs that have required an EA have not been shown to cause environmental effects due to flushing down the drain.

\subsubsection{Canada}

All three levels of government in Canada have a role in waste management. The provincial/territorial governments predominately regulate waste management as they are responsible for issuing licenses and approvals, monitoring operations, and promoting waste diversion. Municipalities tend to be responsible for operating waste management services such as collection, transportation and disposal/recycling facilities. Under the Constitution Act, 1867, municipal institutions are an exclusive power of the provincial government. The provinces set out the powers delegated to municipalities by statute. The federal government also plays a role in waste issues relating to toxic substances, international movement of waste materials, federal lands and operations, and air emissions (Environment Canada, 2012c).

With environment being a matter of shared jurisdiction, the Canadian Council of Ministers of the Environment was formed for intergovernmental discussion of environmental issues. The CCME consists of environment ministers from the federal, provincial and territorial governments and serves "as a principal forum for members to develop national strategies, norms, 
and guidelines that each environment ministry across the country can use" (CCME, 2011). In 1989, the CCME deemed waste management a problem and developed a national packaging policy to reduce packaging waste sent to landfills (CCME, 1998). They developed schedules and targets for waste minimization, including a 50\% reduction in waste generation by 2000 (CCME, 1998). In 2009, the CCME approved the Canada-wide Action Plan for EPR which outlined coordinated policies for creating EPR approaches, and set out timelines for implementing EPR laws for priority products. Drugs and sharps were identified as phase I priority which meant that EPR laws for these materials should be implemented by 2015. Thus, the CCME's strategies have the potential to harmonize provincial waste management frameworks.

A Canada-wide medications return program would be challenging to adopt since waste management is mainly governed by the provinces. Hence, there are various provincial, municipal, and community initiatives that collect the public's unused drugs. Since waste policies tend to be promoted by the provinces, the discussion of post-consumer pharmaceutical waste strategies will begin with the provinces, followed by the municipalities and then the federal government. Currently, provincial governments play the greatest role in managing this waste.

\subsubsection{Provincial Governments}

The majority of provinces have some type of collection system for the public's postconsumer drugs, as seen in Table 10. In general, Canadian consumers can return their unused drugs to pharmacies/depots for safe collection, and incineration is the most common end-of-life treatment. Return programs tend to be initiated by governments, industry or pharmaceutical associations. Unused drugs from residential consumers are accepted while waste from industry (e.g. hospitals, dental offices or doctor offices) tends to be outside the scope of these programs.

As seen in Table 10, the policy models and funding sources differ from province to province. Most have adopted voluntary initiatives. For examples, Alberta, Saskatchewan and Nova Scotia have voluntary programs that are administered and monitored by their respective pharmacists' association. BC, Manitoba and recently Ontario are the only provinces that have adopted regulated programs. Quebec, Nunavut and Yukon do not have province/territory-wide return programs; however, they provide collection opportunities for consumers.

Newfoundland and Labrador receives funding from governments while in Saskatchewan the pharmacies pay. Alberta and Nova Scotia receive funding from drug companies but these programs are not regulated by government, while BC, Manitoba and Ontario require the industry 
to fund $100 \%$ of the program through regulations. $\mathrm{BC}$ was the first province to adopt a regulated MRP in 1999, followed by Manitoba in 2011, and Ontario in $2013^{8}$. These three MRPs are administered by the Health Products Stewardship Association (HPSA), formerly called the PostConsumer Pharmaceutical Stewardship Association (PCPSA).

HPSA is a not-for-profit organization formed in 1999 to "respond to government and environmental issues relating to the efficient collection and safe disposal of unused or expired health products returned by the public in provinces having regulations requiring industry stewardship programs" (HPSA, 2012a). HPSA's mandate is to perform duties on behalf of stewards (brand-owners/first importers of health products). When stewards sign a Membership Agreement with HPSA and pay a fee based on their market share, HPSA will administer the program and stewards will comply with regulations (HPSA, 2012b).

Collection volumes range between the provinces ${ }^{9}$. Alberta's voluntary ENVIRx Program collected over 60,000 kg of unused/expired drugs in 2011 (Alberta Pharmacists' Association, n.d.). BC's regulated MRP collected more than $69,000 \mathrm{~kg}$ of pharmaceutical waste that same year (PCPSA, 2012a). In 2010, the HPSA conducted a customer survey in Manitoba before implementing the MRP in 2011 (PCPSA, 2012b). According to the survey, 88\% of Manitobans indicated that they had medications in their home, including $23 \%$ who had unused/expired drugs, and $34 \%$ of Manitobans said that they would return medications to a pharmacy in the future (PCPSA, 2012b). Manitoba's MRP ended up collecting 8,820 kg (about $0.01 \mathrm{~kg}$ per capita) after only eight months of operation in 2011(PCPSA, 2012b).

Over the last few years, Ontario has experienced setbacks, administrative challenges, monitoring lapses and implementation gaps with managing hazardous waste, including pharmaceuticals. This is analyzed thoroughly in Chapters 4 and 5.

\footnotetext{
${ }^{8}$ Industry was given until January 1, 2013 to meet most of the regulatory requirements in O. Reg. 298/12.

${ }^{9}$ Some program performance data, including collection rates, are not made available to the public.
} 
Table 10. Collection Systems in Canada for Unused/Expired Drugs (Environment Canada, 2012b; Health Canada, 2009; HPSA, 2012b)

\begin{tabular}{|c|c|c|c|c|c|}
\hline Program & $\begin{array}{l}\text { Return } \\
\text { Location }\end{array}$ & $\begin{array}{c}\text { Program } \\
\text { Administrator }\end{array}$ & $\begin{array}{c}\text { Voluntary or } \\
\text { Regulated } \\
\text { Framework }\end{array}$ & $\begin{array}{c}\text { Program } \\
\text { Monitoring } \\
\text { \& Reporting }\end{array}$ & $\begin{array}{l}\text { Funding } \\
\text { Sources }\end{array}$ \\
\hline $\begin{array}{l}\text { Alberta } \\
\text { "ENVIRx" } \\
\text { (Initiated in } \\
1988 \text { ) }\end{array}$ & Pharmacies & $\begin{array}{l}\text { Alberta } \\
\text { Pharmacists' } \\
\text { Association } \\
\text { (RxA) }\end{array}$ & Voluntary & $\begin{array}{l}\text { RxA conducts } \\
\text { program } \\
\text { reviews but } \\
\text { reports are not } \\
\text { publicly } \\
\text { available }\end{array}$ & $\begin{array}{l}\text { Pharmaceutical } \\
\text { companies and } \\
\text { provincial } \\
\text { government }\end{array}$ \\
\hline $\begin{array}{l}\text { British } \\
\text { Columbia } \\
\text { "BC MRP" } \\
\text { (Initiated in } \\
\text { 1999) }\end{array}$ & Pharmacies & $\begin{array}{l}\text { Health Products } \\
\text { Stewardship } \\
\text { Association }\end{array}$ & $\begin{array}{l}\text { Regulated (B.C. } \\
\text { Reg. 449/2004, } \\
\text { under the } \\
\text { Environmental } \\
\text { Management Act) }\end{array}$ & $\begin{array}{l}\text { HPSA submits } \\
\text { annual reports } \\
\text { to BC MOE; } \\
\text { BC MOE } \\
\text { monitors }\end{array}$ & $\begin{array}{l}\text { Pharmaceutical } \\
\text { and consumer } \\
\text { health product } \\
\text { industries }\end{array}$ \\
\hline $\begin{array}{l}\text { Manitoba } \\
\text { "Manitoba } \\
\text { MRP" } \\
\text { (Initiated in } \\
\text { 2011) }\end{array}$ & Pharmacies & HPSA & $\begin{array}{l}\text { Regulated (Man. } \\
\text { Reg. 16/2010, } \\
\text { under The Waste } \\
\text { Reduction and } \\
\text { Prevention Act) }\end{array}$ & $\begin{array}{l}\text { HPSA submits } \\
\text { annual reports } \\
\text { to Manitoba } \\
\text { Conservation; } \\
\text { Manitoba } \\
\text { Conservation } \\
\text { monitors }\end{array}$ & $\begin{array}{l}\text { Pharmaceutical } \\
\text { and consumer } \\
\text { health product } \\
\text { industries }\end{array}$ \\
\hline $\begin{array}{l}\text { New } \\
\text { Brunswick }\end{array}$ & \multicolumn{5}{|c|}{$\begin{array}{l}\text { No province-wide program. Most Solid Waste Commissions accept unused drugs } \\
\text { (funded via user pay model with tipping fees). Some pharmacies accept unused drugs. }\end{array}$} \\
\hline $\begin{array}{l}\text { Newfound- } \\
\text { land and } \\
\text { Labrador } \\
\text { "Household } \\
\text { Hazardous } \\
\text { Waste" } \\
\text { (Initiated in } \\
\text { 1998) }\end{array}$ & $\begin{array}{l}\text { Household } \\
\text { hazardous } \\
\text { waste } \\
\text { depots }\end{array}$ & $\begin{array}{l}\text { Multi-Materials } \\
\text { Stewardship } \\
\text { Board (MMSB, } \\
\text { a Crown } \\
\text { agency) }\end{array}$ & Voluntary & $\begin{array}{l}\text { MMSB } \\
\text { submits annual } \\
\text { reports to the } \\
\text { Minister of } \\
\text { Environment } \\
\text { and } \\
\text { Conservation }\end{array}$ & $\begin{array}{l}\text { Provincial and } \\
\text { municipal } \\
\text { governments }\end{array}$ \\
\hline Yukon & \multicolumn{5}{|c|}{$\begin{array}{l}\text { No territory-wide program. There are local collection events and most pharmacies } \\
\text { accept unused drugs. Incineration takes place at the Whitehorse General Hospital. }\end{array}$} \\
\hline $\begin{array}{l}\text { Nova Scotia } \\
\text { "Medication } \\
\text { Disposal } \\
\text { Program" } \\
\text { (Initiated in } \\
\text { mid 1990s) }\end{array}$ & Pharmacies & $\begin{array}{l}\text { Pharmacy } \\
\text { Association of } \\
\text { Nova Scotia }\end{array}$ & Voluntary & $\begin{array}{l}\text { Pharmacy } \\
\text { Association } \\
\text { responsible for } \\
\text { oversight }\end{array}$ & $\begin{array}{l}\text { Pharmaceutical } \\
\text { companies }\end{array}$ \\
\hline Nunavut & \multicolumn{5}{|c|}{$\begin{array}{l}\text { No territory-wide program. Drugs can be returned to health centers and pharmacies } \\
\text { which are incinerated at Baffin Regional Hospital Pharmacy or a Regional Center. }\end{array}$} \\
\hline Quebec & \multicolumn{5}{|c|}{$\begin{array}{l}\text { No province-wide program. Municipalities have adopted schemes (through depots and } \\
\text { collection events) and pharmacies also accept the public's unused/expired drugs. }\end{array}$} \\
\hline
\end{tabular}




\begin{tabular}{|c|c|c|c|c|c|}
\hline Program & $\begin{array}{c}\text { Return } \\
\text { Location }\end{array}$ & $\begin{array}{c}\text { Program } \\
\text { Administrator }\end{array}$ & $\begin{array}{c}\text { Voluntary or } \\
\text { Regulated } \\
\text { Framework } \\
\end{array}$ & $\begin{array}{c}\text { Program } \\
\text { Monitoring } \\
\text { \& Reporting } \\
\end{array}$ & $\begin{array}{l}\text { Funding } \\
\text { Sources }\end{array}$ \\
\hline $\begin{array}{l}\text { Ontario } \\
\text { a.“Ontario } \\
\text { MRP”- for } \\
\text { drugs only } \\
\text { (Initiated on } \\
\text { Jan. 1, 2013) }\end{array}$ & Pharmacies & HPSA & $\begin{array}{l}\text { Regulated } \\
\text { (O. Reg. 298/12, } \\
\text { under } \\
\text { Environmental } \\
\text { Protection Act) }\end{array}$ & $\begin{array}{l}\text { HPSA submits } \\
\text { annual reports } \\
\text { to ON MOE; } \\
\text { ON MOE } \\
\text { monitors }\end{array}$ & $\begin{array}{l}\text { Pharmaceutical } \\
\text { and consumer } \\
\text { health product } \\
\text { industries }\end{array}$ \\
\hline $\begin{array}{l}\text { b. "Ontario } \\
\text { Sharps } \\
\text { Collection } \\
\text { Program"- } \\
\text { for sharps } \\
\text { (Initiated on } \\
\text { Jan. 1, 2013) }\end{array}$ & Pharmacies & HPSA & $\begin{array}{l}\text { Regulated } \\
\text { (O. Reg. 298/12, } \\
\text { under } \\
\text { Environmental } \\
\text { Protection Act) }\end{array}$ & $\begin{array}{l}\text { HPSA submits } \\
\text { annual reports } \\
\text { to ON MOE; } \\
\text { ON MOE } \\
\text { monitors }\end{array}$ & Sharps industry \\
\hline $\begin{array}{l}\text { c. "Phase } 2 \\
\text { Program" } \\
\text { (Initiated on } \\
\text { Oct. 1, 2012) }\end{array}$ & $\begin{array}{l}\text { Depots and } \\
\text { municipal } \\
\text { collection } \\
\text { events }\end{array}$ & $\begin{array}{l}\text { Recycling } \\
\text { Council of } \\
\text { Ontario (RCO) }\end{array}$ & $\begin{array}{l}\text { Voluntary but } \\
\text { strong incentive } \\
\text { for municipalities } \\
\text { to participate } \\
\text { since RCO } \\
\text { reimburses costs }\end{array}$ & $\mathrm{RCO}$ & $\begin{array}{l}\text { Provincial } \\
\text { government } \\
\text { provides the } \\
\text { fund for RCO to } \\
\text { administer }\end{array}$ \\
\hline $\begin{array}{l}\text { Prince } \\
\text { Edward } \\
\text { Island } \\
\text { "Take It } \\
\text { Back" } \\
\text { (Initiated in } \\
\text { 2004) }\end{array}$ & $\begin{array}{l}\text { Pharmacies } \\
\text { and Waste } \\
\text { Watch } \\
\text { Drop-Off } \\
\text { Centers }\end{array}$ & $\begin{array}{l}\text { Island Waste } \\
\text { Management } \\
\text { Corporation } \\
\text { (IWMC, a } \\
\text { Crown agency) }\end{array}$ & Voluntary & $\begin{array}{l}\text { IWMC } \\
\text { publishes } \\
\text { publicly } \\
\text { available } \\
\text { annual reports }\end{array}$ & IWMC \\
\hline $\begin{array}{l}\text { Saskatch- } \\
\text { ewan } \\
\text { "Pharma- } \\
\text { ceutical } \\
\text { Waste } \\
\text { Disposal" } \\
\text { (Initiated in } \\
\text { 1997) }\end{array}$ & Pharmacies & $\begin{array}{l}\text { Pharmacists' } \\
\text { Association of } \\
\text { Saskatchewan }\end{array}$ & Voluntary & $\begin{array}{l}\text { Pharmacists' } \\
\text { Association } \\
\text { responsible for } \\
\text { oversight }\end{array}$ & Pharmacies \\
\hline
\end{tabular}

\subsubsection{Municipal Governments}

Many municipalities allow the public to return their household hazardous waste, including expired drugs, to waste depots or through community events. For instance, Toronto allows residents to drop off their expired drugs at specific locations on Community Environment 
Days as well as at depots throughout the year (City of Toronto, 2013). The Recycling Council of Ontario received a three-year grant from the MOE to facilitate a program that reimburses municipalities' costs for the management of six household hazardous wastes, including drugs and sharps. This program, called Phase 2, promotes the proper management of hazardous waste collected by depots and local events by reimbursing eligible municipal costs (RCO, 2013).

Municipalities can also enact by-laws to protect the health and welfare of residents from material threats on the condition that they do not breach provincial or federal legislation (Campbell, 2007). The Supreme Court of Canada has recognized the power of municipal governments to ban or restrict hazardous substances to protect health and safety. The Croplife v. Toronto and Spraytech v. Hudson cases are prominent examples in which the courts upheld the validity of municipal by-laws banning the use of pesticides. These judicial decisions were significant as they affirmed the municipal power over environmental and health issues, and set a trend of municipal governments taking action on environmental risk issues.

Many Ontario municipalities have passed sewer by-laws that define maximum allowable levels of toxic and hazardous substances that can be discharged into sewers. For instance, Ottawa enacted Sewer Use By-law 2003-514 and Toronto passed Sewers By-law 457-2000. However, defining unused/expired drugs under one category such as hazardous waste is complex. Experts cannot quantify concentrations of unused medications that definitively cause adverse health effects. This makes it difficult for municipalities to set limits for PhACs in wastewater discharged to sewers. It is also challenging to monitor whether households are flushing drugs down the drain/disposing in the garbage so enforcement would be an issue.

Metro Vancouver (comprised of 22 municipalities and one electoral area) enacted By-law 275 banning various materials from landfills, including electronics, batteries, and unused/expired pharmaceuticals. Garbage loads that arrive at disposal sites containing banned materials are assessed a minimum surcharge of $\$ 50$, plus the cost of removal, clean-up and remediation. Vancouver also enacted Solid Waste By-law 8417 that prohibits medications from garbage containers and from disposal as garbage at the Vancouver Landfill and Vancouver South Transfer Station. Individuals who commit an offence against this by-law can be fined between $\$ 250$ and $\$ 10,000$. Thus, municipalities in $\mathrm{BC}$ have adopted stricter disposal by-laws to regulate PhACs in the environment. However, it is ultimately challenging for municipal governments to monitor their residents' disposal habits at home and enforce such by-laws. 


\subsubsection{Federal Government}

Criminal law measures have been used by the federal government for promoting the proper disposal of drugs through national strategies. Health Minister Leona Aglukkaq unveiled a national 10 year strategy, developed by the Canadian Centre on Substance Abuse and the National Advisory Committee on Prescription Drug Misuse in March of 2013, which identified measures for dealing with Canada's prescription drug misuse crisis, such as promoting appropriate dispensing practices and developing legislation to prevent harms.

The strategy mentions that pharmacists are responsible for disposing of unused/expired drugs when returned to pharmacies, and that while "returned controlled substances should be recorded as part of the pharmacy's inventory of controlled substances, this is rarely done in practice because returns from individuals often contain unmarked or unpackaged medications that are thus not identifiable as controlled substances" (NACPDM, 2013, p. 53). The strategy recommends Health Canada to "[d]etermine whether regulations are required to reduce the risk of diversion associated with the handling of unused prescription drugs when they are returned directly to pharmacies for destruction" (NACPDM, 2013, p. 56). This is an important finding as it identifies a potential gap with the role of the pharmacist in medications return programs.

Not long after this strategy was announced, Public Safety Canada held the "National Prescription Drug Drop-Off Day” on May 11, 2013 which collected over 2 tonnes of medications (Perron, 2013). The goals of the initiative were to reduce the volume of prescription drugs available for misuse, inform the public of the harms of drug misuse, and to promote "actions the public can take to reduce the risks, including bringing back unused pharmaceuticals to local pharmacies for disposal 365 days a year" (Public Safety Canada, 2013).

Canada also has an environmental assessment process for pharmaceuticals. In 2001, Health Canada announced that they would develop EA regulations for new substances in products regulated under the Food and Drugs Act $(F \& D A)$, including pharmaceuticals, veterinary drugs and natural health products (Health Canada, 2003). Until these are adopted, manufacturers/importers of new substances in products regulated under the $F \& D A$ are subject to the New Substances Notification Regulations (NSNR) under the Canadian Environmental Protection Act (CEPA) (Health Canada, 2010). The NSNR require information for a manufacturer/importer to submit to the federal government if a substance for import/manufacture 
is not on the Domestic Substances List ${ }^{10}$.

Information requirements under the NSNR are based on the volume of the substance manufactured in/imported into Canada and are outlined in Schedules. Schedule 1 notification for new substances is submitted when the quantity is greater than $20 \mathrm{~kg}$ but is less than 1,000 $\mathrm{kg} /$ year; or less than 5,000 kg accumulated. Schedule 1 requires the least amount of information requirements, particularly from an environmental perspective. Data regarding the substance's environmental effects, fate or distribution is not required. This information is only required for Schedule II and III substances when the quantity exceeds higher manufacturing/importing volumes. As stated by Health Canada (2003):

For many of the substances in products regulated under the F\&DA (e.g., human and veterinary drugs), it is suspected that manufacture or import volumes that would trigger data for the higher schedules (Schedules II and III) may not be reached for several years after their approval for sale. . . . Consequently, the information required to adequately determine the potential for adverse effects of these substances on the environment and on human health through indirect exposure may not be reported at all or in a timely manner. (p. 13)

The NSNR were initially developed to regulate industrial substances, not substances like pharmaceuticals regulated under the $F \& D A$. Health Canada (2011) acknowledged that drugs "have unique properties and exposure patterns that require a different approach to environmental assessment than what is currently required under the New Substances Notification Regulations."

Health Canada's Environmental Assessment Unit received about 400 new substance notifications for products regulated under the $F \& D A$ from 2001 to 2007 with cosmetic ingredients accounting for $62 \%$ of all notifications and pharmaceutical substances representing 21\% (Kleywegt et al., 2007, p. 16). As stated by Andrew Beck, former head of the EA Unit:

The majority of these submissions however, have been notified at the first notification level - a level that does not require the generation of environmental fate, distribution or effects data. This lack of experimental data is only one of the many challenges facing Health Canada in determining the risks these substances might pose to the environment. (Kleywegt et al., 2007, p. 16)

Health Canada has been in the process of creating new EA regulations since 2001 to address these issues. To date, they have developed two draft frameworks - one for pharmaceuticals and

${ }^{10}$ An inventory of about 23,000 substances manufactured in, imported into or used in Canada under certain conditions between January 1, 1984 and December 31, 1986 (Environment Canada, 2010). Substances not on this list are considered new unless they qualify for exemptions. 
one for all other $F \& D A$ substances, and they expect to publish regulations for pharmaceuticals by 2014 (T. Spack, personal communication from inquiry message, November 28, 2012).

A major difference between Canada, the E.U. and the U.S. regarding the ERA process is the concentration of the substance that triggers an assessment. An ERA in the EU is required when the PEC of the drug in surface water is $0.01 \mu \mathrm{g} / \mathrm{L}$ whereas the trigger concentration in the U.S. is 100 times higher at $1 \mu \mathrm{g} / \mathrm{L}$. According to Dr. Chris Metcalfe (Hemminger, 2005):

In fact, in the States, almost all pharmaceuticals in the Tier A assessment will come out at under one microgram per liter ... whereas in the EU there will be a fair number of pharmaceuticals which will move from the Tier A to the Tier B as a result of their lower thresholds. (p. A 681)

In Canada, an assessment of the substance's ecotoxicology and environmental fate under the NSNR is required for Schedule II substances (trigger quantity is more than 1,000 kg) and Schedule III substances (trigger quantity is more than $10,000 \mathrm{~kg} / \mathrm{year}$ ).

A concern regarding all of these EA processes is that they do not apply to drugs already on the market. Since PhACs are present in the environment in trace concentrations, the impacts

of a substance may not be detected for years after its introduction into the market. Also, all three EA protocols assess individual substances; however, there is the possibility for cumulative effects when PhACs are discharged into the environment (Hemminger, 2005).

\subsection{Summary of Two-Part Literature Review}

In summary, the concerns associated with PhACs have led jurisdictions to implement strategies to mitigate this issue. The scientific uncertainties of the behaviour of drugs in the environment challenge policymaking as it requires decision makers to determine how much potential risk is acceptable and how much scientific information is sufficient to warrant action. Since it is politically difficult to limit the human consumption of drugs, this has led policymakers to focus on disposal policies. The most common approach is medications return programs. Europe, Australia, the U.S. and Canada all have take-back initiatives for the public's unused/expired drugs. In Canada, this predominantly takes place at the provincial level. The federal government has the potential to take an enhanced role in national standard setting and harmonization of MRPs; however, at the current time, it is not exercising this leadership. 
Europe, Canada and the U.S. also have EA policies but it is difficult to assess the potential risks of drugs, given that there are many unknowns and the concentrations are low in the environment. Canada's current EA framework does not allow Health Canada to fully obtain the data required to determine the drug's potential environmental risk (Kleywegt et al., 2007). Thus, it seems that MRPs are favoured by governments over the risk assessment approach as it gives them more flexibility to manage the problem without having to rely entirely on the science. 


\section{Chapter 4: Setting the Context for Analyzing British Columbia and Ontario}

\subsection{Overview of the Cases}

This research has emphasized that although waste management is governed by all three levels of government in Canada, it is mainly a matter of provincial jurisdiction. The provinces predominately regulate waste diversion programs, including the management of post-consumer pharmaceuticals. Both BC and Ontario have implemented programs for managing this type of waste and they have been chosen as cases to compare and evaluate, as described earlier in Section 2.5.1. This chapter provides an overview of these programs.

\subsection{Case 1: British Columbia's Medications Return Program}

After the CCME deemed waste management a problem in Canada and set the national $50 \%$ waste reduction target in 1989, as previously described in Section 3.5.4, BC adopted the municipal solid waste management strategy which required regional districts to submit waste management plans (BC MOE, 1994). As waste generation continued to grow, environmental concerns regarding hazardous waste particularly increased. The BC MOE (2011) stated, "By 1990 , concern about these household hazardous wastes had grown to the point where consumers and local governments called on the province to solve this problem." After the BC government recognized that local governments did not have the financial resources to divert hazardous waste from the environment, it began looking to extended producer responsibility. In the early 1990s, there were return programs for batteries, scrap tires and used oil (BC MOE, 2011).

The pharmaceutical industry voluntarily established the EnviRx stewardship program in November of 1996, administered by the BC Pharmacy Association, which collected and managed post-consumer drugs returned to pharmacies (BC MOE, 1999). The BC government then enacted The Post-Consumer Residual Stewardship Program Regulation in 1997 which required producers of various hazardous materials, including pharmaceuticals, to take responsibility for managing their product's end-of-life. The pharmaceutical industry requested that pharmaceuticals be regulated under this regime to establish a level playing field for the producers (BC MOE, 1999). In 1999, the industry created a not-for-profit organization, the then named Post-Consumer Pharmaceutical Stewardship Association, to administer the EPR program which was rebranded as the Medications Return Program. 
In 2001, the industry requested a results-based (or performance-based) regulation as opposed to the existing prescriptive regulation ${ }^{11}$ (BC MOE, 2011). Businesses tend to criticize prescriptive regulations as being too rigid and restricting innovation as they do not give the industry the flexibility to meet standards even if there is a more cost-effective approach that achieves better outcomes. In 2002, the MOE published their Industry Product Stewardship Business Plan to address this concern and guide the development of a new results-based regulation. On October 7, 2004 the Recycling Regulation (B.C. Reg. 449/2004) was enacted under the newly adopted Environmental Management Act (EMA) which repealed the PostConsumer Residual Stewardship Program Regulation. B.C. Reg. 449/2004 is often described as a results-based regulation based on EPR that sets out the producers' requirements for each product category designated in the regulation. It makes producers liable for providing a way for the public to dispose of their waste in an environmentally responsible manner.

Producers are required to submit a stewardship plan to the BC MOE for approval ${ }^{12}$ which outlines how producers are managing their products, and meeting their program objectives and performance measures. Producers are required to provide information in their plans regarding the following: stakeholder consultation; collection system and consumer access; consumer awareness; performance measurement; management of program costs; dispute resolution; product life cycle management; and pollution prevention hierarchy (BC MOE, 2011). A producer can appoint an agency to carry out their duties as long as they notify the agency of their duties in writing (B.C. Reg. 449/2004). Every five years, producers are required to review their plan and submit proposed amendments to a Director. Annual reports are required which report on items such as the producer's educational strategies, the number and location of collection sites, and the amount of product collected. BC has eight EPR programs regulated under B.C. Reg. 449/2004 for materials like pharmaceuticals (through BC's Medications Return Program), beverage containers, electronics, antifreeze, used oil, lead-acid batteries, paints, solvents, flammables, gasoline and pesticides.

The pharmaceutical product category is outlined in Schedule 2 of the regulation and consists of all unused/expired drugs (except those in reference to animals) as defined in the Food

\footnotetext{
${ }^{11}$ Results-based regulations set an outcome for industry to meet without specifying the means of reaching that outcome whereas prescriptive regulations prescribe procedures, methods and/or technologies regarding how to meet standards (Greenbaum \& Wellington, 2010).

${ }^{12}$ Unless, in the rare case, producers choose to comply with Part 3 of the regulation.
} 
and Drugs Act. BC's Medications Return Program was chosen as the approach to help reduce $\mathrm{PhACs}$ in the environment. It allows consumers to return their unused/expired prescription drugs, over-the-counter drugs and natural health products (such as vitamins, minerals, herbal remedies and homeopathic medicines) to registered pharmacies for safe disposal. Sharps (needles, lancets and syringes) are not accepted since these devices are not defined as a pharmaceutical product under the $F \& D A$ (PCPSA, 2006). Pharmaceutical waste from institutions, hospitals or dental offices is also not included. The waste collected through the program is disposed of in a licensed incineration facility.

The Health Products Stewardship Association has fulfilled its obligations of acting on behalf of the pharmaceutical producers since 2000 (PCPSA, 2006). BC's MRP is funded by the brand owners of pharmaceuticals and natural health products. The fee for brand owners of prescription drugs is based on the products dispensed in BC the previous year, with a minimum fee of \$200 (PCPSA, 2012c). The fee for brand owners of over-the-counter drugs and natural health products is based on the sales in the previous year at $\$ 0.20$ per $\$ 1,000$ of provincial sales of affected natural health products, with a minimum fee of \$200 (PCPSA, 2012c).

Overall, the points below summarize the problem, overarching policy goal and specific policy objective in British Columbia:

- Problem: there is an increasing presence of pharmaceuticals in the natural environment.

- Overarching policy goal: to reduce the potential environmental and health impacts associated with PhACs in a cost-effective manner (BC MOE, 2002; PCPSA, 2012c).

- Specific policy objective: to provide a province-wide system for the public to return their unused drugs for safe disposal based on EPR - shifting $100 \%$ of the responsibility and costs for managing this waste from government (and taxpayers) to the producers (BC MOE, 2002; B.C. Reg. 449/2004; PCPSA, 2012c).

\subsection{Case 2: Ontario's Orange Drop Program}

When the CCME set the national 50\% waste reduction target in 1989, Ontario began developing new waste reduction strategies. They set an aggressive goal of $50 \%$ diversion from disposal by the year 2000 compared to 1987, and developed the "Waste Reduction Action Plan" in 1991 (under the New Democratic Party) outlining how Ontario would reach their diversion target (ON MOE, 1991). In 1995, the Progressive Conservatives initiated their "Common Sense 
Revolution" which included making "red tape" cuts in environmental portfolios, and the MOE budget was cut by about 60\% from 1994 to 2000 (Canadian Institute for Environmental Law and Policy [CIELAP], 2000). Thus, funding diversion initiatives became an issue.

In 1999, the MOE signed a one-year Memorandum of Understanding with the Waste Diversion Organization (consisting of organizations like the Canadian Newspaper Association and the Liquor Control Board of Ontario) to help fund waste diversion programs. The Waste Diversion Organization's (2000) report outlined recommendations for driving waste reduction which included the MOE continuing to use its organization for implementing waste diversion programs. This led the MOE to enact the Waste Diversion Act on June 27, 2002.

The purpose of the WDA is "to promote the reduction, reuse and recycling of waste and to provide for the development, implementation and operation of waste diversion programs" (WDA, s. 1). It allows the MOE to designate materials requiring a diversion program, and provides the legal framework under which Waste Diversion Ontario (WDO), a not-for-profit $\operatorname{organization}^{13}$, operates. WDO is responsible for providing the oversight for the development, implementation and operation of diversion programs. WDO's Board of Directors consists of five directors appointed by the MOE and six directors appointed by the Board's Governance and Nominations Committee (WDO, 2013). A key responsibility for WDO is to "develop, implement and operate waste diversion programs for designated wastes in accordance with this Act and monitor the effectiveness and efficiency of those programs" (WDA, s. 5). They are required to submit annual business plans and reports to the MOE.

Once the Minister designates a material, Waste Diversion Ontario establishes an industry funding organization (IFO) to jointly design the program. WDO then submits the program plan, outlining the rules for fees, program costs and implementation details to the MOE for approval. Once approved, a regulation is enacted designating the IFO. The industry funding organization and Waste Diversion Ontario are then responsible for implementing and operating the program with the IFO's role specified in an agreement with WDO (ON MOE, 2008). The producers (brand owners, manufacturers or first importers) of the products pay fees to the IFO to fund the program.

${ }^{13}$ As described in the WDA, WDO is not an agent of the Crown in right of Ontario. 
The producers are mandated to combine as a collective under these IFOs unless they choose to comply with Section 34 of the $W D A^{14}$. There are currently no programs operating under Section 34. The overall intent of the WDA was to establish an arms-length organization (WDO) to drive waste diversion programs, and to push the concept of extended producer responsibility by making producers liable for managing their products' end-of-life. There are currently four programs legislated under this Act: the Blue Box for packaging and printed paper; the Municipal Hazardous or Special Waste Program for hazardous wastes like paints, solvents and oils; the Waste Electrical and Electronic Equipment Program; and the Used Tires Program.

Ontario's management of post-consumer drugs and sharps has changed over the last two decades. From the 1990s to 2010, most pharmacies were voluntarily collecting the public's unused drugs and sharps. In 2008, about $90 \%$ of pharmacies - around 2,860 locations - funded a voluntary take back service for pharmaceuticals and sharps waste which collected about 250 tonnes of unused drugs and 175 tonnes of sharps waste (Stewardship Ontario [SO], 2009a). Some pharmacies would charge a fee to take back the sharps, and there was little promotion and education about these take-back services (SO, 2009a).

In 2006, the MOE stepped in and asked WDO to develop a diversion program for Municipal Hazardous or Special Waste (MHSW). The MOE designated pharmaceuticals and sharps as "municipal special waste" in the MHSW Regulation (O. Reg. 542/06) with Stewardship Ontario (SO) as the IFO. Pharmaceuticals included all drugs, as defined in Section 2 of the Food and Drugs Act like prescription drugs, non-prescription drugs and pet medications from residential generators (SO, 2009a). Sharps waste included needles, syringes and lancets for administering healthcare for humans and companion animals (SO, 2009a).

Similar to other programs under the WDA, program costs were to be funded by the producers of the designated materials. Phase 1 of the program, called "Do What You Can", was implemented in 2008 and provided safe end-of-life management for nine materials like paint and pressurized containers. SO launched phases 2 and 3 of the program called the "Orange Drop Program" on July 1, 2010, which provided safe end-of-life management for 13 groups of

\footnotetext{
${ }^{14}$ As stated by the WDO (2012), "The WDA (S. 34) provides for an alternative method of managing waste .... Through this alternative approach, an ISP [industry stewardship plan] can be submitted to WDO by an individual steward, a group of stewards, or an organization representing one or more stewards" (p. 1).
} 
materials, including drugs and sharps. Stewardship Ontario (not the producers) was held liable for the program (OWMA, 2013; Valiante, 2012). Pharmacies were not required to participate in SO's program but many chose to since producers were paying for the management of waste returned to their locations.

Overall, Ontario was faced with the same problem as BC, and they had the same overarching policy goal and specific policy objective for mitigating the issue:

- Problem: there is an increasing presence of pharmaceuticals in the natural environment.

- Overarching policy goal: to reduce the potential environmental and health impacts associated with PhACs in a cost-effective manner (ON MOE, 2009a).

- Specific policy objective: to provide a province-wide system for the public to return their unused drugs for safe disposal based on EPR - shifting $100 \%$ of the responsibility and costs for managing this waste from government (and taxpayers) to the producers (ON MOE, 2004; ON MOE, 2009a; SO, 2009b).

On July 20, 2010 the MOE suspended phases 2 and 3 of the Orange Drop for a 90-day review due to "consumer confusion and retail implementation issues with eco-fees" (SO, 2010a). Eco-fees were applied to some hazardous waste products, such as household cleaners, by companies that did not internalize the costs for the Orange Drop. These fees were charged to the consumer at the point of sale (i.e. at the register). Although eco-fees were not applied to drugs, they were a part of the Orange Drop's group of materials to manage. After the review, the MOE (2010b) announced, "The government is permanently ending the household waste program that took effect on July 1. The end of the program means the end of any consumer fees being charged to pay for that particular program." SO continued to manage phase 2 and 3 waste, including drugs, until new programs were in effect; however, the provincial government provided the funding. Thus, what began as an attempt by government to implement an EPR approach resulted in two years of the provincial government (and taxpayers) assuming the costs. 


\subsection{Case 3: Ontario's New Medications Return Program}

On May 31, 2012 the MOE announced that they were scheduling consultations with the pharmaceutical sector to consider options for the collection of drugs and sharps by pharmacies (ON MOE, 2012). A quick three months later on August 2, 2012, the MOE posted a proposal on the Environmental Registry for an EPR regulation under the Environmental Protection Act for the collection of post-consumer waste pharmaceuticals and sharps. On October 1, 2012, O. Reg. 298/12 (Collection of Pharmaceuticals and Sharps - Responsibilities of Producers) came into

force which holds individual producers of pharmaceuticals and sharps financially responsible for safely managing the public's unused/expired drugs and sharps. Producers were given until January 1, 2013 to meet most of the regulatory requirements.

This regulation sets out clear accountability for individual producers and eliminates the mandatory collective approach through IFOs like Stewardship Ontario used under the WDA. A producer may establish and operate a management system on its own or in conjunction with other producers. The producers chose a similar approach to $\mathrm{BC}$ and made an agreement with the Health Products Stewardship Association to administer the return program on behalf of them. The HPSA administers two programs in Ontario: the Medications Return Program collects the public's unused drugs and natural health products, and the Ontario Sharps Collection Program collects the public's sharps - needles, lancets or instruments designed to puncture the skin of individuals/companion animals for medical purposes (O. Reg. 298/12).

Overall, the model for managing post-consumer drugs and sharps in Ontario has gone through a series of regulatory and administrative changes since the 1990s, as seen in Figure 10. The collection began as a voluntary initiative through pharmacies, followed by an unsuccessful attempt by government to implement extended producer responsibility under the WDA, and then recently transitioned to a government-regulated EPR program under the EPA. 


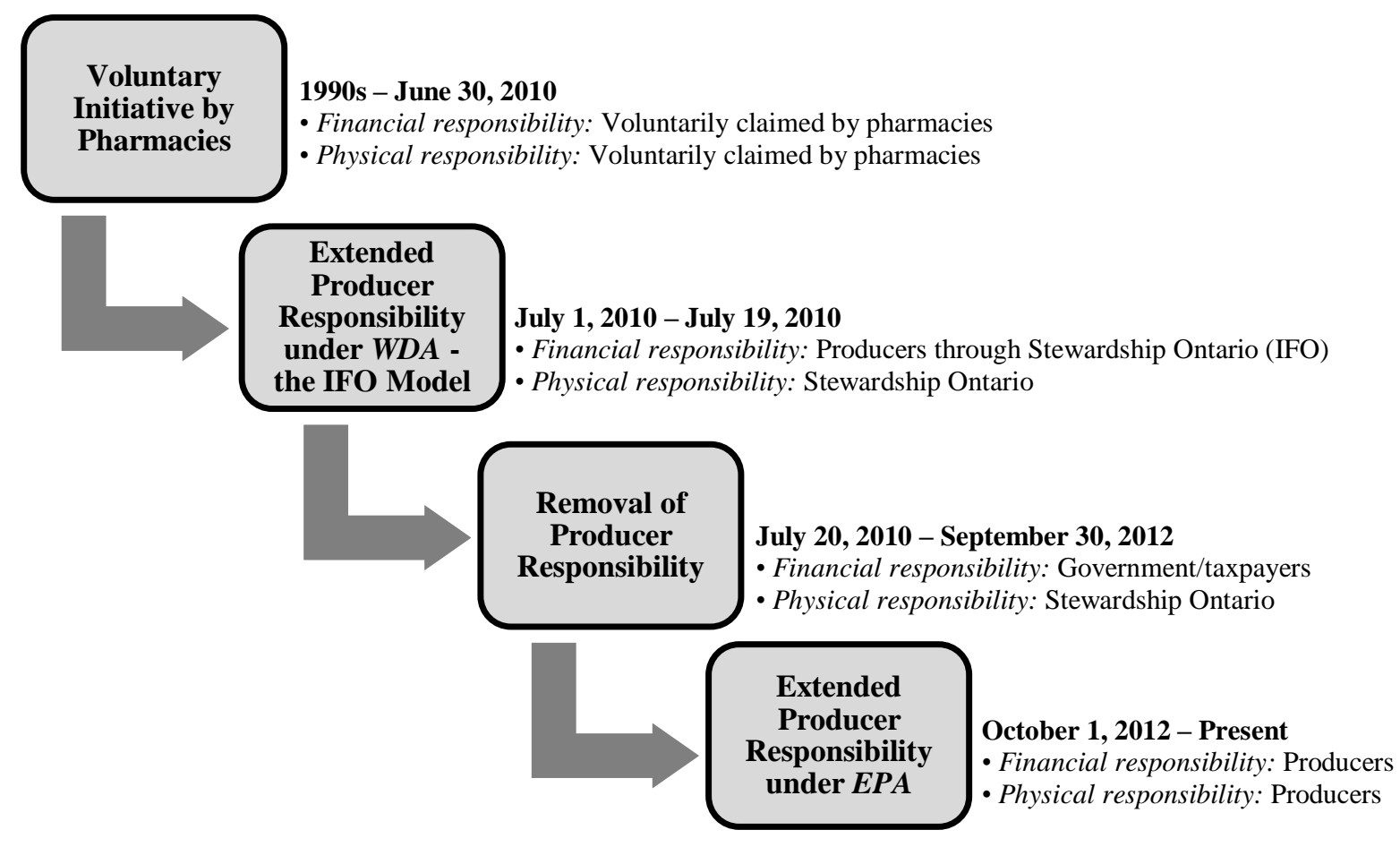

Figure 10. Management of Post-Consumer Pharmaceuticals \& Sharps in Ontario Since the 1990s (Adapted from Kingsmore \& Hargreave, 2012) 


\section{Chapter 5: Analysis}

\subsection{Step 2: Comparative Policy Analysis - BC's Medications Return Program vs. Ontario's Orange Drop Program}

As described in Chapter 2, the following elements were analyzed and compared between BC's Medications Return Program and Ontario's Orange Drop Program: stakeholder roles and responsibilities, supportive policy tools and instruments, and effectiveness in terms of achieving intended policy goals and meeting the criteria for an optimal return program.

\subsubsection{Stakeholder Roles and Responsibilities}

Tables 11 and 12 summarize the stakeholders' responsibilities in BC's Medications Return Program and Ontario's Orange Drop Program (for managing pharmaceuticals), respectively. As a reminder, phases 2 and 3 of the Orange Drop Program which included the end-of-life management of pharmaceuticals, were terminated in 2010.

In both provinces, the role of the physician is to prescribe medications. The physician's decision to prescribe a specific drug is influenced by numerous complex factors including "the physician's initial medical training and efforts to stay on top of current research, the availability of new drugs and technologies, new models of compensation, and the desire to meet patients' expectations" (Health Council of Canada, 2010, p. 4). The physician's choice to prescribe a medication plays a key role in consumer's gaining access to a drug and consuming it.

The consumers play an important role in both programs since they purchase the drugs. Ideally, consumers would take their medications as prescribed by their physicians; however, as discussed earlier, some consumers accumulate unused/expired medications at home. Perhaps they experience unwanted side-effects or maybe during treatment they start feeling better and decide to stop taking the drug. In both Ontario and $\mathrm{BC}$, the programs rely heavily on consumers voluntarily returning their unused drugs to pharmacies. If consumers choose not to participate then the programs have little to no impact in protecting the environment. The unused drug either continues to be stored in the household or the consumer tends to dispose of it in the garbage or down the drain/toilet (Statistics Canada, 2007).

The pharmacies also play a crucial role since they dispense medications and serve as collection sites. Pharmacies in BC and Ontario are not legally required to accept unused drugs 
from the public ${ }^{15}$ or to be involved in province-wide return programs; however, the majority participate to promote safe medicine practices, especially since the producers fund all program costs. Pharmacies are the logical choice since they are knowledgeable in safely handling, storing, and disposing of drugs. In both provinces, participating pharmacies are required to sign a protocol/agreement with the licensed waste company outlining requirements for proper storage and disposal. $\mathrm{BC}$ and Ontario pharmacists are responsible for ensuring that when collecting unused/expired drugs, they are disposed of in a safe and environmentally responsible manner (College of Pharmacists of BC, 2006; National Association of Pharmacy Regulatory Authorities, 2009). They also protect the consumer's confidentiality by removing personal information on the label before disposal (PCPSA, 2012c; SO, 2009a).

The $\mathrm{BC}$ and Ontario governments have mandated or facilitated the creation of collective agencies to represent the producers (Valiante, 2013). This allows for "one stop shopping for regulatory oversight" since it is easier to regulate one agency as opposed to hundreds of producers (Valiante, 2013). The pharmaceutical producers in BC appointed a stewardship agency, the Health Products Stewardship Association, to carry out their duties, including administering and operating BC's MRP. The producers pay fees to HPSA to fund the program. In Ontario, the producers were mandated under the Waste Diversion Act to combine as a collective $^{16}$ through Stewardship Ontario (the IFO). Similar to BC, the producers paid fees to SO to fund the program (although this did not last long). SO was responsible for designing, implementing and operating the Orange Drop with Waste Diversion Ontario.

In $\mathrm{BC}$ and Ontario, waste management service providers are required to obtain $\mathrm{MOE}$ approval for collecting, transporting, processing and incinerating pharmaceutical waste. Ontario's Orange Drop allowed consumers to return unused/expired drugs to depots and collection events, thus municipalities also acted as service providers. The municipalities, ENGOs, waste management advocacy groups and consultants in both BC's MRP and Ontario's Orange Drop were involved in the program development consultation process, and they provided their recommendations.

\footnotetext{
${ }^{15}$ According to the College of Pharmacists of BC (D. Nikkel, personal communication from inquiry message, January 15, 2013) and the Ontario College of Pharmacists (G. Ujiye, personal communication from inquiry message, January 15,2013 ).

${ }^{16}$ The WDA (s. 34) allows individual producers or a group of producers to submit an industry stewardship plan without IFOs. However, the producers did not choose this alternative.
} 
In $\mathrm{BC}$ and Ontario, the MOE designates waste that requires a diversion program, including pharmaceuticals. In $\mathrm{BC}$, the MOE is responsible for monitoring the MRP and enforcing compliance, reviewing and approving program plans and annual reports, and ensuring program outcomes and regulatory requirements are met. In Ontario, there is an arms-length organization, Waste Diversion Ontario, that “helps implement the Minister's priorities by working with [IFOs] to develop diversion programs" (ON MOE, 2008, p. 25).

WDO's key responsibilities in the Orange Drop were to establish an IFO to jointly develop, implement and operate the program; monitor the program's effectiveness and efficiency; enhance public awareness and participation; conduct public consultations; determine the amount of money required by WDO and the IFO to carry out their responsibilities; and establish a dispute resolution process (WDA, s. 5). Thus, a significant difference between the two programs relates to oversight and monitoring program performance. In $\mathrm{BC}$, this is done by the provincial government whereas in Ontario, WDO was responsible. The Ontario MOE would only review program plans once they were approved by WDO. Although the Ontario MOE was responsible for enforcing compliance under the WDA, Waste Diversion Ontario was required to play a dominant oversight role in the Orange Drop Program.

Table 11. Stakeholders' Responsibilities in BC's Medications Return Program

\begin{tabular}{|c|c|}
\hline Stakeholder & Responsibility \\
\hline Physicians & - Prescribe medications to patients. \\
\hline Consumers & $\begin{array}{l}\text { - Purchase and consume medications either prescribed or recommended } \\
\text { by physicians or based on personal desire. } \\
\text { - Can choose to voluntarily return unused products to a pharmacy. }\end{array}$ \\
\hline Pharmacies & $\begin{array}{l}\text { - Dispense medications to consumers. } \\
\text { - Pharmacies voluntarily participate as collection sites - strong incentive } \\
\text { to participate since producers fund program costs. } \\
\text { - Sign an agreement/protocol with the licensed waste company outlining } \\
\text { requirements for proper storage and disposal. } \\
\text { - Responsible for ensuring that when collecting unused drugs, they are } \\
\text { disposed of in a safe and environmentally responsible manner (College } \\
\text { of Pharmacists of BC, 2006). }\end{array}$ \\
\hline $\begin{array}{l}\text { BC Ministry of } \\
\text { Environment }\end{array}$ & $\begin{array}{l}\text { - Designate pharmaceutical waste in B.C. Reg. 449/2004. } \\
\text { - Monitors the program and enforces compliance. } \\
\text { - Reviews and approves program plans and reports. } \\
\text { - Ensures program outcomes and regulatory requirements are met. }\end{array}$ \\
\hline Pharmaceutical Producers & $\begin{array}{l}\text { - Required to have an approved program plan but can appoint an agency } \\
\text { to carry out their duties. } \\
\text { - Required to fund all program expenses such as collection, } \\
\text { transportation, storage, disposal and promotion and education. }\end{array}$ \\
\hline
\end{tabular}




\begin{tabular}{|l|l|}
\hline \multicolumn{1}{|c|}{ Stakeholder } & \multicolumn{1}{c|}{ Responsibility } \\
\hline $\begin{array}{l}\text { Health Products } \\
\text { Stewardship Association } \\
\text { (Appointed agency) }\end{array}$ & $\begin{array}{l}\text { - Administers and operates the program on behalf of the registered } \\
\text { producers as set out in a Membership Agreement. } \\
\text { - Sets and collects fees from the producers to fund the program. }\end{array}$ \\
\hline $\begin{array}{l}\text { Waste Management } \\
\text { Service provider }\end{array}$ & $\begin{array}{l}\text { - Safely collect, transport and destroy the waste using government } \\
\text { licensed incineration facilities. }\end{array}$ \\
\hline Municipalities & $\begin{array}{l}\text { - Provide input in consultation process and help inform the public that } \\
\text { the program is available. }\end{array}$ \\
\hline ENGOs & $\begin{array}{l}\text { - Provide recommendations in consultation process, and promote the } \\
\text { reduction of waste and protection of the environment. }\end{array}$ \\
\hline $\begin{array}{l}\text { Waste Management } \\
\text { Advocacy Groups }\end{array}$ & $\begin{array}{l}\text { Provide recommendations in consultation process, and promote best } \\
\text { practices and fair competition for managing waste. }\end{array}$ \\
\hline
\end{tabular}

Table 12. Stakeholders' Responsibilities for Managing Pharmaceutical Waste in Ontario's Orange Drop Program. Note: In past tense since this part of the program ended in 2010.

\begin{tabular}{|c|c|}
\hline Stakeholder & Responsibility \\
\hline Physicians & - Prescribed medications to patients. \\
\hline Consumers & $\begin{array}{l}\text { - Purchased and consumed medications either prescribed or } \\
\text { recommended by physicians or based on personal desire. } \\
\text { - Could voluntarily return unused products to a pharmacy or depot. }\end{array}$ \\
\hline Pharmacies & $\begin{array}{l}\text { - Dispensed medications to consumers. } \\
\text { - Pharmacies voluntarily participated as collection sites - strong } \\
\text { incentive to participate since producers funded program costs. } \\
\text { - Signed an agreement/protocol with the licensed waste company } \\
\text { outlining requirements for proper storage and disposal. } \\
\text { - Responsible for ensuring that when collecting unused drugs, they were } \\
\text { disposed of in a safe and environmentally responsible manner (National } \\
\text { Association of Pharmacy Regulatory Authorities, 2009). }\end{array}$ \\
\hline $\begin{array}{l}\text { Ontario Ministry of the } \\
\text { Environment }\end{array}$ & $\begin{array}{l}\text { - Responsible for designating the waste through regulation (O. Reg. } \\
542 / 06) \text {, and asking Waste Diversion Ontario to develop the program } \\
\text { with an industry funding organization. } \\
\text { - Responsible for enforcing the program under the WDA. } \\
\text { - Reviewed and approved the program plans and reports. }\end{array}$ \\
\hline $\begin{array}{l}\text { Stewardship Ontario } \\
\text { (Industry Funding } \\
\text { Organization) }\end{array}$ & $\begin{array}{l}\text { - Jointly designed the program plan with WDO. } \\
\text { - Worked with WDO to implement and operate the program. } \\
\text { - Responsible for overseeing program details, monitoring targets, } \\
\text { providing research and development, and P\&E support. } \\
\text { - Made the rules for designating producers, and set and collected fees } \\
\text { from the producers to fund the program. }\end{array}$ \\
\hline $\begin{array}{l}\text { Pharmaceutical \& Sharps } \\
\text { Producers }\end{array}$ & $\begin{array}{l}\text { - Required to combine as a collective under Stewardship Ontario. } \\
\text { - Paid fees to Stewardship Ontario to fund the program. }\end{array}$ \\
\hline Waste Diversion Ontario & $\begin{array}{l}\text { - Required to provide program oversight and establish an IFO to jointly } \\
\text { develop the program. } \\
\text { - Required to jointly design the program plan with the IFO and once } \\
\text { WDO approved, it was submitted to the MOE. } \\
\text { - Worked with the IFO to implement and operate the program. }\end{array}$ \\
\hline
\end{tabular}




\begin{tabular}{|l|l|}
\hline \multicolumn{1}{|c|}{ Stakeholder } & \multicolumn{1}{c|}{ Responsibility } \\
\hline Waste Diversion Ontario & $\begin{array}{l}\text { - WDO was responsible for developing, implementing and operating the } \\
\text { program and monitoring its effectiveness and efficiency; enhancing } \\
\text { public awareness and participation; ensuring that the program affected } \\
\text { Ontario's marketplace in a fair manner; determining the amount of } \\
\text { money required by WDO and the IFO to carry out their responsibilities; } \\
\text { and establishing a dispute resolution process (WDA, s. 5). }\end{array}$ \\
\hline $\begin{array}{l}\text { Waste Management } \\
\text { Service provider }\end{array}$ & $\begin{array}{l}\text { - Safely collected, transported and destroyed the waste using } \\
\text { government licensed incineration facilities. }\end{array}$ \\
\hline Municipalities & $\begin{array}{l}\text { - Pepots and collection events served as collection sites. } \\
\text { about the program. }\end{array}$ \\
\hline ENGOs & $\begin{array}{l}\text { - Provided recommendations in consultation process, and promoted } \\
\text { waste reduction and protection of the environment. }\end{array}$ \\
\hline $\begin{array}{l}\text { Waste Management } \\
\text { Advocacy Groups }\end{array}$ & $\begin{array}{l}\text { Provided recommendations in consultation process, and promoted best } \\
\text { practices and fair competition for managing waste. }\end{array}$ \\
\hline
\end{tabular}

\subsubsection{Supportive Policy Tools and Instruments}

Both BC and Ontario adopted measures to support and reinforce their programs for managing pharmaceutical waste, as seen in Table 13. BC chose to regulate the Medications Return Program under the Environmental Management Act - the province's fundamental statute for protecting the environment. The Act gives the MOE broad powers to prohibit waste (air contaminants, litter, effluent, refuse, biomedical waste and hazardous waste) from entering the environment. Section 6 of the EMA states that "a person must not introduce or cause or allow to be introduced into the environment, waste produced by a prescribed activity or operation" and that "a person must not introduce waste into the environment in such a manner or quantity as to cause pollution." The Act also sets out various offences, penalties and sentencing orders. Thus, the EMA is a pollution prevention tool used to drive environmental protection.

Ontario, on the other hand, chose to regulate the Orange Drop Program under the Waste Diversion Act. The purpose of the Act is "to promote the reduction, reuse and recycling of waste and to provide for the development, implementation and operation of waste diversion programs" (WDA, s. 1). It allows the MOE to designate materials requiring a diversion program. The Act intended to establish an EPR type framework in Ontario but according to the ON MOE (2008):

The Waste Diversion Act does not make explicit reference to extended producer responsibility. However ... the Act allows for fees to be charged to producers, as defined in the approved programs by the rules that are part of the program, to support program development and implementation, thereby creating a degree of financial responsibility for the management of the designated wastes. (p. 6) 
The Waste Diversion Act is a market-based policy instrument that directs waste management in Ontario (CIELAP, 2008). Rather than focusing on pollution prevention (like BC's EMA), the WDA focuses on establishing markets to encourage pollution control through waste diversion. A substantial focus in the WDA is placed on outlining the responsibilities of Waste Diversion Ontario in developing, implementing and operating waste diversion programs. The phrase "Waste Diversion Ontario" is mentioned 66 times in the Act whereas the word "environment" is mentioned only once (when describing the definition of the Minister).

Thus, the provinces have chosen to regulate their programs under two considerably different statutes. BC's EMA is a pollution prevention policy instrument whereas Ontario's WDA is a market-based policy tool used to encourage pollution control activities in the marketplace through waste diversion. BC regulated the MRP under the province's principal environmental statute whereas Ontario relied upon a previously existing statute governing waste management that focused on mandating an arms-length organization to develop, implement, and operate the Orange Drop.

Both provinces also implemented regulations to support their programs, as analyzed in Chapter 4. BC enacted the Recycling Regulation (B.C. Reg. 449/2004) which provides a resultsbased framework for EPR by setting out the producers' requirements for each designated product category. It requires all producers of designated materials to find a way for the public to dispose of their product's waste in an environmentally responsible manner. Rather than having to enact a new regulation for each material requiring a diversion program, the MOE can simply add a schedule to the existing regulation. The MOE designated pharmaceuticals under Schedule 2 in B.C. Reg. 449/2004 which provides the regulatory framework for BC's MRP.

Ontario enacted the Municipal Hazardous or Special Waste Regulation (O. Reg. 542/06) which designates pharmaceuticals as "municipal special waste" and identifies Stewardship Ontario as the industry funding organization. Unlike BC's results-based regulation, O. Reg. 542/06 does not explicitly set out the producer's responsibilities or program performance requirements. Instead, the MHSW Regulation focuses on defining the waste materials and designating the IFO. As opposed to adding schedules to the existing regulation like in $\mathrm{BC}$, in Ontario the MOE is required under the Waste Diversion Act to enact a new regulation for each designated product category requiring a diversion program. 
Table 13. Supportive Policy Tools for BC's and Ontario's Respective Return Program

\begin{tabular}{|l|c|l|}
\hline \multicolumn{1}{|c|}{$\begin{array}{c}\text { Supportive Policy } \\
\text { Tool }\end{array}$} & $\begin{array}{c}\text { Year } \\
\text { Introduced }\end{array}$ & \multicolumn{1}{c|}{ Purpose } \\
\hline British Columbia: & 2004 & $\begin{array}{l}\text { Pollution prevention tool - gives BC MOE broad powers } \\
\text { to protect the environment and human health. }\end{array}$ \\
\hline $\begin{array}{l}\text { Environmental } \\
\text { Management Act }\end{array}$ & 2004 & $\begin{array}{l}\text { Provides results-based framework for extended producer } \\
\text { responsibility; designates pharmaceuticals as waste; sets } \\
\text { out requirements for BC's MRP. }\end{array}$ \\
\hline $\begin{array}{l}\text { Recycling Regulation } \\
\text { (B.C. Reg. 449/2004) }\end{array}$ & 2002 & $\begin{array}{l}\text { Market-based tool to encourage waste diversion - } \\
\text { intended to establish an EPR type framework; sets legal } \\
\text { framework for WDO; promotes reduction, reuse and } \\
\text { recycling of waste; provides for the development, } \\
\text { implementation and operation of Orange Drop Program. }\end{array}$ \\
\hline Ontario: & $\begin{array}{l}\text { Designates pharmaceuticals as “municipal special waste" } \\
\text { and identifies Stewardship Ontario as the industry funding } \\
\text { organization. }\end{array}$ \\
\hline Waste Diversion Act & 2006 \\
\hline $\begin{array}{l}\text { Municipal Hazardous or } \\
\text { Special Waste } \\
\begin{array}{l}\text { Regulation } \\
\text { (O. Reg. 542/06) }\end{array}\end{array}$ & \multicolumn{2}{|l}{} \\
\hline
\end{tabular}

\subsubsection{Evaluation}

This component of the research evaluated the effectiveness of the programs by analyzing two areas: whether the programs and their supportive policy tools have met the intended policy goals and objectives, and whether the programs have met the criteria for an optimal MRP.

\subsubsection{Achieving Policy Goals}

As discussed in Chapter 4, both BC and Ontario had the same overarching policy goal and specific policy objective for mitigating the problem of pharmaceuticals in the environment.

- Overarching policy goal: to reduce the potential environmental and health impacts associated with $\mathrm{PhACs}$ in a cost-effective manner.

- Specific policy objective: to provide a province-wide system for the public to return their unused drugs for safe disposal based on EPR - shifting $100 \%$ of the responsibility and costs for managing this waste from government (and taxpayers) to the producers.

British Columbia's Medications Return Program has generally achieved these goals. For over fourteen years, the program has provided a way for the public to return their unused/expired pharmaceuticals to nearly all pharmacies across the province (95\% of them) for environmentally 
safe disposal to reduce the presence of PhACs in the environment (PCPSA, 2012c). In 2011, BC's MRP collected 69,044 kg of medications from consumers indicating that the program has eliminated these substances from reaching landfills and STPs, and therefore has helped reduce the potential environmental impacts associated with PhACs (PCPSA, 2012a).

BC's approach has also been cost-effective from the taxpayer and government perspective. The program requires the producers of pharmaceuticals and health products to fund all expenses incurred (including the collection, transportation, storage, and disposal) by making payments to HPSA (PCPSA, 2012c). The financial responsibility for managing pharmaceutical waste has been fully placed on the producers and there is no charge to the consumer for returning the products. The $\mathrm{BC}$ government does not provide funding and therefore taxpayer dollars have also been saved. Thus, BC's goal of making producers financially responsible for managing pharmaceutical waste has been achieved.

Although it is clear that the producers are paying for the program, is extended producer responsibility actually being achieved? The Recycling Regulation is the primary tool used to drive EPR in BC. It sets out the outcomes and performance measures for producers to achieve through waste diversion programs. The BC MOE (2012) has described EPR as a management system in which "producers of regulated products are required to manage Industry-led Product Stewardship Programs that include collection and recycling" (p. 4). The drug producers have appointed the Health Products Stewardship Association to carry out their duties including administering, implementing and operating the MRP (as allowed under B.C. Reg. 449/2004).

Although the BC MOE (2012, p. 4) has stated that "[t]he producers remain the obligated party regardless of the agency structure", it could be argued that the HPSA is actually managing the program with little involvement or accountability from the individual producers. The producers seem to pay their annual fees to HPSA and then allow HPSA to meet their obligations of operating the program, and submitting the annual reports and program plans. As articulated by Senior Policy Analyst, Valiante (2013, p. 4), by appointing an agency (like HPSA) they become the regulated party assuming the producers' environmental and financial liabilities, and "it is the agency that is liable for being charged with offences for non-compliance" under Section 2(5) of B.C. Reg. 449/2004.

Thus, BC's MRP has embraced the concept of extended producer responsibility since the costs for managing unused drugs have been shifted from the government to the producers. 
However, it is argued that HPSA is held more accountable for physically managing the program than the producers. As supported by EPR Canada (2012a), "Only programs where producers are solely and fully responsible for designing, operating and financing the diversion program and are accountable for the program's environmental performance are considered full EPR" (p. 3).

Unfortunately, Ontario's Orange Drop failed to achieve its intended policy objectives. On July 1, 2010, Stewardship Ontario launched phases 2 and 3 of the Orange Drop which provided safe end-of-life management for 13 groups of hazardous materials, including pharmaceuticals and sharps. A few weeks later on July $20^{\text {th }}$, the MOE suspended phases 2 and 3 of the program. As announced by John Wilkinson, former Minister of the Environment, "Ontarians quickly recognized that the program that started July 1 was flawed because it applied to some products that made little sense to consumers - and forced consumers to pay fees, in some cases inconsistently, on some routine household purchases" (ON MOE, 2010b).

The backlash from the public regarding the Orange Drop was mainly due to the eco-fee issues, and although pharmaceuticals did not have these fees, they were grouped into the same program with other hazardous materials (e.g. household cleaners and detergent) that did. Headlines from the media at the time included the following: "Ontario's eco fee hoax: Will Dalton's sneaky new tax save the world or just screw the consumer?" (Blizzard, 2010) and "New eco fees catching consumers by surprise" (McLean, 2010).

On October 18, 2010, the government permanently ended phases 2 and 3 through O. Reg. 396/10. There was extensive public criticism regarding the outcome, and Stewardship Ontario demanded \$18 million from the government for the termination (Welsh, 2011). SO continued to manage phase 2 and 3 materials including, drugs, until new programs for managing these wastes were in effect; however, government (and thus taxpayers) were responsible for paying.

It is clear that the Orange Drop did not achieve Ontario's desired policy objectives. Ontario set a policy goal of reducing the potential impacts associated with hazardous wastes, including pharmaceuticals, in a cost-effective manner. They specifically wanted to provide a province-wide system for the public to return their unused/expired drugs for safe disposal based on extended producer responsibility. After the Orange Drop ended, producers were no longer responsible for paying for the pharmaceuticals returned to pharmacies.

An implementation gap has been identified in which the Ontario government failed to act upon their stated public policy goals. As described by Greenbaum and Wellington (2010), "One 
important aspect of implementation is the translation of the broad environmental quality goals developed in the policy-making stage into precise, legally enforceable standards" (p. 235). The Ontario government attempted to make the producers financially liable for managing their products' waste through the Waste Diversion Act and the MHSW Regulation but in the end, the costs were shifted back to the government. This is not consistent with EPR.

The first objective for this comparative study, as identified in Chapter 1, was to investigate why Ontario's Orange Drop failed to achieve its goals whereas BC's MRP has been operational for more than fourteen years? The answer seems to be linked to the choice of policy tools that support and regulate the programs. The problems associated with the Waste Diversion Act have been voiced in several reports by the provincial government (ON MOE, 2008; ON MOE, 2009a; ON MOE, 2013a), Environmental Commissioner of Ontario (ECO, 2012), Ontario Waste Management Association (OWMA, 2013), Canadian Institute for Environmental Law and Policy (CIELAP, 2008); and the media (Dewees \& Valiante, 2012; Lowson, 2013). The points below summarize the major issues with the WDA.

\section{Mandating Collective Agencies (Industry Funding Organizations):}

The WDA requires producers to combine and pay fees to one IFO. Stewardship Ontario managed a wide range of hazardous materials under the Orange Drop (e.g. pharmaceuticals and sharps, batteries, household cleaners and fire extinguishers). This made it difficult to hold individual producers, such as the drug producers, responsible for managing their product's endof-life because they all combined under one group (ON MOE, 2013a; OWMA, 2013).

Since only one IFO exists for each diversion program under the Act, this essentially forms a monopolistic situation. As described by the ON MOE (2013a), "Because only a single IFO exists for each recycling program, IFOs disrupt the marketplace and stifle innovation and healthy competition" (p. 9). Similarly, as stated by the OWMA (2013), "Stewards [producers] under an IFO are also conferred with market power as monopoly buyers of environmental services. The effects of non-competition between producers and their consumers have dramatic effects on the waste diversion service marketplace" (p. 10).

The WDA also allows IFOs to transfer fees to consumers which depart from the concept of holding producers responsible. This was seen in the Orange Drop. When the Minister ended up cancelling phases 2 and 3 of the Orange Drop due to eco-fee issues, the collection of pharmaceuticals and sharps was also affected since all of the materials were managed in one 
program. The ON MOE (2013a) stated that the costs associated with properly managing products should be internalized as this "harnesses the competitive nature that makes producers compete based on the price of their product. This can prompt producers to reduce recycling costs by making their products easier to collect, dismantle, reuse, or recycle" (p. 10).

\section{Unclear Roles \& Responsibilities:}

The WDA has also been criticized for the lack of defined roles and responsibilities (ECO, 2012; ON MOE, 2009a; ON MOE, 2013a; OWMA, 2013). As stated in the ON MOE's (2009a) report, "The overlapping roles and responsibilities established in the current WDA can make it difficult to effectively hold parties accountable for results. Right now, WDO and IFOs share many of the same roles in the development of diversion programs" (p. 24).

Waste Diversion Ontario was specifically created under the Act to provide oversight as well as to develop, implement and operate diversion programs, including the Orange Drop Program, Waste Electrical and Electronic Equipment Program, Used Tire Program, and the Blue Box Program. The ON MOE (2013a) has admitted that WDO's role is unclear as they play “a dual role" as the developer and overseer of diversion programs, and " $[t]$ his lack of clarity contributes to strained relationships among stakeholders involved in the delivery of recycling programs and hampers efforts to adapt to changing circumstances" (p. 10). As a result, it has been difficult for WDO to fulfil its oversight role as they have minimal ability to hold the IFOs and producers accountable. Thus, the Orange Drop was also faced with monitoring lapses due to ineffective oversight.

3. Lack of Compliance and Enforcement Tools:

Under the WDA, there is a lack of enforcement and compliance tools available for the provincial government to enforce accountability and to ensure that the diversion programs, like the Orange Drop, achieve their desired results (ON MOE, 2009a; ON MOE, 2013a; OWMA, 2013). As described by the ON MOE (2013a), "The government has limited powers to set and enforce recycling results, and to require a course correction when needed" (p. 10). The rules under which IFOs operate in diversion programs are set out in contracts with WDO as opposed to regulations under statute (Valiante, 2013). As a result, there is a lack of tools available for government to enforce programs like the Orange Drop. Not only was the Orange Drop Program faced with an implementation gap and monitoring lapses, it was also confronted with 
enforcement deficits under the Waste Diversion Act.

The extensive problems associated with the Act have reached the point to where the Ontario government proposed a new statute (the Waste Reduction Act) on June 6, 2013 to replace the WDA (ON MOE, 2013b). Rather than enacting a new regulation to fix the problems, they decided to replace the Act, indicating that the WDA is fundamentally flawed.

Overall, BC and Ontario had similar policy goals for managing post-consumer drugs but the policy choices made resulted in different outcomes. It is argued that the choice of policy tools used to support the programs played a crucial role in their outcomes. BC's MRP is regulated under a results-based framework that sets the outcomes for producers to achieve. This approach has allowed $\mathrm{BC}$ to meet their policy goals and for the MRP to remain operational since its implementation. However, the full concept of EPR has not been applied since most of the liabilities for managing the program fall on the Health Products Stewardship Association.

Ontario's Orange Drop Program failed to meet its intended policy goals for managing pharmaceutical waste. It is argued that the cancellation of the Orange Drop was more than just eco-fee issues, it was primarily a result of the chosen policy tool: the Waste Diversion Act. This finding is consistent with a report released by the C.D. Howe Institute in which the authors attributed the failure of the Orange Drop Program to poor program and institutional design under the WDA (Green \& Trebilcock, 2010). As stated in the study:

The underlying governance structures are central to the effectiveness, efficiency, and fairness of EPR programs, but are often neglected or poorly designed. EPR programs need not suffer the fate of the failed Ontario hazardous waste program. Policymakers can make these programs work through better institutional design ... (Green \& Trebilcock, 2010, p. 2)

Thus, the eco-fee issues were only a symptom of the WDA. The problems with the Orange Drop Program were rooted in underlying design flaws in the program and institutions. The Act mandates collective agencies; has unclear roles; and has a lack of enforcement tools. These elements contributed to the implementation gap, monitoring lapses and enforcement deficits.

\subsubsection{Stakeholder Perceptions}

As described in Chapter 2, interviews were conducted with professional experts directly involved in or affected by the $\mathrm{BC}$ and Ontario programs to gain an understanding of the roles and responsibilities, implemented measures, and the actors' perceptions of the programs. The 
knowledge obtained helped with measuring the effectiveness of the programs. This section summarized how the actors perceived the programs.

\section{1) Perceptions from BC Stakeholders Regarding the Performance of BC's MRP:}

In general, BC stakeholders were satisfied with the performance of the MRP. As described by one interviewee, “[Collections] are going up every year. We've got high participation rates. No complaints to speak of. So, I would say it's a well-established program that functions fairly well." The interviewees were particularly pleased with the $95 \%$ participation rate from pharmacies (PCPSA, 2012c). The actors mentioned that when regional districts ban pharmaceuticals from the waste stream, this tends to drive consumer awareness.

There was a general consensus that there are improvements to be made with consumer awareness. They all agreed that it is the most important performance measure in this program. As stated by one interviewee:

Consumer awareness is almost impossible to measure effectively. You know, surveys can be misleading, and they can target the wrong people. The disposal of pharmaceutical waste can happen at key times, like the death of a person, you know, when you're suddenly ready to clean out cabinets. ... [Consumer awareness] is a tough one and it's the toughest one that we face. How do we push consumer awareness, which is absolutely the most critical factor in this program?

It was mentioned that certain people might not be aware of the program because they are not regularly picking up prescriptions. It is difficult to target and appeal to this type of customer.

Another weakness of the program relates to government enforcement. It was made clear by all stakeholders that the MOE is responsible for enforcing the program. However, two interviewees indicated that they knew of some free riders in the marketplace (pharmaceutical companies that have products that meet the definition of B.C. Reg. 449/2004 but are not investing into the program). It was stated that the government is aware of this but "they have not been very aggressive in going after them year after year." Although these free riders only have a small portion of the market, they still are not complying and following the rules.

There was also a concern that as the government continues to designate more products under the Recycling Regulation it will create an atmosphere that makes it easier for free riders to exist. There are eight waste diversion programs in $\mathrm{BC}$ covering dozens of materials from electronics and tires to pharmaceuticals. As stated by one interviewee, "I don't think there is any measurement going on [from the MOE] with those programs." Similarly, another individual 
stated, "As we plan to get more stewardship programs . . . if there isn't a mechanism to enforce them, then people will pull out slowly." Thus, issues around enforcement were raised.

\section{2) Perceptions from BC Stakeholders Regarding the Recycling Regulation:}

The stakeholders were generally supportive of the regulation, especially regarding its flexibility with adding new designated products. Rather than enacting a new regulation for each product requiring a diversion program, the Ministry just has to add a schedule to the existing regulation. As described by one interviewee, "I think it [Recycling Regulation] is effective for pharmaceutical waste because of the auditing requirements for non-financial information. That gives [government] some teeth in terms of monitoring a program like this that doesn't charge fees." There was general support of the process outlined in the regulation which requires the producers/the agency to develop their plans, have the Ministry approve them, and then have the producers report on their outcomes. As stated by one interviewee, "One thing I found in this industry . . . is that not one size fits all. You can't make everybody do the same thing because they all have their unique features. It makes sense to let the stewards develop their own plans."

Although the stakeholders generally supported the Recycling Regulation, two interviewees had issues regarding fair competition. It was mentioned that the regulation creates "producer monopolies" by allowing producers to "deliver their own program and transfer their legal liability to a stewardship agency." This transfer of liability is ultimately very attractive for the producers. An example was given by one interviewee:

If I choose to pass my liability to an agency, even if that costs me $40 \%$ more, I would rather them [the agency] pick up my legal liability so the regulator has no way to come after me. . . So, this transfer of liability to stewardship agencies facilitates these corruptive systems that in normal free markets no one would ever consider.

Thus, the issue of the producers transferring their liabilities to the Health Products Stewardship Association was raised which is ultimately inconsistent with the principle of EPR.

There also seems to be a discrepancy regarding how pharmaceuticals are defined. The regulation requires that drugs, as defined in the Food and Drugs Act, be captured in the program which includes natural health products (e.g. vitamins and minerals, herbal remedies, and homeopathic medicines). According to the interviewees, many natural health product companies have advocated that their products are not harmful and thus should not be included in the program. 
As described by one interviewee:

Some of these companies have products that may not require incineration as a disposal method. The active ingredient is basically non-existent. . . . But the public cannot differentiate between a less potentially harmful ingredient versus one that requires incineration for disposal. Either way, they have a product in the marketplace that meets the definition, so they are required to participate.

Thus, natural health products are required to be part of the program regardless of whether these substances pose little or no risk in the environment.

\section{3) Ontario Stakeholders' Lessons Learned from Ontario’s Failed Orange Drop Program:}

All of the Ontario actors stated that there were several problems associated with phase 2 and 3 of the Orange Drop which included managing pharmaceuticals. The stakeholders were in consensus that while some of the issues were driven by politics rather than policy (in which the interviewees chose not to comment on the politics), many problems developed due to how the program was designed through the Waste Diversion Act. As described by one interviewee, “There's lots of things that went wrong and I think they were largely a result of how the program was put together in the Act." These issues with the WDA were discussed in Section 5.1.3.1.

A key lesson learned mentioned by all stakeholders was that the framework used to drive EPR programs should shift towards a results-based framework that sets measurable environmental outcomes for producers to meet. Three interviewees criticized the Waste Diversion Act as being heavily process driven, and instead, recommended that the framework should focus on setting outcomes. There was also a consensus from the stakeholders that the roles and responsibilities of the parties involved in this type of program must be clearly defined.

Another lesson learned stated by the actors was that the producers should be held liable (not IFOs). As stated by one interviewee, "If you have these agencies taking on this reputation of managing the program, it takes the heat off of the producer. So what motivates producers to improve performance? The agency basically prevents them from being further regulated."

Overall, the interviews conducted in BC and Ontario helped to highlight the stakeholders' perceptions of the programs. The BC actors were generally satisfied with the MRP's performance but there are improvements to be made regarding consumer awareness and eliminating free riders. They were also supportive of the Recycling Regulation; however, there are issues with agencies taking on the producers' liabilities and with the inclusion of "less 
harmful" natural health products. Therefore, although BC's MRP has generally achieved its policy goals, the interviews revealed that there are some weaknesses.

Key lessons learned in Ontario is that they should move forward to a results-based framework that clearly defines the roles and responsibilities and holds producers (not IFOs) liable for the program. The interviews with Ontario stakeholders further confirmed that many of the problems associated with the Orange Drop were attributed to the Waste Diversion Act.

\subsubsection{Meeting Criteria for an Optimal Return Program}

The effectiveness of the $\mathrm{BC}$ and Ontario programs was also measured by determining whether they met the criteria for an optimal return program (as discussed in Section 3.4.4).

- Criterion \#1: Clearly defined scope - the program's objectives, product definitions, and roles and responsibilities of the parties are clearly stated.

BC's MRP has met this criterion. The objective is stated in the program plan: "to run a province-wide, industry-administered product stewardship program in compliance with the Regulation" (PCPSA, 2012c, p. 4). The pharmaceutical definitions and roles and responsibilities are stated in B.C. Reg. 449/2004.

Ontario's Orange Drop partially achieved this criterion. The objective was stated in the program plan which was to develop a program that incorporates EPR "under which the stewards will bear the full cost of management, inclusive of collection through to final diversion or disposal of MHSW" including pharmaceuticals and sharps (SO, 2009b, p. 2). The pharmaceutical product definitions were also clearly stated; however, there was confusion regarding the roles and responsibilities in the Orange Drop, as analyzed in Section 5.1.3.1.

- Criterion \#2: Results-based regulatory framework - the program sets measurable outcomes in regulations/legislation and gives producers flexibility to meet outcomes.

BC's program has met this criterion. As thoroughly discussed in Section 5.1.3.1, BC's Recycling Regulation is a performance-based framework that sets out the producers' requirements for each designated product, including pharmaceuticals.

Ontario's Orange Drop did not meet this benchmark. The Waste Diversion Act is known as a market-based, process driven policy tool as opposed to a performance-based framework. 
Also, the pharmaceutical producers were not given the flexibility to manage the waste since the WDA required the producers to combine and pay fees to one IFO: Stewardship Ontario.

- Criterion \#3: Accountability - the producers are held accountable for financing and operating the program, and for achieving performance measures.

$\mathrm{BC}$ has partially achieved this criterion. Although the producers have been financing the program it is argued that HPSA is held more accountable than the producers for operating the program and for achieving performance.

Ontario did not meet this benchmark. They attempted to make the producers, including drug producers, pay for the program; however, when the Minister cancelled phases 2 and 3 a few weeks after its implementation, this financial responsibility was placed back on the provincial government (and thus taxpayers). Not only were the pharmaceutical producers no longer financially liable, Stewardship Ontario was held more accountable for operating the program.

- Criterion \#4: Internalizing costs - program costs are internalized as a factor of production.

$\mathrm{BC}$ has achieved this benchmark. According to the HPSA, the producers fund the program's costs; consumers are not charged when returning their unused drugs; and the costs of medicines have not increased as a result of BC's MRP (PCPSA, 2010). In 2010, the program cost $\$ 478,471$ - the producers' yearly fees to HPSA typically ranged from $\$ 200$ to $\$ 15,000$, and only eight companies paid more than $\$ 20,000$ for the year (PCPSA, 2010).

Ontario did not meet this criterion. After phases 2 and 3 of the Orange Drop ended, the provincial government bore the costs associated with collecting the waste from the public.

- Criterion \#5: Effective monitoring and enforcement - the program has effective oversight to monitor the program and ensure a level playing field is established. The jurisdictional authority enforces the program and dedicates sufficient resources to monitor compliance.

BC has partially met this criterion. Under B.C. Reg. 449/2004, Section 16 sets out offences (a person can be fined up to $\$ 200,000$ ), and agencies can also be charged with offenses under Section 2(5). There is an enforcement process in place if producers are non-compliant with the regulation. Non-compliance has been defined as "a lack of responsiveness from a brand-owner/producer after more than two notices on producers' responsibilities have been sent 
from PCPSA [now the HPSA]" (PCPSA, 2012c, p. 15). After the HPSA has made three attempts within 120 days to contact the non-compliant producer, then a "request for noncompliance actions" is sent to the MOE (PCPSA, 2012c). It was revealed in the interviews (see Section 5.1.3.2) that there is allegedly a group of free riders in the pharmaceutical market, and the $\mathrm{BC}$ government is aware but "they have not been very aggressive in going after them year after year." Thus, a level playing field has not been established.

Ontario's Orange Drop did not meet this benchmark. It was analyzed earlier that under the WDA, it was difficult for WDO to fulfil its oversight and monitoring role since they had minimal ability to hold the IFOs (like Stewardship Ontario) accountable. There was also a lack of effective enforcement measures available for the MOE to enforce results (ON MOE, 2013a).

- Criterion \#6: Open consultation process - there is an open consultation process during program development that allows stakeholders to participate.

$\mathrm{BC}$ has achieved this. Since the HPSA was required to renew their five-year program plan in 2012, they invited stakeholders to attend a joint public consultation process with three other stewardship programs held on four dates in May of 2011 (PCPSA, 2012c). Notifications were sent to 329 stakeholders in April (PCPSA, 2012c). The program plan was made available for public comment from June $5^{\text {th }}$ to June $17^{\text {th }}$ in 2011. The HPSA summarized the questions and comments made during the consultation in their 2012-2016 program plan (PCPSA, 2012c).

Ontario's Orange Drop achieved this criterion. Prior to launching phase 2 and 3 of the Orange Drop in 2010, Stewardship Ontario held three public consultation meetings from October 28, 2008 to May 19, 2009, and they also conducted a series of material-specific consultations (SO, 2009c). They developed a report on the consultation process, including a summary of the comments and questions, and the attendance of the stakeholders (SO, 2009c). The public was given 30 days to comment on SO's program plan in the summer of 2009.

- Criterion \#7: Performance measure for Promotion and Education (P\&E) - producers should be required to make investments in $\mathrm{P} \& \mathrm{E}$ to maximize customer knowledge about the program and proper disposal, and these materials (e.g. brochures and posters) should be available at the point of purchase. This is an important indicator as it drives awareness. 
BC has not met this criterion. HPSA's 2012-2016 program plan set a promotion indicator target to reach by 2017 which is to have "publicity on the Medications Return Program in 25 regional districts or municipalities' websites with recycling sections" and "promotion of [the] program in participating pharmacies and other sites" (PCPSA, 2012c, p. 13). Key strategies are to display signage in pharmacies regarding BC's MRP and to develop an advertising plan with a firm (PCPSA, 2012c). The drug producers are responsible for funding the P\&E materials and the pharmacies can complete and fax a promo order form on the HPSA website to receive the items (HPSA, n.d.). However, how much P\&E is actually taking place?

In November of 2012, this author visited 20 pharmacies participating in BC's MRP in Vancouver and Victoria to see what kind of P\&E materials are available. Of the pharmacies visited, 9 were categorized as large (i.e. retail chain with over 25 locations in $\mathrm{BC}$ ) and 11 were categorized as small (i.e. the company had 1 to 5 locations in BC). The author spent 10 minutes in each pharmacy and looked for items such as posters, brochures and flyers about the program.

This does not represent a comprehensive analysis of $\mathrm{P} \& \mathrm{E}$ taking place across $\mathrm{BC}$ since only 20 pharmacies within two cities were visited. Also, it is possible that the pharmacies have implemented more P\&E materials since the visit. Ideally, more pharmacies would have been visited; however, due to time and funding constraints, only a small sample size was analyzed.

As seen in Table 14, only 4 pharmacies ( 3 large and 1 small) out of the 20 visited had some type of P\&E either about BC's MRP or how to dispose of drugs. Rexall Drug Store \#7129 had the most P\&E: a large poster at checkout that outlined the 3 steps for returning unused drugs, and a brochure explaining the harms of improper disposal and how to safely dispose of expired drugs (refer to Appendix A). View Street Pharmacy was the only pharmacy that had a P\&E item from the HPSA (formerly called PCPSA), as seen in Appendix B. Safeway Food \& Drug Pharmacy \#2 and Shoppers Drug Mart \#202 each had one P\&E item (see Appendices C and D).

London Drugs \#29 displayed 4 posters for the pharmacy's “Diabetes Needles Disposal Program" (see Appendix E for example); however, needles are not accepted in BC's MRP. Hence, they only had P\&E in place for their own initiative. Both London Drugs \#29 and London Drugs \#74 had a brochure stating that consumers should "dispose of outdated or unused medications" but it did not say how or where to dispose of them (Appendix E).

It was surprising to see a lack of P\&E for the program, especially since BC's MRP has been operating since 1999. Thus, BC did not meet this criterion. 
The P\&E for Ontario's Orange Drop Program cannot be evaluated since it has been replaced with a revised Medications Return Program that does not involve Stewardship Ontario. Thus, the P\&E cannot be evaluated for Ontario’s Orange Drop in this research.

Table 14. Promotion \& Education in 20 Pharmacies Participating in BC's Medications Return Program

\begin{tabular}{|c|c|c|c|}
\hline Pharmacy & Type & Address & Promotion and Education \\
\hline $\begin{array}{l}\text { London Drugs } \\
\text { \#29 }\end{array}$ & Large & $\begin{array}{l}\text { \#201- } 911 \text { Yates St. } \\
\text { Victoria, BC }\end{array}$ & $\begin{array}{l}\text { None. There were } 4 \text { posters for the pharmacy's } \\
\text { "Diabetes Needles Disposal Program" (see } \\
\text { Appendix E for example); however, needles are not } \\
\text { accepted in BC's MRP. There was also a First Aid } \\
\text { and Medication Safety brochure which said that you } \\
\text { should "dispose of outdated or unused medications" } \\
\text { but it did not say how or where to dispose of them } \\
\text { (Appendix E). }\end{array}$ \\
\hline $\begin{array}{l}\text { Rexall Drug } \\
\text { Store \#7129 }\end{array}$ & Large & $\begin{array}{l}\text { Victoria Med- } \\
\text { Dental Bldg. } \\
\# 120-1120 \text { Yates } \\
\text { St. Victoria, BC }\end{array}$ & $\begin{array}{l}\text { Yes. There was a large poster at checkout that } \\
\text { outlined the } 3 \text { steps for returning unused drugs to } \\
\text { the pharmacy for disposal (Appendix A). Rexall } \\
\text { also had a Medicine Cabinet Cleanup brochure that } \\
\text { explained how to dispose of expired medications } \\
\text { and the harms associated with improper disposal } \\
\text { (Appendix A). }\end{array}$ \\
\hline $\begin{array}{l}\text { Victoria } \\
\text { Compounding } \\
\text { Pharmacy Ltd }\end{array}$ & Small & $\begin{array}{l}1089 \text { Fort St. } \\
\text { Victoria, BC }\end{array}$ & None. \\
\hline $\begin{array}{l}\text { View Street } \\
\text { Pharmacy }\end{array}$ & Small & $\begin{array}{l}867 \text { View St } \\
\text { Victoria, BC }\end{array}$ & $\begin{array}{l}\text { Yes. There was } 1 \text { brochure from the previously } \\
\text { named PCPSA (now HPSA) specifically regarding } \\
\text { BC's MRP (Appendix B). }\end{array}$ \\
\hline $\begin{array}{l}\text { Shoppers } \\
\text { Drug Mart } \\
\# 221\end{array}$ & Large & $\begin{array}{l}1222 \text { Douglas St. } \\
\text { Victoria, BC }\end{array}$ & None. \\
\hline $\begin{array}{l}\text { Aaronson's } \\
\text { Pharmacy }\end{array}$ & Small & $\begin{array}{l}1711 \text { Cook St. } \\
\text { Victoria, BC }\end{array}$ & None. \\
\hline $\begin{array}{l}\text { Pandora } \\
\text { Pharmacy }\end{array}$ & Small & $\begin{array}{l}922 \text { Pandora Ave. } \\
\text { Victoria, BC }\end{array}$ & None. \\
\hline $\begin{array}{l}\text { Lallicare } \\
\text { Pharmacy \#1 }\end{array}$ & Small & $\begin{array}{l}1139 \text { Yates Street } \\
\text { Victoria, BC }\end{array}$ & None. \\
\hline $\begin{array}{l}\text { Pharmasave } \\
\text { James Bay } \\
\# 130\end{array}$ & Large & $\begin{array}{l}230 \text { Menzies St. } \\
\text { Victoria, BC }\end{array}$ & None. \\
\hline Finlandia & Small & $\begin{array}{l}111 \text { West } \\
\text { Broadway } \\
\text { Vancouver, BC }\end{array}$ & None. \\
\hline
\end{tabular}




\begin{tabular}{|c|c|c|c|}
\hline Pharmacy & Type & Address & Promotion and Education \\
\hline $\begin{array}{l}\text { MacDonald's } \\
\text { Prescriptions } \\
\# 3\end{array}$ & Small & $\begin{array}{l}2188 \text { West } \\
\text { Broadway } \\
\text { Vancouver, BC }\end{array}$ & None. \\
\hline $\begin{array}{l}\text { Vita Vie } \\
\text { Pharmacy }\end{array}$ & Small & $\begin{array}{l}2215 \text { West } \\
\text { Broadway } \\
\text { Vancouver, BC }\end{array}$ & None. \\
\hline $\begin{array}{l}\text { Gaia Garden } \\
\text { Herbals Inc. }{ }^{17}\end{array}$ & Small & $\begin{array}{l}2672 \text { West } \\
\text { Broadway } \\
\text { Vancouver, BC }\end{array}$ & None. \\
\hline $\begin{array}{l}\text { Safeway Food } \\
\& \text { Drug - } \\
\text { Pharmacy \#2 }\end{array}$ & Large & $\begin{array}{l}2733 \text { West } \\
\text { Broadway } \\
\text { Vancouver, BC }\end{array}$ & $\begin{array}{l}\text { Yes. There was } 1 \text { brochure from the BC Pharmacy } \\
\text { Association about how to dispose of unused drugs. } \\
\text { (Appendix C). }\end{array}$ \\
\hline $\begin{array}{l}\text { The Medicine } \\
\text { Shoppe \#221 }\end{array}$ & Large & $\begin{array}{l}\# 101-777 \text { West } \\
\text { Broadway } \\
\text { Vancouver, BC }\end{array}$ & None. \\
\hline $\begin{array}{l}\text { Lancaster } \\
\text { Medical } \\
\text { Supplies \& } \\
\text { Prescriptions } \\
\# 1\end{array}$ & Small & $\begin{array}{l}\text { Unit } 1-601 \text { West } \\
\text { Broadway } \\
\text { Vancouver, BC }\end{array}$ & None. \\
\hline $\begin{array}{l}\text { London Drugs } \\
\text { \#74 }\end{array}$ & Large & $\begin{array}{l}2230 \text { West } \\
\text { Broadway } \\
\text { Vancouver, BC }\end{array}$ & $\begin{array}{l}\text { None. There was a First Aid and Medication Safety } \\
\text { brochure which said that you should "dispose of } \\
\text { outdated or unused medications" but it did not say } \\
\text { how or where to dispose of them (Appendix E). }\end{array}$ \\
\hline $\begin{array}{l}\text { Shoppers } \\
\text { Drug Mart } \\
\# 2221\end{array}$ & Large & $\begin{array}{l}1780 \text { West } \\
\text { Broadway } \\
\text { Vancouver, BC }\end{array}$ & None. \\
\hline $\begin{array}{l}\text { Regency } \\
\text { Prescriptions } \\
\# 1\end{array}$ & Small & $\begin{array}{l}\# 1-1530 \text { West } 7^{\text {th }} \\
\text { Ave. } \\
\text { Vancouver, BC }\end{array}$ & None. \\
\hline $\begin{array}{l}\text { Shoppers } \\
\text { Drug Mart } \\
\# 202\end{array}$ & Large & $\begin{array}{l}2888 \text { Granville } \\
\text { Street } \\
\text { Vancouver, BC }\end{array}$ & $\begin{array}{l}\text { Yes. There was a small sign at checkout indicating } \\
\text { that they accept unused drugs and sharps (Appendix } \\
\text { D). }\end{array}$ \\
\hline
\end{tabular}

- Criterion \#8: Performance measure for Consumer Awareness - this is the most important indicator because if consumers are not aware of the program then disposal behaviour will likely not change. The producer should measure the percentage of the population aware of the program and that have participated, and monitor how awareness changes over time.

${ }^{17}$ Not a licensed community pharmacy - they specialize in selling plant-based herbal remedies. 
BC's MRP has achieved this benchmark. In 2010, the HPSA retained a polling firm to conduct a public awareness survey with 509 British Columbians and found that $48 \%$ are able to identify pharmacies as a place to dispose of unwanted health products (without prompting), and $51 \%$ have returned their unwanted health products to pharmacies (PCPSA, 2012c). HPSA's target to reach by 2017 is to increase public awareness by $25 \%$ and usage of the program by $10 \%$ (PCPSA, 2012c).

Ontario did not meet this criterion as Stewardship Ontario did not establish a measurable awareness indicator for pharmaceuticals in their program plan (SO, 2009a).

- Criterion \#9: Performance measure for Accessibility - There should be accessible and convenient locations that are familiar, free and frequent to consumers.

BC's MRP has met this benchmark. There are 1,025 pharmacies registered in the program which represent about $95 \%$ of the community pharmacies in BC (PCPSA, 2012c). Pharmacies are frequent and familiar to customers since this is where they purchase their drugs. The HPSA set a target to maintain or exceed the 95\% participation rate (PCPSA, 2012c).

Ontario's Orange Drop also achieved this criterion. Consumers were able to return their unused/expired drugs to over 2,500 pharmacies (out of an approximate total of 3,181 community pharmacies) as well as depots and collection events (SO, 2009a; SO, 2010b).

- Criterion \#10: Performance measure for Product Collection - Since drugs are a consumable product and are to be taken as prescribed by physicians, then there should not be any waste. Hence, a stringent collection target should not be set. It is difficult to interpret what high or low collections actually mean. Low return rates may indicate that consumers are taking their drugs as directed and the resulting low collection rates could still potentially mean good performance. Alternately, low return rates may mean that consumer awareness is low thus indicating poor performance and $\mathrm{P} \& \mathrm{E}$. Either way, collection data should be acquired to understand program size and impact.

$\mathrm{BC}$ has met this criterion. The HPSA reports yearly on the amount of waste collected. In 1999, the program collected about 10,105 kg of returns while in 2011 the program collected 69,044 kg (BC MOE, 1999; PCPSA, 2012a). The HPSA's current target is to "maintain a minimum collected quantity of 65 tons on a three-year rolling average" (PCPSA, 2012c, p. 12). 
Ontario has also achieved this criterion. Stewardship Ontario did not set a stringent collection target but they kept track of the weight of the returns. Even though the MOE ended phase 2 and 3 of the Orange Drop in 2010, Stewardship Ontario continued to collect unused drugs and sharps from the public (but producers no longer funded the program). From July to December of 2010 the program collected 137 tonnes of drugs and 82 tonnes of sharps and syringes; in 2011 the program collected 315 tonnes of drugs and 188 tonnes of sharps and syringes; from January to September 2012 the program collected 299 tonnes of drugs and 171 tonnes of sharps and syringes ( $\mathrm{T}$. Burns, personal communication from inquiry message, July 12 , 2013).

- Criterion \#11: Proper end-of-life management - unused/expired pharmaceuticals should not be reused or recycled; they should be safely destroyed by high temperature incineration.

$\mathrm{BC}$ and Ontario achieved this criterion. Both programs used government approved incineration facilities for end-of-life management (PCPSA, 2012c; SO, 2009b). Although incinerating waste could potentially raise public health and environmental concerns, in the case of pharmaceuticals, the amounts being incinerated are substantially small. For example, the waste collected through BC's MRP represents less than $1 \%$ of the total load destroyed at the incineration facility annually (PCPSA, 2012c).

- Criterion \#12: Reporting and auditing requirements - publicly available reports (annual or bi-annual) are submitted to the authority outlining progress towards meeting program targets. There are independent third-party audits on the operational performance of the program.

BC's MRP has met this benchmark. HPSA is required to submit annual reports. The MOE also requires third-party verification of non-financial information in the annual reports on the following: location of collection facilities, description of how the product was managed, and total amount of product sold and collected (BC MOE, 2012). Effective July 2013, annual reports are required to have a "reasonable assurance" opinion by a qualified third-party (e.g. Chartered Accountant or Certified General Accountant) using procedures from the Canadian Institute of Chartered Accountants Handbook on Assurance and Related Services and ISAE 3000 Standard on Assurance Engagements (BC MOE, 2012). 
Ontario's Orange Drop partially met this criterion. Stewardship Ontario submitted annual reports; however, since the MOE cancelled phases 2 and 3 of the program in 2010, they were no longer required to publicly report on phase 2 and 3 materials like pharmaceuticals. SO was also only required to submit independently audited financial statements.

Table 15 summarizes the evaluation of BC's MRP and Ontario's Orange Drop against the criteria for an optimal return program for managing pharmaceutical waste.

Table 15. Evaluation of BC's MRP and Ontario's Orange Drop Against Criteria for an Optimal Return Program

\begin{tabular}{|l|c|c|}
\hline \multicolumn{1}{|c|}{ Criterion } & British Columbia & Ontario \\
\hline Clearly defined scope & Achieved & Partially achieved \\
\hline Results-based regulatory framework & Achieved & Not achieved \\
\hline Accountability & Partially achieved & Not achieved \\
\hline Internalizing program costs & Achieved & Not achieved \\
\hline Effective monitoring \& enforcement & Partially achieved & Not achieved \\
\hline Open consultation process & Achieved & Achieved \\
\hline Promotion \& education indicator & Not achieved & Unable to evaluate \\
\hline Consumer awareness indicator & Achieved & Not achieved \\
\hline Accessibility indicator & Achieved & Achieved \\
\hline Product collection indicator & Achieved & Achieved \\
\hline Proper end-of-life management & Achieved & Achieved \\
\hline Reporting and auditing requirements & Achieved & Partially achieved \\
\hline
\end{tabular}

Overall, a comparative analysis was conducted in this chapter to compare and evaluate BC's MRP and Ontario's Orange Drop. After applying the evaluation framework, it was found that BC's approach is substantially more effective from a procedural perspective than Ontario's approach for managing post-consumer pharmaceuticals.

$\mathrm{BC}$ has generally achieved the intended policy goals - their program has provided a system for the public to return their unused drugs and it has been cost-effective since the producers pay. However, it is argued that the full concept of EPR has not been adopted since most of the liabilities for managing the program fall on the Health Products Stewardship Association. Having one agency represent the industry makes it difficult to hold individual producers responsible. The interviews revealed that the $\mathrm{BC}$ actors were generally satisfied with the MRP's performance but they acknowledged that there are improvements to be made regarding consumer awareness and establishing a level playing field. It was found that BC's program met 9 out of the 12 criteria for an optimal return program, further indicating that it is an 
effective program. It also helps explain why BC's MRP has been operational for over 14 years. However, there are improvements to be made with holding individual producers accountable; monitoring and enforcement; and promotion and education.

In contrast, Ontario's Orange Drop failed to meet the policy goals - the government attempted to make producers responsible for funding the program but instead the costs were placed on the government (and thus taxpayers). In addition, the management of pharmaceutical waste through the Orange Drop only achieved 4 of the criteria for an optimal return program, thus further indicating the flaws associated with the initiative.

The choice of policy instruments used to support these programs has played a significant role in their outcomes. $\mathrm{BC}$ regulated under the $E M A$, a pollution prevention policy tool, whereas Ontario regulated under the $W D A$, a process driven and market-based policy tool used to encourage waste diversion. The BC actors generally supported BC's results-based framework under the Recycling Regulation as it focuses on setting outcomes and performance measures for producers to meet. On the other hand, Ontario's process driven framework under the WDA has caused major problems. Rather than setting outcomes, the WDA focuses on prescribing the process for developing, implementing and managing diversion programs like the Orange Drop. The Act mandates collective agencies which make it challenging to hold producers responsible; it has unclear roles and responsibilities; and it has a lack of enforcement tools.

As a result, this analysis revealed that the problems and failures associated with the Orange Drop was a result of more than eco-fee issues, it was about the design of the policy tools under the WDA. The interviews with Ontario stakeholders further confirmed this finding. There was a consensus that Ontario should move forward to a results-based framework that holds producers (not IFOs) liable for the program. The question is: What positive and negative lessons can Ontario learn from BC's long-standing program? The following section sets out to address this objective.

\subsection{Step 3: Lesson Drawing \& Policy Convergence}

There are some positive and negative lessons that policy actors could draw from BC's Medications Return Program based on its achievement of the criteria for an optimal MRP. First, the positive lessons were identified. It is later determined in Section 5.4 whether these lessons have been applied in Ontario, and whether there is evidence of lesson-drawing taking place in practice. 


\section{Positive Lesson \#1: One size does not fit all.}

BC's MRP has made it clear that expired drugs are a unique type of waste. Since drugs cannot be recycled or reused there is really only one way to manage their end-of-life: incineration. This means that there needs to be different objectives, performance measures and targets for medications return programs. Pharmaceuticals should not be grouped with other materials that focus on meeting product recovery targets. As discussed earlier, it is challenging to interpret what a high or low collection rate means for MRPs. Low return rates may indicate that consumers are taking their drugs as directed, meaning that the low collection rates could still reflect good performance. Alternately, low return rates may mean that consumer awareness is low thus indicating poor program performance.

British Columbia has recognized that pharmaceuticals need to be handled on their own as the program focuses on managing one material category: pharmaceuticals. This has given HPSA the flexibility to establish targets (like consumer awareness, P\&E and accessibility) for measuring program performance that are applicable to this type of waste. This has allowed BC to more accurately measure their program's successes and weaknesses. Thus, Ontario should stop grouping pharmaceuticals with other hazardous materials (like fire extinguishers, paints and batteries) under one program, and instead manage them on their own.

\section{Positive Lesson \#2: It is about protecting the environment.}

BC's MRP is regulated under the province's principal statute for protecting the environment: the Environmental Management Act. The Act gives the MOE broad powers to prohibit waste from entering the environment. Regulating the MRP under this type of statute puts more focus on protecting the environment and less effort in establishing markets to manage the material. This makes sense considering that the pharmaceutical waste is destined for incineration - there is essentially no economic opportunity for end markets to recycle or reuse the material (especially when compared to materials like electronics or glass bottles). Thus, BC's MRP has framed the issue of PhACs as an environmental problem and has used the EMA as a pollution prevention tool to drive environmental protection activities. Ontario should regulate their program under a statute that primarily focuses on protecting the environment, such as the Environmental Protection Act, as opposed to a market-based economic tool like the WDA. 


\section{Positive Lesson \#3: Set outcomes.}

BC's program is regulated under a results-based framework. B.C. Reg. 449/2004 sets out the producers' requirements for each product category designated. Producers are required to submit a stewardship plan to the BC government for approval which outlines the producers' program objectives, performance measures and targets. By requiring producers to renew and resubmit their program plan every five years, this means that the government can measure whether there has been continuous improvement with performance. In BC, fewer efforts are placed on prescribing the process of developing and operating BC's MRP - achieving outcomes is more important. Hence, Ontario should utilize a results-based framework (instead of focusing on prescribing processes) for managing their medications return program.

Positive Lesson \#4: Clearly define stakeholder roles.

The stakeholders involved in BC's MRP do not seem to have any confusion regarding the roles of the parties involved. Government enforces and monitors the program; pharmaceutical producers fund the program and can appoint an agency (the HPSA) to meet their obligations; and the HPSA administers and operates the program. The duties of the producers are outlined in B.C. Reg. 449/2004. There is not a third-party agent that jointly designs, oversees or monitors the program. Thus, there is no overlap in the roles of the parties involved which makes it easier to hold parties accountable. Ontario should clearly define the duties of the parties involved in their medications return program in regulation, especially for the producers.

Positive Lesson \#5: Make producers internalize the costs.

BC's MRP is completely funded by the brand owners of health products (prescription drugs and natural health products). In 2010, the producer's annual fee to HPSA typically ranged from $\$ 200$ to $\$ 15,000$, and only eight companies paid more than $\$ 20,000$ (PCPSA, 2010). This is a nominal fee considering that the sales of patented drug products in Canada reached $\$ 12.9$ billion in 2010 (Patented Medicine Prices Review Board, 2011). As stated by Ginette Vanasse, Executive Director of the HPSA, "[T]he costs of medicines have not increased in British Columbia as a result of their medicine return program. Rather the relatively small costs are internalized and have become a part of doing business" (PCPSA, 2010). Thus, BC's MRP has shown that the program costs are relatively low and can be internalized by the producers without 
raising prices. As a result, Ontario should make the drug producers (instead of the taxpayers) pay for the medications return program, and they should require them to internalize the costs.

\section{Positive Lesson \#6: Require operational audits.}

The BC Ministry of Environment requires programs regulated under B.C. Reg. 449/2004 to have third-party verification of non-financial information in the annual reports on the following: location of collection facilities, description of how the product was managed, and total amount of product sold and collected (BC MOE, 2012). Effective July 2013, annual reports are required to have a "reasonable assurance" opinion by a qualified third-party using procedures from the Canadian Institute of Chartered Accountants Handbook on Assurance and Related Services and ISAE 3000 Standard on Assurance Engagements (BC MOE, 2012).

$\mathrm{BC}$ 's requirement to have an operational audit for the MRP, as opposed to a financial audit, makes sense. Since producers are required to fund the program, why would the government or the public even be concerned with management costs? When governments set environmental standards, such as emissions standards for factories, they do not ask the factories to report on how much the technology cost, they simply tell them to manage their emissions. An EPR program, like a medications return program, is no different. It is more appropriate to think of EPR as a management obligation - a cost of doing business. Thus, Ontario should require producers to submit operational audits, rather than financial audits, for their medications return program to verify the program's effectiveness.

The following are negative lessons that policy actors could draw from BC's Medications Return Program based on its failure to achieve some of the criteria for an optimal MRP. These lessons should be avoided in Ontario:

Negative Lesson \#1: Hold the producers accountable.

In $\mathrm{BC}$, the pharmaceutical producers are allowed to appoint an agency, the HPSA, to carry out their duties. Although it is not required to appoint an agency, what producer would not want to discharge their liability to another party? This transfer of liability to the HPSA is obviously very attractive for the drug producers. However, this is not consistent with extended producer responsibility. EPR is more than just producers footing the bill; it is about producers being solely and fully responsible for designing, operating as well as financing their program and being held liable for the program's environmental performance (EPR Canada, 2012a). When 
agencies, like the HPSA, take over with managing and overseeing the program, then there is little motivation for the producers to want to improve or enhance performance (i.e. promotion and education). Thus, Ontario should avoid allowing pharmaceutical producers to discharge their liabilities to agencies like IFOs.

Negative Lesson \#2: Avoid free riders.

BC's MRP has an enforcement process in place if producers do not comply with the HPSA (i.e. the producers do not pay their annual fee). However, it was revealed in the interviews that there are allegedly some free riders in the marketplace. It was stated that the government is aware of this but "they have not been very aggressive in going after them year after year." Even if there is a small group of free riders, it still indicates that the system is inequitable with some companies bearing the costs of others. This is not a fair competitive marketplace. Thus, Ontario should avoid free riders by ensuring that proper enforcement tools and sufficient resources are in place to establish a level playing field.

Negative Lesson \#3: Avoid poor promotion and education efforts.

BC's MRP provides P\&E materials like bookmarks and flyers for the pharmacies. The pharmacies can complete and fax a promo order form on the HPSA website to receive the materials for free (HPSA, n.d.). The question is: How likely is a pharmacist, who is busy providing safe health care to the public, going to go out of his/her way to fill out and fax a form? What is the incentive? Pharmacists advocate for consumers to take their medications as prescribed by their physicians. If pharmacists actively encourage consumers to return their unused medications, is this potentially encouraging bad behaviour?

Either way, based on this author's small sample size of visiting BC pharmacies, there is a lack of $\mathrm{P} \& \mathrm{E}$ for the program. This is surprising for a program that has been implemented for over a decade. Perhaps the government needs to require drug producers/the agency to partner with distributors and retailers to adopt P\&E strategies (RCO, 2012). As a result, Ontario should avoid poor promotion and education efforts, and instead, ensure that there are requirements for producers to invest in robust $\mathrm{P} \& \mathrm{E}$ strategies. If consumers are not educated about the program then consumer awareness will likely be low. 
All of these lessons could potentially be feasible in the Ontario context. However, in order for them to work, the government would likely need to move away from regulating under the process driven WDA, and instead regulate under a statute that focuses on setting outcomes for protecting the environment. Ontario's Environmental Protection Act seems to be a good fit, especially since it has similar attributes to BC's Environmental Management Act.

The Ontario government has recently adopted a new program for managing postconsumer pharmaceuticals. In the next section, this new Medications Return Program is investigated and compared with the previously implemented Orange Drop program, and in Section 5.4, it is determined if there has been evidence of inter-jurisdictional lesson-drawing.

\subsection{Step 4: Comparative Policy Analysis - Ontario's Orange Drop Program vs. Ontario's Medications Return Program}

On October 1, 2012, more than two years after the suspension of Ontario's Orange Drop, the MOE enacted O. Reg. 298/12 (Collection of Pharmaceuticals and Sharps - Responsibilities of Producers) under the Environmental Protection Act. This provides the regulatory framework for Ontario's new Medications Return Program. In this section, the new program was analyzed and compared with the previous Orange Drop to identify similarities and differences. The key questions asked were: What makes this new program similar or different from the Orange Drop? Has anything even really changed in Ontario? Since Ontario's MRP is still in its early implementation stage (it only launched on January 1, 2013), a comprehensive analysis and evaluation (as done in Step 2 of this study) was not conducted. Instead, this author analyzed the requirements in O. Reg. 298/12 and compared them with the Orange Drop.

The MOE chose to regulate drugs and sharps waste under the EPA. This is Ontario's central piece of legislation for protecting the environment. It gives the MOE broad powers to regulate and prohibit the discharge of contaminants into the environment if the discharge causes or may cause an adverse effect (EPA, s. 14). The EPA allows the MOE to issue environmental penalties, control orders and stop orders. The Act also regulates waste management activities. Section 27 of the EPA prohibits the operation of waste facilities and waste-related activities without an MOE environmental compliance approval.

Ontario's recent regulation, O. Reg. 298/12, defines “pharmaceuticals" as drugs within the meaning of section 2 of the Food and Drugs Act. This includes prescription and over the counter drugs and natural health products (e.g. vitamins and minerals). It defines "sharps" as 
needles, safety engineered needles, lancets or other instruments "designed to puncture the skin of individuals or companion animals for medical purposes" (O. Reg. 298/12, s. 1). It does not include materials generated from the industrial, commercial or institutional (IC\&I) sector such as hospitals, doctors' offices, dental offices and veterinary clinics.

This regulation focuses on extended producer responsibility as it sets out requirements, standards and outcomes for producers to meet. It requires drug and sharps producers to provide a way for the public to return their post-consumer drugs and sharps waste to designated sites for safe disposal. They must ensure that there is a collection site in $80 \%$ of the retail locations or accredited pharmacies in which their product is sold, and effective January 1, 2014 this increases to $90 \%$. They must have at least one collection site in each municipality where there is a retail location in which their product is sold. The producers are also required to collect the drug or sharp (with no quantity limit) for free from the consumers.

As seen in O. Reg. 298/12, the producers are required to ensure that any person collecting and managing the consumer's waste has an environmental compliance approval. They must also have an agreement in place with each collection site that addresses the types of containers used to store the waste, and procedures and training for handling and storage. The producers must also meet promotion and education requirements. They are required to make the following information available to the public: location of collection sites and description of how consumers should safely return the sharps or drugs. This must be available on the producer's website and in print at each collection site. The drug and sharps producers are not required to develop or submit a program plan; however, they are required to submit annual reports to the MOE.

As seen in O. Reg. 298/12, the annual report must outline the following: number of collection sites; total weight of pharmaceuticals or sharps collected; and a description of the effectiveness and outcomes achieved with meeting the regulatory requirements. The producers must also describe any actions that "exceeded the actions required for the purposes of section 7 , with respect to educational and public awareness activities in order to promote to consumers the collection locations and the availability of collection" (O. Reg. 298/12, s. 9). The report is also required to have a third-party audit from a licensed public accountant confirming the accuracy of the report. The report can be prepared on behalf of more than one producer of pharmaceuticals or sharps as long as each producer's name is identified. Thus, the majority of the producers have chosen a similar approach to BC and made an agreement with the Health Products Stewardship 
Association to administer a return program on behalf of them.

Since January 1, 2013 the HPSA has administered two programs in Ontario to meet the producers' requirements in O. Reg. 298/12: Ontario's Medications Return Program collects the public's unused/expired prescription and non-prescription drugs and natural health products, and the Ontario Sharps Collection Program collects the public's sharps. The drugs and cytotoxic sharps (used for chemotherapeutic application) collected are destroyed by incineration while the biomedical sharps are sterilized using a commercial autoclave (HPSA, 2013a; HPSA, 2013b).

As of March 31, 2013 there were 2,962 pharmacies participating in the programs (about $84 \%$ of all eligible pharmacies), indicating that they are above the $80 \%$ accessibility requirement (HPSA, 2013c). According to the HPSA (2013c), the programs collected 50,440 kg of sharps waste and 83,313 kg of medications from January to March of 2013.

The question is: What makes Ontario's new MRP similar or different from the previously implemented Orange Drop? There are only a few similarities. Both programs have offered a way for the public to return their unused/expired drugs and sharps, they both have used pharmacies as the main collection sites, and they have both required the producers to fund the program (although in the Orange Drop this did not last long).

On the other hand, there are several significant differences between the two. The first and most notable is that they have been legislated under different statutes that serve very distinct purposes. The Orange Drop was regulated under the Waste Diversion Act, a process driven and market-based policy tool, whereas the new MRP is regulated under the EPA, a pollution prevention tool. This has caused the actors involved in the program to change since the EPA does not make reference to Waste Diversion Ontario or an industry funding organization that were previously used in the WDA. Under Ontario's new MRP, the regulation only focuses on the proper collection of pharmaceuticals and sharps; they are not grouped with other hazardous waste materials like the Orange Drop was.

Another key difference is that Ontario's new framework under O. Reg. 298/12 is more results-based. Rather than prescribing the management approach (as seen with the WDA), this new regulation has set outcomes for individual producers to meet, such as accessibility targets and $P \& E$ requirements. There is no government involvement in how producers finance their programs or how the fees are set, the government simply sets the standards and outcomes and enforces compliance. The MOE does not even require a program plan. In contrast, in the 
Orange Drop, the government prescribed the process for managing the waste, and Stewardship Ontario set the outcomes and targets in their program plan.

One of the most important differences between the two programs relates to the issue of accountability. O. Reg. 298/12 makes the producers responsible through EPR, and they are required to offer the collection services for free. Even though the Ontario drug and sharps producers have chosen to work through the HPSA, the individual producers still remain liable for program performance (Valiante, 2012). While under the Orange Drop, Stewardship Ontario was held accountable for program delivery and the producers were not held liable for the failure of the program to meet its objectives (Valiante, 2012). This indicates that HPSA, a not-for-profit organization incorporated in the province of BC (HPSA, 2012c), is now taking over the role in Ontario that previously was carried out by the not-for-profit Stewardship Ontario. If HPSA were going to perform a similar, more comprehensive role in Ontario than they presently do, it is possible that incorporation in Ontario (under provincial laws for incorporation) may be required.

There is also a distinction regarding the enforcement tools available for the provincial government. Under the new program, the EPA allows the MOE to assign environmental responsibilities and it gives them broad powers to regulate and prohibit the discharge of contaminants into the environment. It also allows the MOE to issue environmental penalties, control orders and stop orders. By contrast, the government had limited powers under the WDA to enforce diversion programs like the Orange Drop (ON MOE, 2013a).

In addition, O. Reg. 298/12 requires the producers of pharmaceuticals and sharps to have a third-party audit from a licensed public accountant confirming the accuracy of the program's performance, whereas the Orange Drop only required independently audited financial statements. Thus, Ontario's new MRP is required to have third-party verification regarding its performance.

Overall, there are many important differences between Ontario's new Medications Return Program and the previously implemented Orange Drop. Many of the issues and challenges faced under the Waste Diversion Act have been addressed using the Environmental Protection Act. It seems that the management of post-consumer drugs and sharps has changed in Ontario; however, the new MRP is still in its early operational stages. Thus, it will have to be monitored over a longer time period to evaluate its effectiveness.

\subsubsection{Stakeholder Perceptions}

As described in Chapter 2, interviews were conducted with Ontario stakeholders to gain 
an understanding of how the actors' perceived the new Medications Return Program. Since the program recently launched, it is too early to measure how effective it is; however, the interviews helped gain insight regarding the MRP's strengths and weaknesses from the perspective of professional experts in the waste management field. The stakeholders were asked: What are your views regarding Ontario's new regulation for managing pharmaceutical and sharps waste?

There was widespread support from the stakeholders regarding the regulation. As stated by one interviewee, "When you look at what was brought forward with the [government's] WDA review, I think really, the EPA provides many of the attributes that they were looking for." The three common themes that emerged from the interviews were the following: holding producers accountable, setting outcomes, and enforcement.

All of the actors supported the government's approach for holding the individual producers of pharmaceuticals and sharps accountable. The stakeholders had been advocating for an extended producer responsibility model for the last few years. They were pleased that the regulation does not mandate producers to group together and work under one agency, like an IFO, and they supported making the producers ultimately responsible for program performance. As described by one interviewee, "Holding individual producers liable for their obligations is the right approach to take ... not a third party agent or these IFOs. It has to be the producers."

The stakeholders were also supportive of the regulation's outcomes-based framework. They agreed that it is better to focus on setting outcomes, standards and targets for producers to meet as opposed to stipulating the process of managing the waste. As stated by one individual, "The WDA has been criticized for being heavily about process and not about outcomes, so this reg. offers a chance to move away from that and start seeing results."

However, there was a concern regarding the lack of collection targets for the sharps producers. As argued by one interviewee, "I know government can't really set a collection target for drugs but for sharps it's one for one; all of [the sharps waste] is available for collection." It was mentioned that the government could easily calculate a sharps recovery target based on the units of sharps sold in the marketplace. According to the interviewee, if the government were to have set a collection target for sharps then this would likely motivate the producers to achieve higher collection rates and thus better performance, as opposed to accepting status quo. However, it is possible that the government did not include a collection target in O. Reg. 298/12 since Ontario was the first province in Canada to require sharps producers to fund an EPR 
program. Perhaps as the program progresses, and as there is more data available on return rates, the government may choose to set a collection target.

The actors had both positive and negative views regarding the enforcement of Ontario's new Medications Return Program. There was a general consensus that the EPA is a better enforcement tool for the MOE compared to the Waste Diversion Act. As stated by one interviewee, "The EPA gives enough flexibility that the government can assign responsibility and set requirements for measuring outcomes. It provides a very streamlined way to regulate the producers, especially compared to the WDA." Another interviewee had similar views, "What [we] like about the EPA is that it's a very flexible policy tool that can be adapted to any waste. The Ministry has the ability in that regulation to apply a penalty as it sees fit."

Although it was agreed that the EPA can be an effective policy tool for enforcement, there was a concern from all of the stakeholders regarding how the program will actually be enforced. As stated by one interviewee, "Most would agree that based on what's put forth in the regulation, it's the right approach to take. But there's still caution as to how it becomes a reality and the concern really is about government enforcement." Similarly, another Ontario interviewee stated, "The tool [the EPA] is great but it's only as good as the enforcement actually behind it, and that's where we usually are lacking."

This concern was not only raised by the interviewees in this study. The lack of government enforcement of waste regulations, particularly the " 3 Rs" Regulations ${ }^{18}$, has been widely criticized by other stakeholders as well. As stated by Kelleher Environmental (2007), "The 3Rs regulations were enforced for a very short period of time in the mid 1990s, but enforcement ceased over time because of a lack of MOE resources" (p. 13). Similarly, the Auditor General of Ontario (2010) stated:

The packaging audit and the packaging reduction work plan, among other things, are intended to provide information on the type and amount of packaging these companies use ... and plans to reduce the amount of packaging. We noted that the Ministry has never enforced this regulation since its implementation in 1994, except for having performed one inspection in May 2007. (p. 226-227)

\footnotetext{
${ }^{18}$ Ontario regulations O. Reg. 101/94, O. Reg. 102/94, O. Reg. 103/04, and O. Reg. 104/94 under the EPA are known as the "3Rs" regulations which outline recycling requirements for municipalities and industry (e.g. waste reduction work plans and source separation programs).
} 
Thus, since Ontario has not rigorously enforced other waste regulations under the $E P A$, there is the potential for a similar situation to take place with the Medications Return Program.

Overall, the interviews revealed that the stakeholders support the use of O. Reg. 298/12 enacted under the Environmental Protection Act for regulating pharmaceuticals and sharps. On paper, the regulation holds individual producers accountable through EPR, it sets outcomes for producers to achieve, and it gives the MOE greater ability to enforce the program (especially compared to the Waste Diversion Act). However, the actors are concerned that government enforcement may become an issue and ultimately hamper the effectiveness of the program.

\subsection{Step 5: Lesson-Drawing \& Policy Convergence}

Now that Ontario's Medications Return Program has been analyzed, and the opinions from experts in the waste management field have been reviewed, it is critical to ask the question: What are the positive and negative indicators in this program? Since Ontario has experienced setbacks and implementation gaps in the past with the Orange Drop Program, it was important to look to the lessons learned from Canada's mature program in British Columbia to identify whether or not the policy actors have applied them in Ontario's revised MRP. Thus, this section analyzed whether the positive and negative lessons drawn in step 3 of this study (Section 5.2) have been applied or avoided in Ontario's revised program, and whether there is evidence of lesson-drawing taking place by the policy actors.

As seen in Table 16, Ontario's MRP has all of the positive indicators present from BC's MRP. Ontario has recognized that unused/expired pharmaceuticals are a unique type of waste and should be managed on their own. In the past, Ontario grouped drugs and sharps with other materials like paints and batteries. However, they have learned that pharmaceuticals require distinct targets to accurately measure program performance (like consumer awareness and $\mathrm{P} \& \mathrm{E}$ ) and need to be managed separately. Ontario has also shifted from regulating the program under a market-based, economic tool (the Waste Diversion Act) to the Environmental Protection Act: Ontario's central piece of legislation for protecting the environment. Another positive indicator present is that O. Reg. 298/12 provides a results-based framework (like BC's Recycling Regulation) that allows government to set outcomes for the pharmaceutical producers to achieve. 
The roles of the parties involved in the program are also clearly defined. The title of the regulation alone ("Collection of Pharmaceuticals and Sharps - Responsibilities of Producers") emphasizes that the producers are held responsible. The government sets out the standards and requirements for the producers to meet through the regulation and then the producers are given the flexibility to meet them. The producers are not mandated to jointly develop a program with a third-party agent or an arms-length oversight organization. This was previously required under the WDA which resulted in overlapping roles and responsibilities in the Orange Drop Program.

Another positive indicator present is that Ontario's MRP requires drug producers to provide the collection service to the public for free like in BC. Thus, taxpayer dollars are not being used to finance the program (as was done for two years under the Orange Drop). In addition, the Ontario government requires the drug producers to have third-party audits on the annual reports to verify the program's performance. In the past under the Orange Drop, the government only required an audited financial statement.

All of the positive lessons learned from BC's MRP have been applied but are the negative lessons present in Ontario? As seen in Table 17, negative indicator \#1 has been avoided. Ontario's MRP does not hold agencies accountable; it holds the individual producers accountable. Even though HPSA is facilitating the program, the producers remain the liable party (Valiante, 2012).

On the other hand, negative indicators \#2 and \#3 have only been partially avoided. Based on BC's experience, it was learned that Ontario should avoid free riders by ensuring that proper enforcement tools and sufficient resources are in place to establish a level playing field.

Although the EPA gives the Ontario MOE broad powers to enforce compliance, there have been issues in the past with government not rigorously enforcing waste-related regulations under the $E P A$, as discussed in Section 5.3.1. The interviewees further expressed this concern. It is too early to ascertain whether there is sufficient government enforcement to establish a level playing field; however, the lack of enforcement in the past has made stakeholders cautious. Thus, at this time, Ontario’s MRP has only partially avoided negative indicator \#2. 
Table 16. Positive Indicators Present in Ontario’s new Medications Return Program

\begin{tabular}{|l|l|c|}
\hline \multicolumn{1}{|c|}{ Positive Indicator } & \multicolumn{1}{|c|}{ Recommendation } & Present? \\
\hline $\begin{array}{l}\text { \#1. One size does not fit } \\
\text { all. }\end{array}$ & $\begin{array}{l}\text { Ontario should stop grouping pharmaceuticals with other } \\
\text { hazardous materials (like fire extinguishers, paints and } \\
\text { batteries) under one program, and instead manage them on } \\
\text { their own. }\end{array}$ & Yes \\
\hline $\begin{array}{l}\text { \#2. It is about protecting } \\
\text { the environment. }\end{array}$ & $\begin{array}{l}\text { Ontario should regulate their program under a statute that } \\
\text { primarily focuses on protecting the environment, such as the } \\
\text { Environmental Protection Act, as opposed to a market-based } \\
\text { economic tool like the WDA. }\end{array}$ & Yes \\
\hline \#3. Set outcomes. & $\begin{array}{l}\text { Ontario should utilize a results-based framework (instead of } \\
\text { focusing on prescribing processes) for managing their MRP. }\end{array}$ & Yes \\
\hline $\begin{array}{l}\text { \#4. Clearly define } \\
\text { stakeholder roles. }\end{array}$ & $\begin{array}{l}\text { Ontario should clearly define the duties of the parties } \\
\text { involved in their medications return program in regulation, } \\
\text { especially for the producers. }\end{array}$ & Yes \\
\hline $\begin{array}{l}\text { \#5. Make producers } \\
\text { internalize the costs. }\end{array}$ & $\begin{array}{l}\text { Ontario should make the drug producers (instead of the } \\
\text { taxpayers) pay for the MRP, and they should require them to } \\
\text { internalize the costs. }\end{array}$ & Yes \\
\hline $\begin{array}{l}\text { \#6. Require operational } \\
\text { audits. }\end{array}$ & $\begin{array}{l}\text { Ontario should require producers to submit operational } \\
\text { audits, rather than financial audits, for their MRP to verify } \\
\text { the program's effectiveness. }\end{array}$ & Yes \\
\hline
\end{tabular}

Table 17. Negative Indicators Avoided in Ontario’s new Medications Return Program

\begin{tabular}{|l|l|c|}
\hline \multicolumn{1}{|c|}{ Negative Indicator } & \multicolumn{1}{|c|}{ Recommendation } & Avoided? \\
\hline $\begin{array}{l}\text { \#1: Hold the producers } \\
\text { accountable. }\end{array}$ & $\begin{array}{l}\text { Ontario should avoid allowing pharmaceutical producers to } \\
\text { discharge their liabilities to agencies like IFOs. }\end{array}$ & Yes \\
\hline \#2: Avoid free riders. & $\begin{array}{l}\text { Ontario should avoid free riders by ensuring that proper } \\
\text { enforcement tools and sufficient resources are in place to } \\
\text { establish a level playing field. }\end{array}$ & Partially \\
\hline $\begin{array}{l}\text { \#3. Avoid poor } \\
\text { promotion and } \\
\text { education efforts. }\end{array}$ & $\begin{array}{l}\text { Ontario should avoid poor P\&E efforts by ensuring that there } \\
\text { are requirements for producers to invest in robust P\&E } \\
\text { strategies. }\end{array}$ & Partially \\
\hline
\end{tabular}

As learned from British Columbia, Ontario must ensure that there are requirements for producers to invest in robust $\mathrm{P} \& \mathrm{E}$ strategies. Promotion and education is arguably the most significant performance measure for this type of program. If people are not educated or even aware of the program then the initiative has little impact in reducing PhACs in the environment.

O. Reg. 298/12 has some P\&E requirements which include producers providing the following information to the public: location of collection sites and a description of how consumers should safely return the sharps or drugs. This information is to be made available on 
the producer's website and in print at each collection site. However, similar to BC's program, the Ontario pharmacies are required to complete and fax a promo order form on the HPSA website to receive P\&E materials about the program (HPSA, n.d.). As discussed earlier, what are the chances of a pharmacist going out of his/her way to do this? Since P\&E is such a critical component of this program, it seems necessary to mandate additional efforts.

For example, the Recycling Council of Ontario (2012) recommended that the MOE add a provision in the regulation "that requires producers to partner with their distributors and retailers to provide point of sale information to consumers. This can be done effectively when and where pharmaceuticals and/or sharps are dispensed and given over the counter to consumers" (p. 4). It would also be effective to have $\mathrm{P} \& \mathrm{E}$ about the program on the package provided by the pharmacist that contains the drugs (RCO, 2012).

The European Medicines Agency recommends that all packaging of medicinal products include this statement: "Medicines should not be disposed of via wastewater or household waste. Ask your pharmacist how to dispose of medicines no longer required. These measures will help to protect the environment" (EMA, 2006 p. 10). Since Ontario's MRP recently launched, it is too early to ascertain whether there is sufficient $P \& E$ about the program. However, based on BC's experience, if there is not a stringent requirement in the regulation for producers to promote the program then it is likely that P\&E will remain low. Hence, Ontario has only partially avoided this negative indicator.

Overall, it has been determined that Ontario's revised MRP has applied all six of the positive indicators learned from British Columbia's program, and that there are similarities between the two programs. As discussed earlier in Section 2.6, interview data was also obtained and analyzed to determine if there was evidence of inter-jurisdictional lesson-drawing taking place between BC and Ontario, or if the similarities exist due to policy convergence. The question asked to the Ontario actors was:

- Are you aware if the Ontario provincial government examined Medications Return Programs in other jurisdictions, or consulted with other jurisdictions, before or during the development of O. Reg. 298/12? 
As stated by an interviewee from the Ontario provincial government:

We talked to BC quite a bit and we also talked to Manitoba. ... We did say [during consultations] that a voluntary approach is still an option, and certainly one worth discussing but the reaction we got back from the industry was 'we want a regulated approach because we want to make sure that there's a level playing field and that everyone has to participate.'

Another interviewee indicated that Ontario policy actors communicated with the BC government to gain insight regarding the establishment of key performance measures, including promotion and education requirements and accessibility targets (pharmacy participation rates). As articulated by one of the Ontario interviewees, "We built in promotion and education requirements because we talked to $\mathrm{BC}$, and we recognized that that's a big component of this type of program."

For setting the accessibility target, the interviewee further stated:

We also looked at what's been achieved in BC, and in BC they have a 95\% participation rate with pharmacies, so $80 \%$ is where we thought we could start ... . BC's a very mature program in the sense that it's been around for a while.

Overall, there is some evidence in the interview data that policymakers in Ontario reached out to the British Columbia and Manitoba governments prior to adopting the revised MRP, and specifically looked to BC's program as a benchmark to help set program performance measures. The Ontario government seemed to consider the option of adopting a voluntary initiative; however, the pharmaceutical industry preferred a regulatory approach to promote a level playing field in the market.

There seems to be an indication that officials in Ontario actually looked to BC to learn from the experiences in that province with managing post-consumer pharmaceuticals; however, the degree to which lesson-drawing actually took place was not revealed in the interviews. As a result, the similarities between the programs may also be due to convergence taking place.

\subsection{Potential Inclusion of a Sharps Program}

Many individuals use sharps (i.e. needles, lancets and syringes) to manage health conditions, such as diabetes, allergies, HIV, and cancer (U.S. FDA, 2013b). In Canada, there are more than 9 million people living with diabetes or prediabetes with more than 20 individuals diagnosed every hour (Canadian Diabetes Association, 2012). Sharps differ from drugs as they 
are not a consumable product. This means that $100 \%$ of the sharps purchased are potentially available for collection after use (SO, 2009a). It is estimated that there are 294,023,963 units of sharps (about 362 tonnes) in the Ontario market, indicating that there is potentially 362 tonnes available for collection (SO, 2009a).

The British Columbia government has not designated sharps as a product requiring a waste diversion program under B.C. Reg. 449/2004, and thus, BC's MRP does not accept sharps. In contrast, Ontario has regulated sharps (needles, lancets and syringes) under O. Reg. 298/12, and safely manages this waste through Ontario's Sharps Collection Program. Table 18 outlines the advantages and disadvantages of regulating sharps under an EPR framework.

Adopting an EPR program for sharps may help motivate the public to return their sharps to pharmacies/designated sites if there is a free and familiar system to dispose of this waste, which may reduce the potential harms (i.e. injuries or infections) associated with improper disposal. Bureaucratic and administrative efficiencies can be expected with combining the waste management of sharps with drugs since they are typically dispensed in the same places (i.e. pharmacies) and could be bundled together for ease of management. Regulated EPR programs can help establish a level playing field in the market by requiring all producers to participate, and can allow governments to set stringent performance measures.

It may be challenging for some governments to regulate sharps under environmental protection legislation since there are not substantial environmental protection benefits to be gained from regulating sharps; instead, there are public health and social benefits that could ensue. Perhaps this is why British Columbia has avoided including sharps in its Medications Return Program. A disadvantage from the perspective of the sharps producers is that a regulated EPR program would require company funding and resources to comply with the regulatory requirements.

The BC government, as well as other provincial governments in Canada, should recognize sharps waste as a priority material and regulate them under an EPR framework to ensure that the public has a free, familiar and convenient service to dispose of this waste safely. Sharps are classified as a biohazard and can be a source of disease transmission if not properly managed (ON MOE, 2009b; WHO, n.d.). Also, in order to be consistent with the Canada-wide Action Plan developed by the CCME, sharps need to have an EPR regulatory framework by 2015, as discussed in Section 3.5.4 (CCME, 2009). 
Table 18. Advantages and Disadvantages of Regulating Sharps under an EPR Framework

\begin{tabular}{|l|l|}
\hline \multicolumn{1}{|c|}{ Advantages } & \multicolumn{1}{c|}{ Disadvantages } \\
\hline $\begin{array}{l}\text { May provide the public with a free, familiar } \\
\text { \& convenient way to dispose of sharps waste. }\end{array}$ & $\begin{array}{l}\text { May be challenging to regulate sharps under } \\
\text { environmental protection legislation - There } \\
\text { are not significant ecological or environmental } \\
\text { protection benefits to be gained from regulating } \\
\text { sharps; instead, there are public health and } \\
\text { social benefits that could ensue. }\end{array}$ \\
$\begin{array}{l}\text { May encourage the public to return their } \\
\text { sharps to pharmacies/collection sites vs. } \\
\text { disposing in the garbage which can place } \\
\text { others, including family members and waste } \\
\text { management workers, at risk of injury and } \\
\text { severe infections (U.S. FDA, 2013b). }\end{array}$ & $\begin{array}{l}\text { Requires monitoring and enforcement costs } \\
\text { from governments. }\end{array}$ \\
$\begin{array}{l}\text { Bureaucratic and administrative efficiencies } \\
\text { can be expected with combining the waste } \\
\text { management of sharps with pharmaceuticals } \\
\text { since they are typically dispensed in the same } \\
\text { places (i.e. pharmacies) and could be bundled } \\
\text { together for ease of management. }\end{array}$ & $\begin{array}{l}\text { Can be challenging to monitor hundreds of } \\
\text { producers and hold individual companies } \\
\text { accountable. }\end{array}$ \\
$\begin{array}{l}\text { Regulated programs can promote fair } \\
\text { competition in the market by requiring all } \\
\text { sharps producers to participate. }\end{array}$ & $\begin{array}{l}\text { Regulations can be rigid and may not } \\
\text { encourage innovation or creativity from the } \\
\text { sharps industry. }\end{array}$ \\
$\begin{array}{l}\text { Governments can set stringent standards and } \\
\text { performance measures. }\end{array}$ & $\begin{array}{l}\text { Requires funding and resources from sharps } \\
\text { producers. }\end{array}$ \\
$\begin{array}{l}\text { Since sharps are not a consumable product, it } \\
\text { is easier (compared to unused/expired drugs) } \\
\text { to set a collection target. }\end{array}$ &
\end{tabular}

\subsection{Summary of Lesson-Drawing \& Policy Convergence}

Overall, positive and negative lessons were drawn from BC's mature program based on its achievement of the criteria for an optimal MRP. It was determined that Ontario's revised MRP has applied all six of the positive indicators from BC's MRP indicating that it may have the potential to achieve similar successes. However, there are some concerns regarding the promotion and education requirements and whether there is sufficient government enforcement to ensure that producers are meeting their obligations. 
Based on the interview data, there seems to be an indication that Ontario policy actors looked to British Columbia to learn from its experiences with managing post-consumer pharmaceuticals; however, the extent to which lesson-drawing actually took place in practice was not revealed in the interviews. Thus, this study could not fully ascertain if interjurisdictional lesson-drawing occurred. As a result, the Ontario and $\mathrm{BC}$ programs may resemble each other due to policy convergence taking place. 


\section{Chapter 6: Conclusion}

Overall, the issue of PhACs in the environment has created a dilemma. Drugs are designed to exert a biological effect in humans; however, excretion and uncontrolled disposal are in turn causing potential risks to the environment. Since it is unreasonable to force individuals to stop taking drugs required for optimal health, jurisdictions are forced to develop strategies that will help reduce their presence in the environment as opposed to eliminating consumption.

Regulating the human use of drugs to limit their potential environmental impacts is politically difficult. Applying a tax or using another economic instrument is typically not an attractive policy option since many people are in critical need of drugs to avoid life-threatening health risks. Government investment in STP infrastructure to enhance performance would help mitigate this problem at the source; however, this is perceived to be unachievable economically. At some point, this may become the most practical measure if the health and ecological consequences associated with PhACs are confirmed.

Currently, the approach most favoured by governments is the adoption of medications return programs. They seem to be the most politically acceptable given the current perceived levels of harm caused by PhACs. They are also relatively inexpensive due to the small volumes recovered, particularly when under the conditions of extended producer responsibility. British Columbia and Ontario adopted regulatory MRPs based on EPR. BC's MRP has remained operational for over 14 years whereas Ontario's Orange Drop failed within weeks of implementation. A comparative analysis was conducted to compare and evaluate these cases.

It was found that BC's MRP is an effective program. It has generally achieved the intended policy goals although it is argued that the full concept of EPR has not been adopted since most of the liabilities fall on the Health Products Stewardship Association. BC's MRP met 9 out of the 12 criteria for an optimal return program, further indicating its effectiveness and why it has remained operational for over a decade. However, there are improvements to be made with holding individual producers accountable; monitoring and enforcement; and promotion and education. On the other hand, Ontario's Orange Drop failed to meet the intended policy goals as the costs were placed on the government (and hence taxpayers), as opposed to the producers. In addition, the program only achieved about a third of the criteria for an optimal return program, thus further emphasizing the flaws associated with the initiative. 
It is argued that the policy tools used to support these programs has played a significant role in their outcomes. BC regulated under the Environmental Management Act, a pollution prevention tool, whereas Ontario regulated under the Waste Diversion Act, a process driven policy tool that makes it difficult to hold producers responsible; has unclear roles; and has a lack of enforcement options. The problems associated with the Orange Drop Program were rooted in underlying design flaws in the program and institutions.

After two years of taxpayers financing the failed Orange Drop collection scheme, Ontario launched a new MRP under the Environmental Protection Act. This program is significantly different than the Orange Drop as it embraces the true concept of EPR. It was found that Ontario's revised MRP incorporates all of the positive indicators learned from BC's program indicating that it may have the potential to achieve similar successes. However, there are some concerns regarding the promotion and education requirements and whether there is sufficient government enforcement to ensure that producers are meeting their obligations. Thus, Ontario's second attempt with making pharmaceutical producers responsible for managing post-consumer drugs seems to be on a positive path.

The interview data revealed that Ontario policy actors seemed to examine and look to BC's MRP to learn from BC's experiences with managing post-consumer pharmaceuticals; however, this study could not fully ascertain if lesson-drawing occurred in practice. Thus, the similarities in the programs may simply be a result of policy convergence.

This thesis revealed that drugs are a unique type of waste. One of the greatest difficulties faced with managing this waste is the embedded unknowns. What are the risks of pharmaceutical cocktails interacting in the environment? How much medication will go unused/expired? How much will people actually return? What is the contribution of PhACs from excretion versus the contribution of waste from human disposal? These are extremely challenging to predict which makes it even harder to adopt management schemes. The magnitude of the problem remains unknown.

Even though there are economic, environmental, and public health or other social benefits associated with extended producer responsibility, its greatest weakness is that even if it is regulated by government it is a version of voluntary compliance. The producer's responsibility only begins when the product is voluntarily returned by consumers. Thus, the consumer's voluntary cooperation is essential. The toughest challenge for governments is convincing the 
public to return their unused/expired drugs. Unless individuals are convinced about the potential environmental concerns, there does not seem to be a real incentive to return post-consumer drugs, especially when compared to other initiatives like deposit return systems. In addition, EPR systems usually involve third-party agencies/stewardship associations which ultimately reduce individual producer accountability.

Although there are challenges with managing this waste, policymakers continue to adopt strategies to alleviate the problem. Thus, it is critical to conduct studies now that evaluate management approaches to reduce $\mathrm{PhACs}$, rather than waiting for the science to evolve. 


\section{Chapter 7: Policy Recommendations and Directions for Future Research}

The following policy recommendations were made in relation to specific stakeholder groups:

\section{Municipal Governments - Ontario:}

- It is recommended that the municipalities of Ontario pass by-laws that ban pharmaceuticals from residential garbage.

\section{Provincial Governments - British Columbia and Ontario:}

- Since consumer awareness is such an important performance measure for medications return programs, it seems necessary to mandate additional promotion and education efforts from the drug producers. It is recommended that the governments require producers to partner with distributors and retailers to adopt P\&E strategies (RCO, 2012). It would also be effective to have $\mathrm{P} \& \mathrm{E}$ about the program on the package provided by the pharmacist that contains the drugs (RCO, 2012).

- The governments should launch awareness campaigns to help increase consumer awareness about the medications return programs and the potential risks of improper drug disposal. It is important for the provincial governments to ensure that the public is educated about the potential harms of improper drug disposal and what options they have for disposing of unused/expired drugs. This may drive program participation.

- It is also crucial to drive stakeholder knowledge and awareness, especially for those directly involved in the programs e.g. the pharmacies that voluntarily serve as collection sites and physicians that prescribe drugs for the public. It is recommended that the governments reach out to the parties involved in the respective programs or perhaps the industry associations (like the College of Pharmacists) to provide promotion and education.

- It is recommended that the governments ensure that the drug producers and/or Health Products Stewardship Association are measuring the percentage of the population aware of the program and have actually participated, and how this awareness changes over time. This can be done through public surveys. The producers should be required to report on continuous improvement with both consumer awareness and promotion and education. 
- It is recommended that the governments ensure that sufficient resources are in place to properly monitor and enforce the program. There needs to be frequent monitoring and evaluating to enhance program performance.

- The governments should ban pharmaceuticals from disposal. In Ontario, this recommendation is consistent with actions discussed in the province's new "Waste Reduction Strategy" in which the Ontario MOE stated that "banning designated wastes from disposal would drive greater participation in diversion programs and help producers meet their producer responsibility requirements" (ON MOE, 2013a).

- Ontario's MRP and British Columbia's MRP do not accept materials generated in the IC\&I sector like doctors' offices and hospitals. To help divert PhACs from the environment, it may be helpful to have programs in place that accept waste generated from these sources.

- It is recommended that the governments collaborate with funeral home directors to educate the public that when clearing out a medicine cabinet after a death, any unused/expired drugs should be returned to pharmacies.

Provincial Government - British Columbia Only:

- British Columbia should consider more effective enforcement measures in order to address the problem of free riding in the market.

- It is recommended that the government of British Columbia follow the lead of the Ontario government, and implement an extended producer responsibility program for sharps. This is consistent with the CCME's Canada-wide Action Plan for Extended Producer Responsibility (CCME, 2009).

- It is also recommended that the $\mathrm{BC}$ government consider utilizing additional measures to motivate the pharmaceutical companies and pharmacies to more effectively promote and advertise the MRP to the public.

Provincial Government - All Provinces:

- Ontario, British Columbia and Manitoba all have provincially regulated medications return programs based on extended producer responsibility. As more Canadian jurisdictions continue to adopt this approach, it is important to have harmonization across the country. This would make it easier for the drug producers to participate and comply as they are 
required to follow the laws in each jurisdiction. All three of the MRPs in Canada are administered by the Health Products Stewardship Association so there is an opportunity to provide streamlined management frameworks across the country. It is recommended that other Canadian jurisdictions harmonize their programs with Ontario, BC and Manitoba.

\section{Federal Government:}

- It is recommended that the Federal government launch awareness campaigns regarding the harms associated with prescription drug misuse and promoting how the public can safely dispose of their unused/expired drugs.

- It is recommended that the federal government take the initiative to develop national guidelines and/or voluntary standards for adopting province-wide medications return programs, and to pursue negotiations with the provinces to bring about further harmonization across the country.

\section{All Levels of Government:}

- All three levels of government in Canada, perhaps with the involvement of the CCME, should consider updating the current STP and/or drinking water infrastructure to properly remove PhACs present in water sources.

\section{Private Sector-Corporate Social Responsibility:}

- It is recommended that the producers of drugs and sharps promote a greater sense of CSR by developing corporate strategies that prompt companies to actively promote and publicize the medications return programs, and that also help establish a level playing field in the market.

- It is also recommended that pharmacies be encouraged to undertake greater efforts to obtain, display and disseminate promotional materials provided by the pharmaceutical producers.

\section{Civil Society - Environmental Non-Governmental Organizations:}

- It is recommended that ENGOs consider the development and dissemination of public awareness campaigns on the environmental implications of disposal options for unused/expired medications and sharps. 
- Over time, the ENGOs should examine province-wide medications return programs taking place across Canada and evaluate their effectiveness in reducing PhACs in the environment.

Directions for future research were also identified:

- Ontario's requirements set out in O. Reg. 298/12 for the collection of pharmaceuticals and sharps may seem effective in theory; however, how it translates into a fully operational program is too early to ascertain. Over the next few years, it is crucial for studies to evaluate the following regarding Ontario's new Medications Return Program:

- Are the pharmacy participation targets being achieved?

○ Is the program achieving its objectives and performance outcomes?

○ Is there a sufficient amount of promotion and education about the program, and have there been efforts to drive consumer awareness?

- Is there sufficient oversight and enforcement?

- Is the pharmaceutical industry complying with their obligations?

- Are the environmental standards for end-of-life management under the EPA being maintained by the waste management companies?

- There is also a need to collect data from several jurisdictions that identifies the following about medications return programs: customer participation rates, reasons for customers accumulating expired drugs, reasons for returning unused drugs, the demographics of individuals returning drugs, the most common drugs returned, etc. This information would help identify trends and address the proper $P \& E$ strategies required to enhance performance.

- This research analyzed two cases with regulatory programs for managing post-consumer drugs. Further research can be done to compare and evaluate voluntary models (e.g. Alberta's program) for managing this waste.

- Medications return programs have limitations as they only collect and safely dispose of waste that has not been metabolized. Human excretion has been identified as the main route of entry of drugs into the environment. Thus, further work is required to develop STP technologies that can effectively remove drugs from wastewater effluent. Specifically, there is a need to investigate the effectiveness of treatment technologies in reducing pharmaceutical parent compounds, their metabolites, and their degradation products. 
- More studies are needed to investigate the potential environmental and human health risks posed by PhACs in the environment. Further work would be warranted to understand the impacts of complex mixtures of drugs in STP effluent, as opposed to testing individual drug compounds in the lab setting. Currently, scientists cannot quantify the biological effects in fish posed by these mixtures of drugs ("pharmaceutical cocktails") in wastewater effluent (Environment Canada, 2012a). This would provide policymakers with the scientific knowledge to set wastewater treatment standards and drinking water standards.

- There are more scientific studies needed that measure the occurrence of pharmaceuticals in untreated and finished drinking water to monitor their concentration and frequency, and to detect trends. 


\section{Appendices}

Appendix A. Rexall's Poster and Brochure for Promoting Safe Drug Disposal

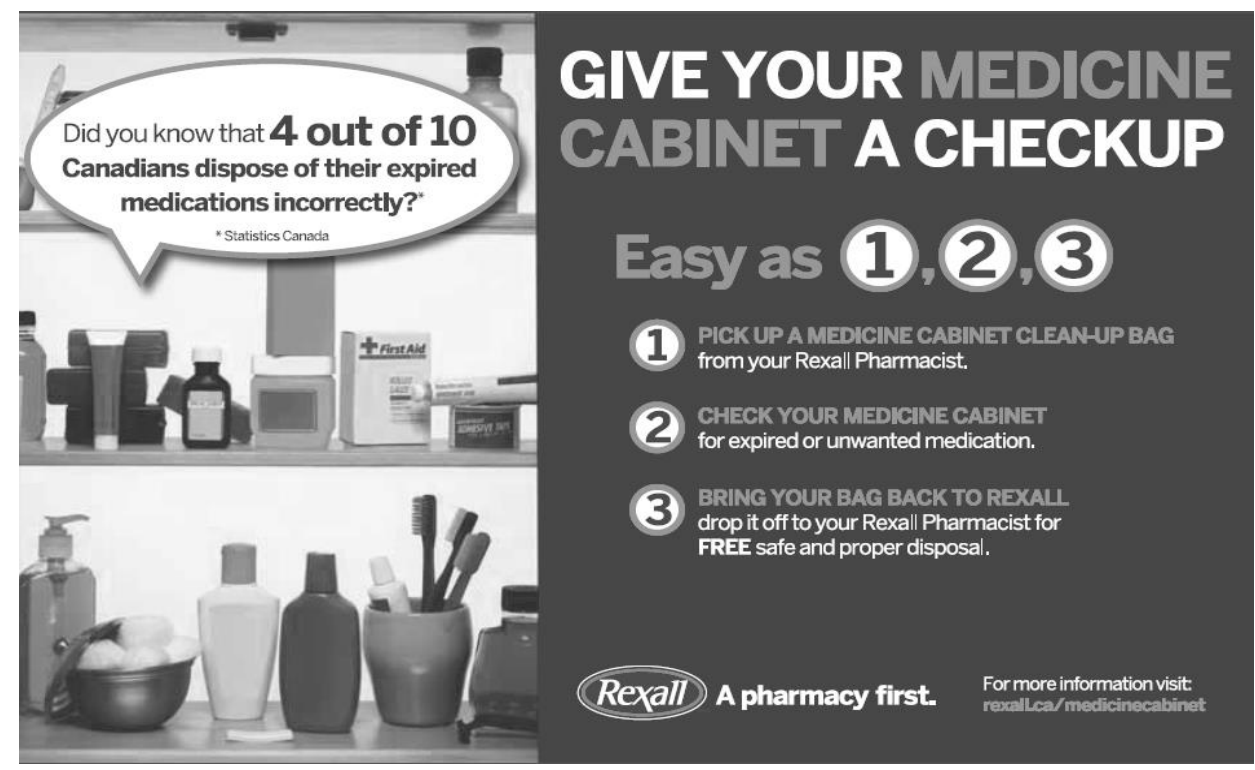

Poster

Medicine Chest 101

In a busy household, especially with

children, it's very important to look

through your medicine cabinet to decide

What stays and what goes - and to keep all

the contents up to date and stored safely.

It's a great idea to include your medicine

cabinet review in your spring cleaning

every year. Here are some simple steps to

ensure that you have safe and effective

products in your medicine cabinet.

Essential Medicine

Cabinet Checkup

Step 1 Check For Expired Medication

When boching througb your meticine cabinet, chech for cid or

expired medications - they are not helphil to your family in a time of neet and, in some cases, may be harmtul The expiraton cate on a manuatcture's pascige is bassd on the stability of the drug in its crignal unopened container. The expiration date for new druzs is. usually two to three years from the date of manutacture. $A$ good nik of thumb: when in doubt, throw in tout. (Read $\mathrm{cn}$ and weI tell you how to preperiy dispose of enpired inedication.

- Once the original container has been coened for use, the

expration date on the container may no longer apply. Please check with your Rexall fanily pharriacist far the 'begond use' date.

- Storage in areas with bigh humielity (e.g. the bathrocm) misy

interfere with the stability of various medications

- Some eapired medications may becone ineffective or taic.
Step 2 Dispose Of Medications Safely

It you find that you have old or expired medication, it is safter to get rid of it and purchase new products.

With a fresht supply, you can rest assured your family will be safe Disposing of old medicatian properly is very important.

- Do not fush medicine domn the toilet or throw it the trash. Doing so is harmbul to the environment. Medications can pollute

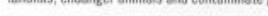
- Take all old medications to your Rexall pharmacy for safe disposal

Step 3 Medicine Cabinet Checklist Restocking your medicine cabinet and first aid kits is easy with buying these trusted Rexall products:

\section{Top 5 Items For Your Medicine Cabinet}

Assorted Bandages

A Rexall Allergy Relief

(Rexall Acetaminephen or ibuproten)

] Rexall Mation Sciness

a Rexall Antidiarthea!

With a ferall Medicine Spoon or oral syinge (to measere accurately?

\section{First Aid Supplies}

ב Rexall Elastic Bandages

ב Rexall Gaure and Surgical Tape

- Rexall Antibiotic Ointment for sprains and strains)

a Rexall Calamine Lotion

ב Rexall Rubbing Alcohol or Alcohol Swabs

G Rexall Hydrogen Peroxide

- Reerall Hot/Cold Compress

口 Rexall Scissors and Twezers

G Recall Flexitle Thermoneter ( $(\mathrm{C}$ - $\mathrm{F}$ )

a Rexall Hydrooxatisone Crean(for minox imitations and itching)

a Arnica Creant

$\square$ E)e Wash

Don't torget your ounce of prevention -

Reral Sunscteen (SPF 15 or higher) as well as insect Repellent!
Step 4 Store Medication Safely

After you have purchased all the items you need to complete and saiely to ensure that the product stars effective.

- Keep all medication out of reach of children and pets

- Stoce all medication in a cool place, away trom light. heat and humidity. Try a top shelf of your linen cleset.

- Refrigerate medication only if labelled to do so. Unnecessary refrigeration may change the stability and consistency of the medication

- Keep medization in its original labelled container, 95 that you know ahat's in the bottle, the exoir date and how to use 1 .

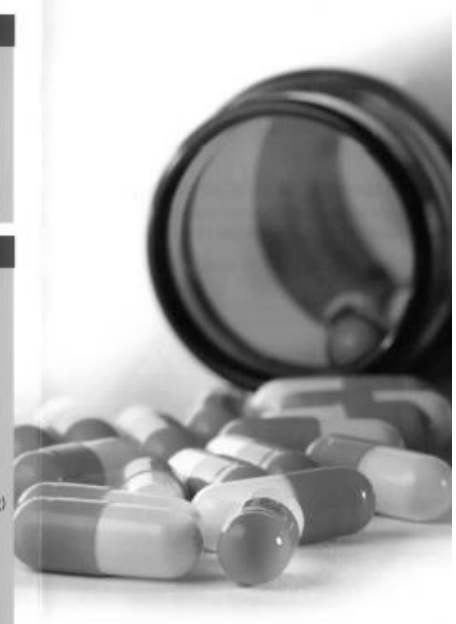

"Medicine Cabinet Cleanup" Brochure 
Appendix B. Brochure at View Street Pharmacy about BC's Medications Return Program

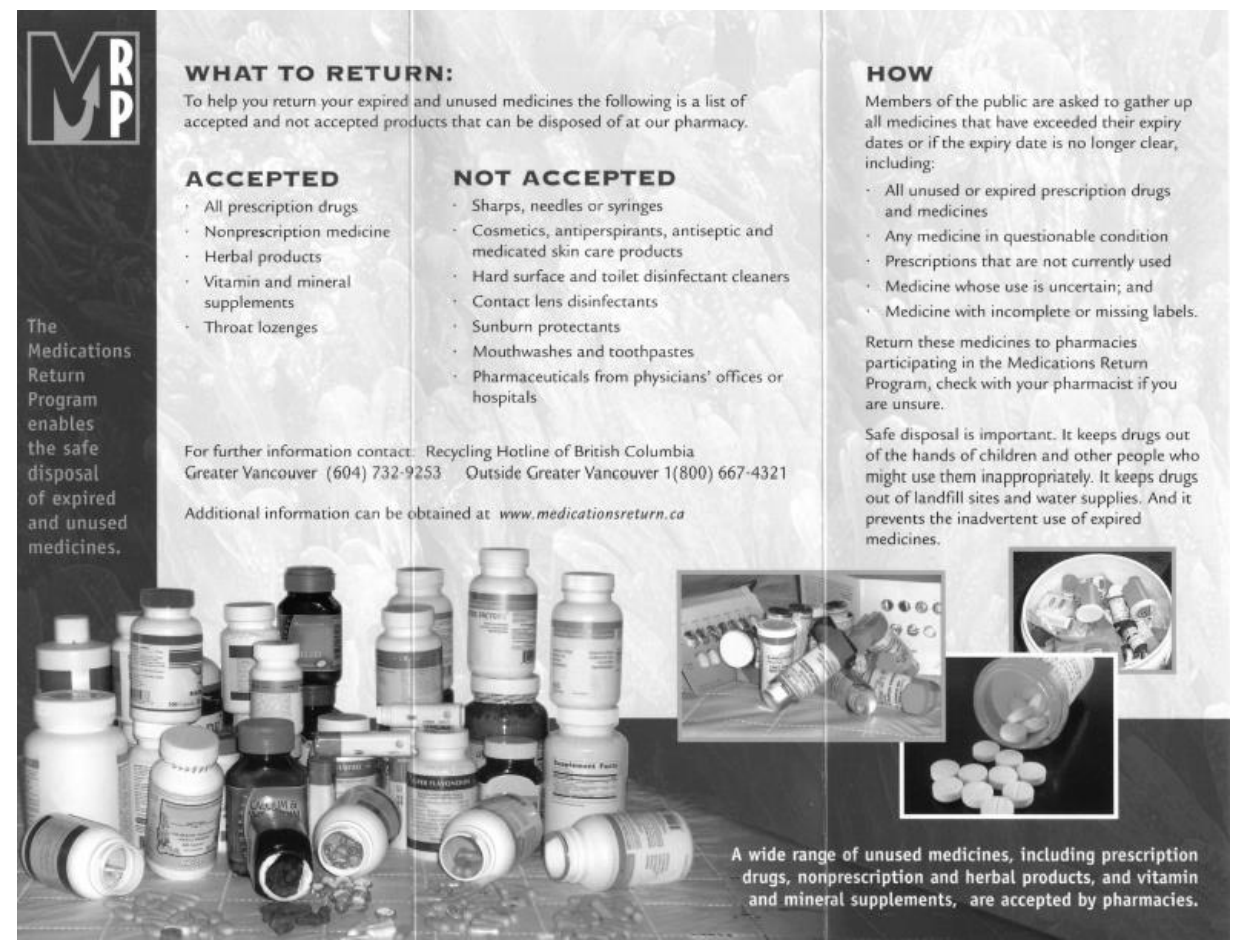


Appendix C. Brochure at Safeway Food \& Drug Regarding Proper Drug Disposal

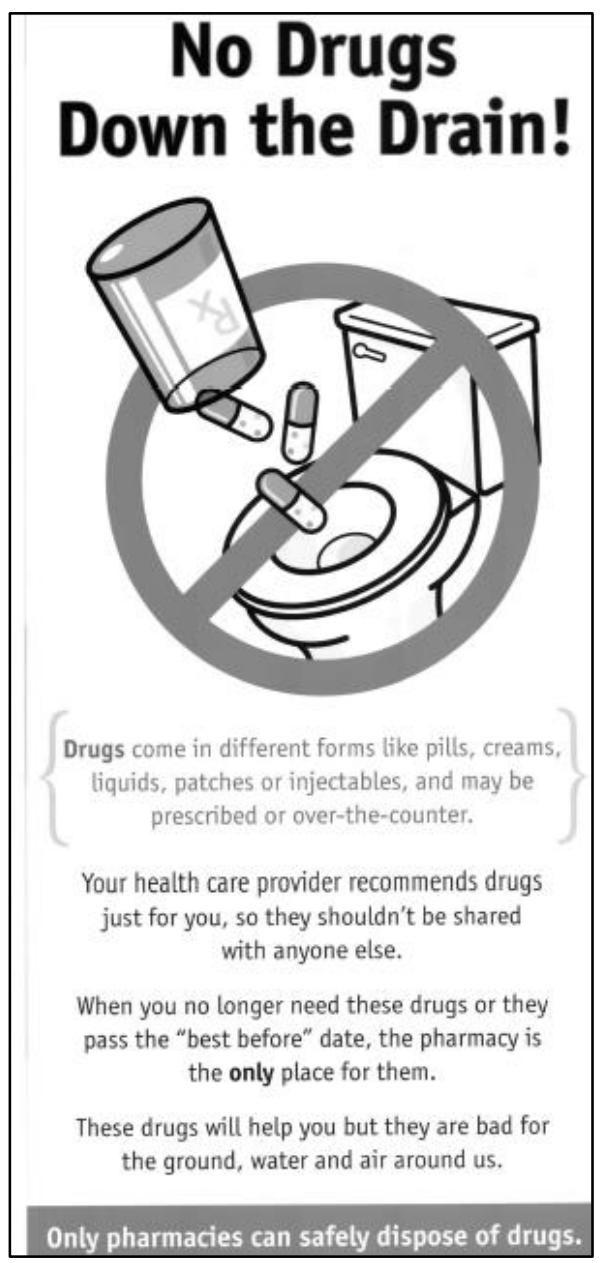


Appendix D. Poster at Shoppers Drug Mart Regarding Proper Drug Disposal

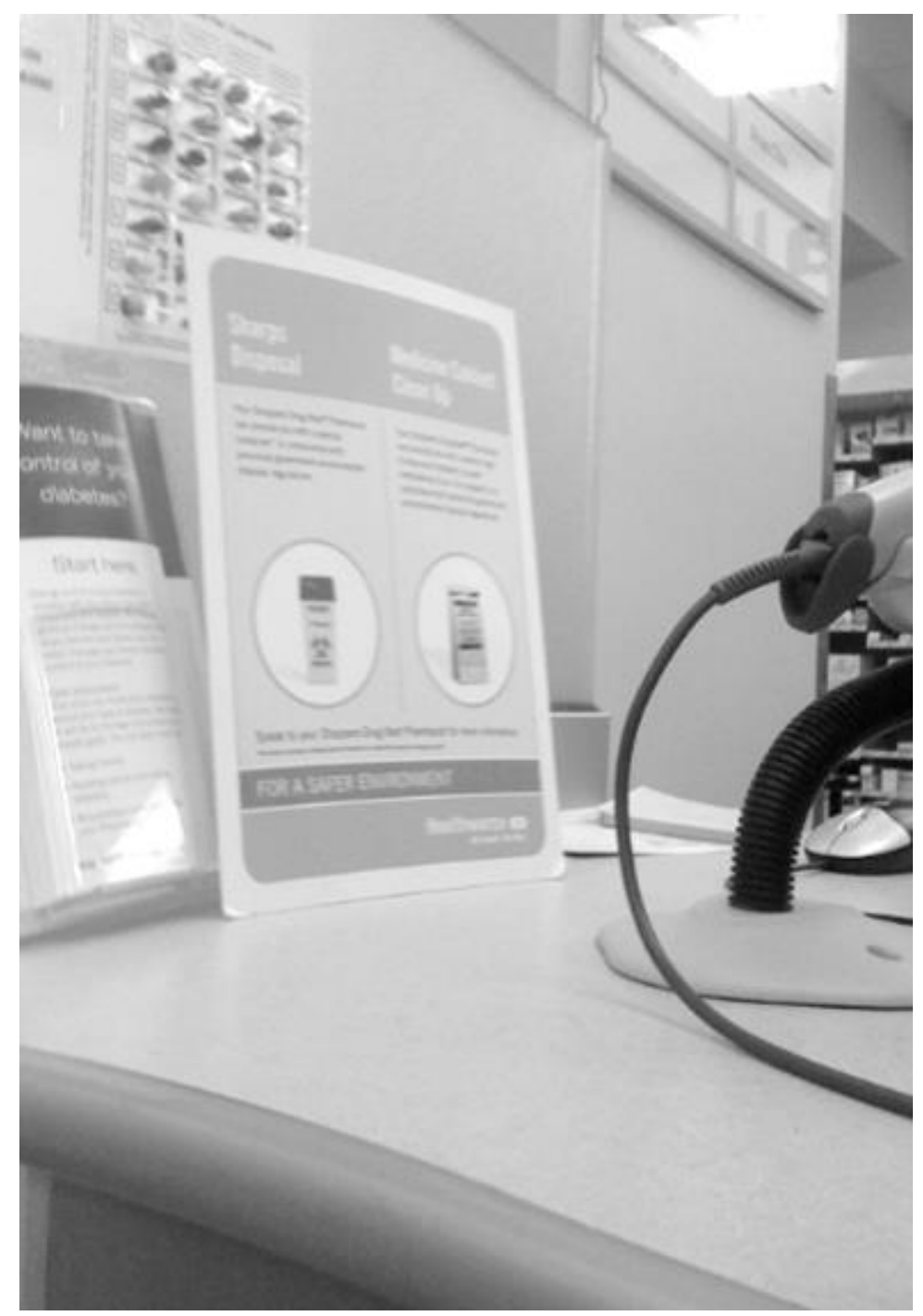


Appendix E. London Drugs' Poster about Safe Sharps Disposal and Brochure about Drug Safety

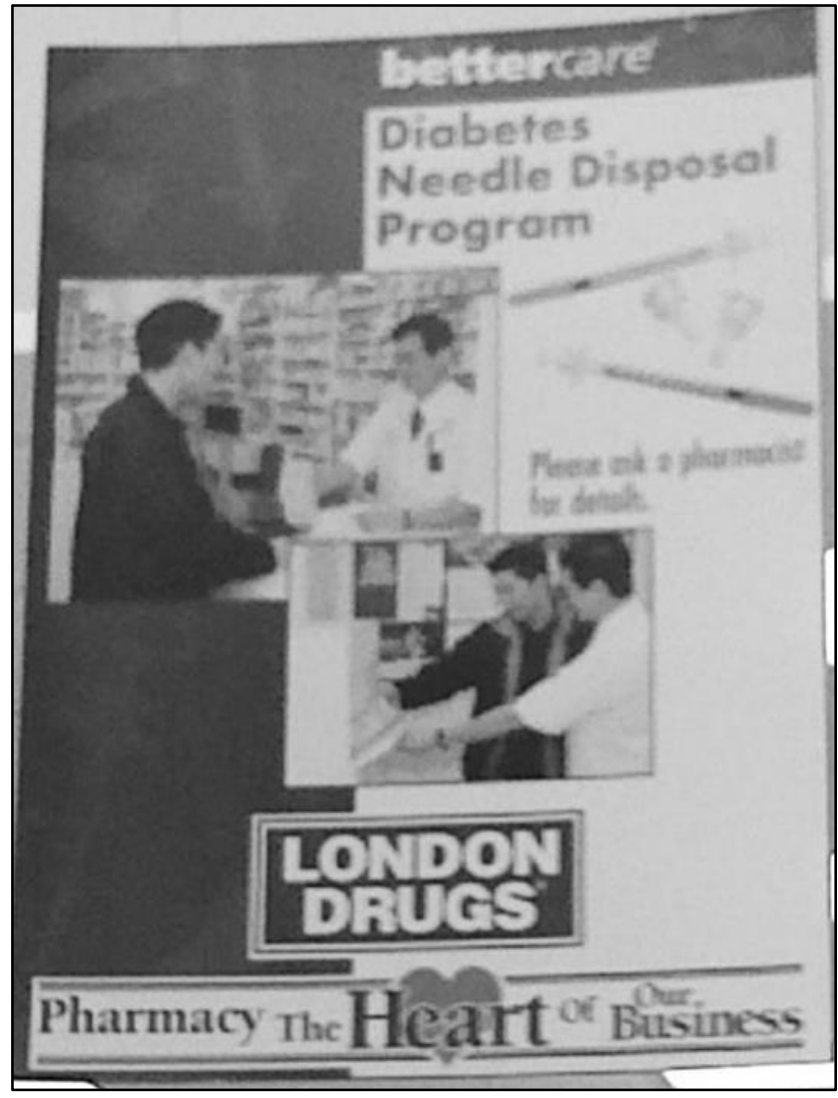

Poster

\section{Medication Safety}

Chances are your family has a cabinet full of medications-from over-the-counter products to prescription drugs. Lurking in the back corner of your medicine cabinet may be some expired medications, and perhaps some prescription drugs you no longer use.

An inportant step in the proper use of medications is to educate yourself about the specific drugs you and your family are taking. All of your family's medications need to be carefully organized to avoid dangerous mistakes. Here are a few tips to help keep you and your family safe:

- Storage: Ask your doctor or pharmacist for directions on how to store your medications. Certain medications need to be refrigerated and others should be kept in a cool, dry place. Make sure that all medications are in child-proof containers and are stored well out of your children's reach.

- Drug interactions: If you've taking morc than one medication, ask your pharmacist to check for any passible drug interactions.

- Side effects: If you denclop what you think is a side effect, contact your doctor or pharmacist immediately. There may be another medication with lewer side tffects that can be substituted.

- Allergic reactions: Allergic reactions frum medications may include difficulty breathing. skin rashes, itching, swelling, racing heartbeat, nausea, severe diarrhea, and focling faint. Tell your doctor or pharmacist if you experience any of these symptoms afler taking a ncw medicine. If the reaction involves difficulty breathing, call for emergency assisstance immediately.

- Expiny dates: Linused and expired medications can be dangerous. Do a yearly inventory of your medicine cabinet and dispose of outdated or unused medications.

- Never share: The medications prescribed by your doctor were meanl to treat your particular medical problem. Newer share your medication with anyone elsc.

- Follow directions: Rcad the labels carefully and follow the directions to the letter Be sure to finish the full course of your medication. Stopping a medication tor early can cause the illness to return or make it more difficult io treat.

\section{Lonpos bettercare}

"First Aid and Medication Safety" Brochure (p. 4) 


\section{References}

Alberta Pharmacists' Association. (n.d.). About RxA - Medication disposal. Retrieved from http://www.rxa.ca/ForthePublic/MedicationDisposal.aspx

Apoteket AB. (2006). Environment and pharmaceuticals. Retrieved from http://www.noharm.org/lib/downloads/pharmaceuticals/Environment_and_ Pharmaceuticals.pdf

Apoteket AB. (2012). Annual report 2011 - Apoteket. Retrieved from http://www.apoteket.se/ privatpersoner/om/Documents/Apoteket\%20AR-11\%20eng_120629.pdf

Auditor General of Ontario. (2010). 2010 Annual report. Retrieved from http://www.auditor.on .ca/en/reports_en/en10/2010ar_en.pdf

Barnes, K.K., Christenson, S.C., Kolpin, D.W., Focazio, M.J., Furlong, E.T., Zaugg, S.D., . . Barber, L.B. (2004). Pharmaceuticals and other organic waste water contaminants within a leachate plume downgradient of a municipal landfill. Ground Water Monitoring and Remediation, 24(2), 119-126.

Behr, R., Stahler, D., \& Pistell, A. (2010). Preliminary characterization of the pharmaceutical content of municipal solid waste landfill leachate from three landfills in Maine. Retrieved from http://productstewardship.us/associations/6596/files/Landfill\%20leachate\%20 testing \%20study\%201\%2010.pdf

Bennett, C.J. (1991). What is policy convergence and what causes it? British Journal of Political Science, 21(2), 215-233.

Benotti, M.J., Trenholm, R.A., Vanderford, B.J., Holady, J.C., Stanford, B.D., \& Snyder, S.A. (2009). Pharmaceuticals and endocrine disrupting compounds in U.S. drinking water. Environmental Science and Technology, 43(3), 597-603.

Blizzard, C. (2010, July 13). Ontario's eco fee hoax: Will Dalton's sneaky new tax save the world or just screw the consumer? Toronto Sun. Retrieved from http://www.torontosun.com /comment/columnists/christina_blizzard/2010/07/13/14702351.html

Bound, J.P., Kitsou, K., \& Voulvoulis, N. (2006). Household disposal of pharmaceuticals and perception of risk to the environment. Environmental Toxicology and Pharmacology, 21(3), 301-307.

Boxall, A.B.A., Rudd, M.A., Brooks, B.W., Caldwell, D.J., Choi, K., Hickmann, S., . . Van Der Kraak, G. (2012). Pharmaceuticals and personal care products in the environment: 
What are the big questions? Environmental Health Perspectives, 120(9), 1221-1229.

British Columbia Ministry of Environment [BC MOE]. (1994, Dec.). Guide to the preparation of regional solid waste management plans for regional districts - Revised edition. Retrieved from http://www.env.gov.bc.ca/epd/mun-waste/waste-solid/sw-mgmt-plan/guideplan /pdf/guide-swmplan.pdf

British Columbia Ministry of Environment [BC MOE]. (1999). Annual report by the Director: 1999 Reporting period. Retrieved from http://www.env.gov.bc.ca/epd/recycling/pharm/ reports/index.htm

British Columbia Ministry of Environment [BC MOE]. (2002, Sept. 30). British Columbia industry product stewardship business plan 2002/2003 - 2004/2005. Retrieved from http://www.env.gov.bc.ca/epd/recycling/history/pdf/prodstew_plan.pdf

British Columbia Ministry of Environment [BC MOE]. (2009, Sept.). Water quality guidelines for pharmaceutically-active-compounds (PhACs): 17 $\alpha$-ethinylestradiol (EE2) - Technical appendix. Retrieved from http://www.env.gov.bc.ca/wat/wq/BCguidelines/PhACsEE2/PhACs-EE2-tech.pdf

British Columbia Ministry of Environment [BC MOE]. (2011, Mar. 24). Product stewardship in B.C. Retrieved from http://www.env.gov.bc.ca/epd/recycling/history/history.htm

British Columbia Ministry of Environment [BC MOE]. (2012, April). Recycling regulation guide. Retrieved from http://www.env.gov.bc.ca/epd/recycling/guide/pdf/ recycling_regulation_guide_2012.pdf

Brodin, T., Fick, J., Jonsson, M., \& Klaminder, J. (2013). Dilute concentrations of a psychiatric drug alter behavior of fish from natural populations. Science, 339, 814-815.

Brusca, I., \& Montesinos, V. (2009). International experiences in whole of government financial reporting: Lesson-drawing for Spain. Public Money \& Management, 29(4), 243-250.

Brushin, B. (2005). Return unwanted medicines survey- Victorian report. Melbourne Metropolitan Area. Melbourne, Australia.

Burton, I., \& Pushchak, R. (1984). The status and prospects of risk assessment. Geoforum, 15(3), 463-475.

Campbell, J. (2007). Drugs on tap - Pharmaceuticals in our drinking water. Pharmacy Practice. Retrieved from http://envirolaw.com/wp-content/uploads/2007-jan-drugs-on-tap-articlejc.pdf 
Canadian Council of Ministers of the Environment [CCME]. (1998, Jan.). National packaging protocol 1996 milestone report. Retrieved from http://www.ccme.ca/assets/pdf/ milestone_e.pdf

Canadian Council of Ministers of the Environment [CCME]. (2009, Oct. 29). Canada-wide action plan for extended producer responsibility. Retrieved from http://www.ccme.ca/ assets/pdf/epr_cap.pdf

Canadian Council of Ministers of the Environment [CCME]. (2011, May 10). About CCME. Retrieved from http://www.ccme.ca/about/

Canadian Diabetes Association. (2012). Diabetes and you. Retrieved from http://www.diabetes .ca/diabetes-and-you/

Canadian Generic Pharmaceutical Association. (2012, July). The Ontario's prescription drug expenditures - 2011. Retrieved from http://www.canadiangenerics.ca/en/advocacy/docs/ OntarioDrugExpenditures.pdf

Canadian Institute for Environmental Law and Policy [CIELAP]. (2000). Ontario's environment and the common sense revolution: A fifth year report. Retrieved from http://www.cielap.org/pdf/csr5.pdf

Canadian Institute for Environmental Law and Policy [CIELAP]. (2008, Nov.). Ontario's waste diversion act: Moving beyond recycling - A background paper on the review of the waste diversion act. Retrieved from http://www.cielap.org/pdf/WDA_BeyondRecycling.pdf

Canadian Medical Association [CMA], \& Collier, R. (2012). Swallowing the pharmaceutical waters. Canadian Medical Association Journal, 184(2), 163-164.

City of Toronto. (2013). 2013 Community environment days. Retrieved from http://www.toronto.ca/environment_days/index.htm

College of Pharmacists of British Columbia [College of Pharmacists of BC]. (2006, Mar.). Framework of professional practice. Retrieved from http://library.bcpharmacists.org/DLegislation_Standards/D-2_Provincial_Legislation/1009-FPP.pdf

Cooper, K., \& Vanderlinden, L. (2009). Pollution, chemicals, and children's health: The need for precautionary policy in Canada. In C.D. Gore \& P.J. Stoett (Eds.), Environmental challenges and opportunities: Local-global perspectives on Canadian issues (pp. 183224). Toronto, ON: Emond Montgomery Publications Limited.

County of Alameda California. (2012, July 24). New county policy requires drug makers to pick 
up disposal costs. Retrieved from http://productstewardship.us/associations/6596/files 17_24_2012_SafeMed_FINAL.pdf

Crabbé, A., \& Leroy, P. (2008). The handbook of environmental policy evaluation. London, UK: Earthscan.

Cyclamed. (2008). Rapport annuel 2007. Retrieved from http://www.cyclamed.org/rapportannuel-2007-602

Cyclamed. (2012). Rapport annuel 2011. Retrieved from http://www.cyclamed.org/rapportannuel-2011-2-1168

Cyr, A., \& deLeon, P. (1975). Comparative policy analysis. Policy Sciences, 6(4), 375-384.

Dewees, D. \& Valiante, U. (2012, Aug. 23). Eco-fee monopolies must end. Globe and Mail. Retrieved from http://m.theglobeandmail.com/commentary/eco-fee-monopolies-mustend/article1212529/?service $=$ mobile

Dolliver, H., \& Gupta, S. (2008). Antibiotic losses in leaching and surface runoff from manureamended agricultural land. Journal of Environmental Quality, 37(3), 1227-1237.

Dolowitz, D., \& Marsh, D. (1996). Who learns what from whom: A review of the policy transfer literature. Political Studies, 44(2), 343-357.

Dunn, C. (1996a). Premiers and cabinets. In C. Dunn (Ed.), Provinces: Canadian provincial politics (pp. 165-204). Peterborough, ON: Broadview Press.

Dunn, C. (1996b). Introduction. In C. Dunn (Ed.), Provinces: Canadian provincial politics (pp. 9-17). Peterborough, ON: Broadview Press.

Dunsmuir, M. (1991, Sept.). Culture and communications: The Constitutional setting. Retrieved from http://publications.gc.ca/Collection-R/LoPBdP/BP/bp277-e.htm

Edwards, M., Topp, E., Metcalfe, C.D., Li, H., Gottschall, N., Bolton, P., . . Lapen, D.R. (2009). Pharmaceutical and personal care products in tile drainage following surface spreading and injection of dewatered municipal biosolids to an agricultural field. Science of the Total Environment, 407(14), 4220-4230.

Enick, O.V., \& Moore, M.M. (2007). Assessing the assessments: Pharmaceuticals in the environment. Environmental Impact Assessment Review, 27(8), 707-729.

Environment Canada. (2008, Oct. 21). Threats to sources of drinking water and aquatic ecosystem health in Canada. Retrieved from https://www.ec.gc.ca/inrenwri/default.asp?lang=En\&n=235D11EB-1\&offset=14\&toc=show 
Environment Canada. (2010, July 28). Substances lists - Domestic substances list. Retrieved from http://www.ec.gc.ca/lcpe-cepa/default.asp?lang=En\&n=5F213FA8-1

Environment Canada. (2012a, June 18). Emerging threats - Pharmaceuticals polluting lakes and rivers. Retrieved from http://www.ec.gc.ca/scitech/default.asp?lang=En\&n=64B32D19-1

Environment Canada. (2012b, July 3). Inventory of programs. Retrieved from https://www.ec.gc.ca/gdd-mw/default.asp?lang=En\&n=9FB94989-1

Environment Canada. (2012c, Aug. 15). Pollution and waste - Managing solid waste. Retrieved from https://www.ec.gc.ca/gdd-mw/default.asp?lang=En\&n=EF0FC6A9-1

Environmental Commissioner of Ontario [ECO]. (1996, Nov. 14). Round table: Self regulation, voluntary compliance and environmental protection, November 14, 1996 - Summary of the discussion. Retrieved from http://www.eco.on.ca/uploads/Reports\%20\%20Background,\%20Discussion,\%20Roundtable/1996\%20roundtable\%20summary.pdf Environmental Commissioner of Ontario [ECO]. (2012, Nov. 28). Summary report on the Environmental Commissioner of Ontario's roundtable on extended producer responsibility. Retrieved from http://www.eco.on.ca/uploads/Reports\%20-\%20Back ground,\%20Discussion,\%20Roundtable/2012\%20Roundtable\%20on\%20EPR.pdf

Escher, B.I., Bramaz, N., Maurer, M., Richter, M., Sutter, D., Känel, C.V., \& Zschokke, M. (2005). Screening test battery for pharmaceuticals in urine and wastewater. Environmental Toxicology and Chemistry, 24(3), 750-758.

European Environment Agency [EEA]. (2010). Pharmaceuticals in the environment - Results of an EEA workshop. Retrieved from http://www.eea.europa.eu/publications/ pharmaceuticals-in-the-environment-result-of-an-eea-workshop/at_download/file European Medicines Agency [EMA]. (2006, June 1). Guideline on the environmental risk assessment of medicinal products for human use. Retrieved from http://www.ema.europa. eu/ema/pages/includes/document/open_document.jsp?webContentId=WC500003978

Extended Producer Responsibility Canada [EPR Canada]. (2012a, July). 2011 EPR report card. Retrieved from http://www.eprcanada.ca/reports/2011/report/index.html Extended Producer Responsibility Canada [EPR Canada]. (2012b, July 12). News release: BC scored highest in actions to make brandowners and manufacturers $100 \%$ responsible for post-consumer product and packaging waste. Retrieved from http://www.eprcanada.ca/ reports/2011/EPR-Canada-Report-Card-News-Release.pdf 
Fischer, B., Ialomiteanu, A., Boak, A., Adlaf, E., Rehm, J., Mann, R.E. (2013). Prevalence and key covariates of non-medical prescription opioid use among the general secondary student and adult populations in Ontario, Canada. Drug and Alcohol Review, 32(3), 276287.

Flyvbjerg, B. (2006). Five misunderstandings about case-study research. Qualitative Inquiry, 12(2), 219-245.

Flyvbjerg, B. (2011). Case study. In N.K. Denzin and Y.S. Lincoln (Eds.), The sage handbook of qualitative research (4th ed.). (pp. 301-316). Thousand Oaks, CA: Sage.

Foreign Affairs, Trade and Development Canada. (2013). Corporate social responsibility. Retrieved from http://www.international.gc.ca/trade-agreements-accordscommerciaux/topics-domaines/other-autre/csr-rse.aspx?lang=eng

Fram, M.S., \& Belitz, K. (2011). Occurrence and concentrations of pharmaceutical compounds in groundwater used for public drinking-water supply in California. Science of the Total Environment, 409(18), 3409-3417.

Garrison, A.W., Pope, J.D., \& Allen, F.R. (1976). GC/MS analysis of organic compounds in domestic wastewaters. In L.H. Keith (Ed.), Identification and analysis of organic pollutants in water (pp. 517-556). Ann Arbor, MI: Ann Arbor Science Publishers.

Gornick, J.C., \& Meyers, M.K. (2001). Lesson-drawing in family policy: Media reports and empirical evidence about European developments. Journal of Comparative Policy Analysis: Research and Practice, 3(1), 31-57.

Government of Canada Privy Council Office. (2010, April 26). Environment and health. Retrieved from http://www.pco-bcp.gc.ca/aia/index.asp?lang=eng\&page=federal $\&$ sub=legis\&doc=env-eng.htm

Green, A., \& Trebilcock, M. (2010). The eco-fee imbroglio: Lessons from Ontario's troubled experiment in charging for waste management. Commentary - C.D. Howe Institute, 316, $1-28$.

Greenbaum, A., \& Wellington, A. (2010). Environmental law and policy in the Canadian context. Concord, ON: Captus Press Inc.

Halling-Sørensen, B., Nors Nielsen, S., Lanzky, P.F., Ingerslev, F., Holten Lützhøft, H.C., Jørgensen, S.E. (1998). Occurrence, fate and effects of pharmaceutical substances in the environment - A review. Chemosphere, 36(2), 357-393. 
Hanisch, C. (2000). Is extended producer responsibility effective? Environmental Science \& Technology, 34(7), 170A-175A.

Harries, J.E., Janbakhsh, A., Jobling, S., Matthiessen, P., Sumpter, J.P., \& Tyler, C.R. (1999).

Estrogenic potency of effluent from two sewage treatment works in the United Kingdom. Environmental Toxicology and Chemistry, 18(5), 932-937.

Health Canada. (2003, Jan.). Final issue identification paper. Retrieved from http://www.hcsc.gc.ca/ewh-semt/alt_formats/hpfb-dgpsa/pdf/contaminants/final_iip-dde-eng.pdf

Health Canada. (2009, Nov. 6). Pharmaceutical disposal programs for the public: A Canadian perspective. Health Canada environmental impact initiative. Retrieved from http://www.enviroadvisory.com/pdf/Takeback.pdf

Health Canada. (2010, Sept. 21). Environmental assessment regulations. Retrieved from http://www.hc-sc.gc.ca/ewh-semt/contaminants/person/impact/reg/index-eng.php

Health Canada. (2011, Feb. 22). More information about the environmental assessment regulations. Retrieved from http://www.hc-sc.gc.ca/ewh-semt/contaminants/person/ impact/reg/faq-eng.php

Health Council of Canada. (2010, Sept.). Decisions, decisions: Family doctors as gatekeepers to prescription drugs and diagnostic imaging in Canada. Retrieved from: http://www.healthcouncilcanada.ca/tree/2.33-DecisionsHSU_Sept2010.pdf

Health Products Stewardship Association [HPSA, formerly the Post-Consumer Pharmaceutical Stewardship Association or PCPSA]. (2012a). About us - History. Retrieved from http://www.healthsteward.ca/about-us/history

Health Products Stewardship Association [HPSA, formerly the Post-Consumer Pharmaceutical Stewardship Association or PCPSA]. (2012b). Health products stewardship association. Retrieved from http://www.healthsteward.ca/

Health Products Stewardship Association [HPSA, formerly the Post-Consumer Pharmaceutical Stewardship Association or PCPSA]. (2012c). About us - Corporate. Retrieved from http://www.healthsteward.ca/about-us/corporate

Health Products Stewardship Association [HPSA, formerly the Post-Consumer Pharmaceutical Stewardship Association or PCPSA]. (2013a, April). Program plan for the Ontario medications return program. Retrieved from http://www.healthsteward.ca/sites/default/ files/Ontario\%20Medications\%20Stewardship\%20plan\%20vf.pdf 
Health Products Stewardship Association [HPSA, formerly the Post-Consumer Pharmaceutical Stewardship Association or PCPSA]. (2013b, April). Program plan for the Ontario sharps collection program. Retrieved from http://www.healthsteward.ca/sites/default /files/Ontario\%20Sharps\%20Collection\%20Program\%20Plan\%20-\%20\%28FINAL\% 29.pdf

Health Products Stewardship Association [HPSA, formerly the Post-Consumer Pharmaceutical Stewardship Association or PCPSA]. (2013c, June 30). Interim report on the Ontario medications return program and the Ontario sharps collection program. Retrieved from http://www.healthsteward.ca/sites/default/files/Interim\%20Report\%20to\%20Director\%20 Final.pdf

Health Products Stewardship Association [HPSA, formerly the Post-Consumer Pharmaceutical Stewardship Association or PCPSA]. (n.d.). Promotional tools order form. Retrieved from http://www.healthsteward.ca/sites/default/files/Promo\%20Order\%20 Form\%20BC.pdf

Heberer T., Butz, S., \& Stan, H.J. (1995). Analysis of phenoxycarboxylic acids and other acidic compounds in tap, ground, surface and sewage water at the low ng/l level. International Journal of Environmental Analytical Chemistry, 58(1-4), 43-53.

Heberer, T.H., \& Stan, H.J. (1997). Determination of clofibric acid and N-(Phenylsulfonyl)Sarcosine in sewage, river and drinking Water. International Journal of Environmental Analytical Chemistry, 67(1-4), 113-124.

Hemminger, P. (2005). Spheres of influence - Damming the flow of drugs into drinking water. Environmental Health Perspectives, 113(10), A678-A681.

Hignite, C., \& Azarnoff, D.L. (1977). Drugs and drug metabolites as environmental contaminants: Chlorophenoxyisobutyrate and salicylic acid in sewage water effluent. Life Sciences, 20, 337-342.

Hinck, J.E., Blazer, V.S., Schmitt, C.J., Papoulias, D.M., \& Tillitt, D.E. (2009). Widespread occurrence of intersex in black basses (Micropterus spp.) from U.S. rivers, 1995-2004. Aquatic Toxicology, 95(1), 60-70.

Hirsch, R., Ternes, T.A., Haberer, K., Mehlich, A., Ballwanz, F., \& Kratz, K.L. (1998). Determination of antibiotics in different water compartments via liquid chromatographyelectrospray tandem mass spectrometry. Journal of Chromatography A, 815(2), 213-223. 
Holm, J.V., Ruegge, K., Bjerg, P.L., \& Christensen, T.H. (1995). Occurrence and distribution of pharmaceutical organic compounds in the groundwater downgradient of a landfill (grindsted, denmark). Environmental Science \& Technology, 29(5), 1415-1420.

Howlett, M., \& Lindquist, E. (2004). Policy analysis and governance: Analytical and policy styles in Canada. Journal of Comparative Policy Analysis: Research and Practice, 6(3), 225-249.

Hua, W.Y., Bennett, E.R., Maio, X.S., Metcalfe, C.D., \& Letcher, R.J. (2006). Seasonality effects on pharmaceuticals and s-triazine herbicides in wastewater effluent and surface water from the Canadian side of the upper Detroit river. Environmental Toxicology and Chemistry, 25(9), 2356-2365.

Huerta-Fontela, M., Galceran, M.T., \& Francesc, V. (2011). Occurrence and removal of pharmaceuticals and hormones through drinking water treatment. Water Research, 45(3), 1432-1442.

Hummel, D., Löffler, D., Fink, G., \& Ternes, T.A. (2006). Simultaneous determination of psychoactive drugs and their metabolites in aqueous matrices by liquid chromatography mass spectrometry. Environmental Science \& Technology, 40(23), 7321-7328.

Illical, M., \& Harrison, K. (2007). Protecting endangered species in the US and Canada: The role of negative lesson drawing. Canadian Journal of Political Science, 40(2), 367-394.

Imbeau, L.M., \& Lachapelle, G. (1996). Comparative provincial public policy in Canada. In C. Dunn (Ed.), Provinces: Canadian provincial politics (pp. 401-422). Peterborough, ON: Broadview Press.

Imm, M. (2010). An evaluation of British Columbia's medications return program as a management framework for collecting unused/expired pharmaceuticals. (Master's thesis). Retrieved from Ryerson University Library, Toronto. (TD789.C22 I44 2010).

James, O., \& Lodge, M. (2003). The limitations of 'policy transfer' and 'lesson drawing' for public policy research. Political Studies Review, 1(2), 179-193.

Jasanoff, S. (2005). Designs on nature: Science and democracy in Europe and the United States. Princeton, NJ: Princeton University Press.

Johnson, A.C., Jürgens, M.D., Williams, R.J., Kümmerer, K., Kortenkamp, A., \& Sumpter, J.P. (2008). Do cytotoxic chemotherapy drugs discharged into rivers pose a risk to the environment and human health? An overview and UK case study. Journal of Hydrology, 
$348(1), 167-175$.

Jorgensen, S. E., \& Halling-Sorensen, B. (2000). Drugs in the environment. Chemosphere, 40, 691-699.

Kamieniecki, S., \& Sanasarian, E. (1990). Conducting comparative research on environmental policy. Natural Resources Journal, 30(2), 321-339.

Kaye, L., Crittenden, J., \& Gressitt, S. (2010, April). Executive summary: Reducing prescription drug misuse through the use of a citizen mail-back program in Maine. Retrieved from http://www.epa.gov/aging/RX-report-Exe-Sum/

Kelleher Environmental. (2007, Dec.). IC\&I waste diversion in Ontario - Report to Ontario waste management association.

Kidd, K.A., Blanchfield, P.J., Mills, K.H., Palace, V.P., Evans, R.E., Lazorchak, J.M., \& Flick, R.W. (2007). Collapse of a fish population after exposure to a synthetic estrogen. Proceedings of the National Academy of Sciences of the United States of America, 104(21), 8897-8901.

Kim, S.D., Cho, J., Kim, I.S., Vanderford, B.J., \& Snyder, S.A. (2007). Occurrence and removal of pharmaceuticals and endocrine disruptors in South Korean surface, drinking, and waste waters. Water Research, 41(5), 1013-1021.

Kingsmore, L., \& Hargreave, P. (2012). Pharmaceutical and sharps waste: Has Ontario finally got it right? Waste Edge, 8(2), 10-11.

Kleywegt, S., Smyth, S-A., Parrott, J., Schaefer, K., Lagacé, E., Payne, M., ... Ostapyk, K. (2007). Pharmaceuticals and personal care products in the Canadian environment: Research and policy directions - Workshop proceedings. Niagara-on-theLake, ON: NWRI Scientific Assessment Report Series No.8. 53 p.

Knill, C. (2005). Introduction: Cross-national policy convergence: Concepts, approaches and explanatory factors. Journal of European Public Policy, 12(5), 764-774.

Knoepfel, P., Larrue, C., Varone, F., \& Hill, M. (2007). Public policy analysis. Bristol, UK: The Policy Press.

Kolluru, R.V. (1996). Health risk assessment: Principles and practices. In R.V. Kolluru, S. Bartell, R. Pitblado, \& S. Stricoff (Eds.), Risk assessment and management handbook for environmental, health, and safety professionals (pp. 4-3-4.68). New York, NY: McGraw-Hill. 
Kolpin, D.W., Furlong, E.T., Meyer, M.T., Thurman, M.E., Zaugg, S.D., Barber, L.B., \& Buxton, H.T. (2002). Pharmaceuticals, hormones, and other organic wastewater contaminants in U.S. streams, 1999-2000: A national reconnaissance. Environmental Science and Technology, 36(6), 1202-1211.

Kopstein, J., \& Lichbach, M. (2005). What is comparative politics? In J. Kopstein \& M. Lichbach (Eds.), Comparative politics: Interests, identities, and institutions in a changing global order (2nd ed.). (pp. 1-15). New York, NY: Cambridge University Press.

Kristiansson, E., Fick, J., Janzon, A., Grabic, R., Rutgersson, C., Weijdegard, B., .. . Larsson, D.G.K. (2011). Pyrosequencing of antibiotic-contaminated river sediments reveals high levels of resistance and gene transfer elements. PLoS One, 6(2), 1-8.

Kümmerer, K. (2004). Pharmaceuticals in the environment - Scope of the book and introduction. In K. Kümmerer (Ed.), Pharmaceuticals in the environment - Sources, fate, effects and risks (2nd ed.). (pp. 1-11). Berlin, Germany: Springer.

Lai, K.M., Scrimshaw, M.D., \& Lester, J.N. (2002). The effects of natural and synthetic steroid estrogens in relation to their environmental occurrence. Critical Reviews in Toxicology, $32(2), 113-132$.

Loraine, G.A., \& Pettigrove, M.E. (2006). Seasonal variations in concentrations of pharmaceuticals and personal care products in drinking water and reclaimed wastewater in Southern California. Environmental Science \& Technology, 40(3), 687695.

Lowson, G. (2013, April 27). Ontario's costly recycling program for electronics falls short: Editorial. Toronto Star. Retrieved from http://www.thestar.com/opinion/editorials/2013 /04/27/ontarios_costly_recycling_program_for_electronics_falls_short_editorial.html

Lubick, N. (2010). Drugs in the environment: Do pharmaceutical take-back programs make a difference? Environmental Health Perspectives, 118(5), A210-A214.

McKerlie, K., Knight, N., \& Thorpe, B. (2006). Advancing extended producer responsibility in Canada. Journal of Cleaner Production, 14(6), 616-628.

McLaughlin, K. (2002). Lesson drawing from the international experience of modernizing local governance. Public Management Review, 4(3), 405-410.

McLean, J. (2010, July 7). New eco fees catching consumers by surprise. Toronto Star. Retrieved from http://www.thestar.com/business/2010/07/07/new_eco_fees_catching_ 
consumers_by_surprise.html

Myers, N. (2007, Aug. 9). Scientific uncertainty and public policy. In Encyclopedia of the Earth. Retrieved from http://www.eoearth.org/article/Scientific_uncertainty_and_ public_policy

National Advisory Committee on Prescription Drug Misuse [NACPDM]. (2013). First do no harm: Responding to Canada's prescription drug crisis. Retrieved from http://www.drugs andalcohol.ie/19622/1/Canada-Strategy-Prescription-Drug-MisuseReport_Full_report.pdf

National Association of Pharmacy Regulatory Authorities. (2009). Resources for pharmacy operators. Retrieved from http://www.napra.org/pages/Practice_Resources/resources_ for_pharmacy_operators.aspx?id=2128

National Association of Pharmacy Regulatory Authorities. (n.d.). About NAPRA. Retrieved from http://napra.ca/pages/About/default.aspx

National Institute of Environmental Health Sciences. (2010, May). Endocrine disruptors. Retrieved from http://www.niehs.nih.gov/health/materials/endocrine_disruptors_508.pdf New Jersey Division of Consumer Affairs. (2013, Feb. 4). Project medicine drop- Drop box locations. Retrieved from http://www.njconsumeraffairs.gov/meddrop/locations.htm

Northwest Product Stewardship Council. (2009). Product stewardship in Canada - Legislative framework of provincial programs. Retrieved from: http://productstewardship.net/PDFs/policiesNWPSCCanadianPSPrograms10_09.pdf

Ontario Medical Association [OMA]. (2013, Mar.). OMA policy paper: When antibiotics stop working. Retrieved from https://www.oma.org/Resources/Documents/ Antibiotics03192013.pdf

Ontario Ministry of the Environment [ON MOE]. (1991, Feb. 21). Ontario's waste reduction action plan: Backgrounder. Retrieved from http://archive.org/details/wastereduction ac00ontauoft

Ontario Ministry of the Environment [ON MOE]. (2004, June 10). Ontario's 60\% waste diversion goal - A discussion paper. Retrieved from http://www.ene.gov.on.ca/stdprod consume/groups/1r/@ene/@ resources/documents/resource/std01_079752.pdf

Ontario Ministry of the Environment [ON MOE]. (2008, Oct.). Toward a zero waste future: Review of Ontario's waste diversion act, 2002 - Discussion paper for public consultation. Retrieved from http://www.downloads.ene.gov.on.ca/envision/env_reg/er/ 
documents/2008/010-4676.pdf

Ontario Ministry of the Environment [ON MOE]. (2009a, Oct.). From waste to worth: The role of waste diversion in the green economy - Minister's report on the waste diversion act 2002 review. Retrieved from http://www.dsa.ca/fileBin/mediaLibrary/WDA_Report.pdf

Ontario Ministry of the Environment [ON MOE]. (2009b, Nov.). Guideline C-4: The management of biomedical waste in Ontario. Retrieved from http://www.safetyoffice .uwaterloo.ca/hse/bio_safety/documents/Guideline\%20C4[1].pdf

Ontario Ministry of the Environment [ON MOE]. (2010a). Survey of the occurrence of pharmaceuticals and other emerging contaminants in untreated source and finished drinking water in Ontario. Retrieved from http://www.ene.gov.on.ca/environment/en/ resources/STD01_076260.html

Ontario Ministry of the Environment [ON MOE]. (2010b, Oct. 12). Statement from Ontario minister of the environment John Wilkinson regarding waste diversion. Retrieved from http://news.ontario.ca/ene/en/2010/10/statement-from-ontario-minister-of-theenvironment-john-wilkinson-regarding-waste-diversion.html

Ontario Ministry of the Environment [ON MOE]. (2012, May 31). Letter to the association of municipalities of Ontario. Retrieved from http://www.owma.org/lib/db2file.asp? fileid $=1146$

Ontario Ministry of the Environment [ON MOE]. (2013a, June). Waste reduction strategy. Retrieved from http://www.downloads.ene.gov.on.ca/envision/env_reg/er/documents/ 2013/011-9262.pdf

Ontario Ministry of the Environment [ON MOE]. (2013b, June 6). Waste reduction act. EBR registry number: 011-9260. Retrieved from: http://www.ebr.gov.on.ca/ERS-WEBExternal/displaynoticecontent.do?noticeId=MTE5NzM0\&statusId=MTc5MTM1

Ontario Waste Management Association [OWMA]. (2013, Mar. 6). Rethink waste: A blue print for harnessing the economic benefits of resource management in Ontario. Retrieved from http://www.owma.org/Publications/OWMAReportsandPolicies/tabid/180/ctl/DisplayAtta chment/mid/624/AnnotationId/9b3991b7-0bd2-e211-9cac-00155d607900/Default.aspx

Organisation for Economic Co-operation \& Development [OECD]. (2001). Extended producer responsibility - A guidance manual for governments. Paris, France: OECD Publishing. Organisation for Economic Co-operation \& Development [OECD]. (n.d.). Guidelines for 
multinational enterprises - Corporate responsibility: Frequently asked questions.

Retrieved from http://www.oecd.org/daf/inv/mne/corporateresponsibility frequentlyaskedquestions.htm

Partnership for a Drug-Free America. (2009, Feb. 26). The partnership attitude tracking study (PATS) - Teens 2008 report. Retrieved from http://www.drugfree.org/wpcontent/uploads/2011/04/Full-Report-FINAL-PATS-Teens-2008_updated.pdf

Patented Medicine Prices Review Board. (2011). Annual report 2010 - Key pharmaceutical trends. Retrieved from http://www.pmprb-cepmb.gc.ca/english/view.asp?x= $1503 \&$ mid $=1329$

Perron, M. (2013, July 8). It's time to talk about drugs - The legal kind. The Vancouver Sun. Retrieved from http://www.vancouversun.com/opinion/time+talk+about+drugs+ legal+kind/8628947/story.html

Post-Consumer Pharmaceutical Stewardship Association [PCPSA, now the Health Products Stewardship Association or HPSA]. (2006, July). Medications return program - postconsumer pharmaceutical stewardship association. Retrieved from http://www.env.gov.bc.ca/epd/recycling/pharm/plans.htm

Post-Consumer Pharmaceutical Stewardship Association [PCPSA, now the Health Products Stewardship Association or HPSA]. (2010). Producer provided medications return program in British Columbia. Retrieved from http://www.takebackyourmeds.org/pdffiles/bc-factsheet

Post-Consumer Pharmaceutical Stewardship Association [PCPSA, now the Health Products Stewardship Association or HPSA]. (2012a, June 30). Pharmaceutical annual report January to December 2011. Retrieved from http://www.healthsteward.ca/sites/default/ files/2011\%20Annual\%20Report\%20PSPCA.pdf

Post-Consumer Pharmaceutical Stewardship Association [PCPSA, now the Health Products Stewardship Association or HPSA]. (2012b, Mar. 30). Manitoba medications return program annual report 2011. Retrieved from http://greenmanitoba.ca/umedia/annual_ reports/2011-MRP-Annual_Report.pdf

Post-Consumer Pharmaceutical Stewardship Association [PCPSA, now the Health Products Stewardship Association or HPSA]. (2012c). PCPSA 2012-2016 program plan. Retrieved from http://www.healthsteward.ca/sites/default/files/2012\%20Medications $\% 20$ 
Stewardship\%20Plan\%20.pdf

Product Stewardship Institute. (2012a). Pharmaceuticals home. Retrieved from http://www.productstewardship.us/displaycommon.cfm?an=1\&subarticlenbr=181

Product Stewardship Institute. (2012b). Pharmaceutical legislation. Retrieved from http://www.productstewardship.us/displaycommon.cfm?an=1\&subarticlenbr=540

Public Safety Canada. (2013, May 9). Harper government encourages Canadians to participate in national prescription drug drop-off day. Retrieved from http://www.publicsafety.gc.ca/ media/nr/2013/nr20130509-2-eng.aspx

Purdom, C. E., Hardiman, P. A., Bye, V.V. J., Eno, N. C., Tyler, C. R., \& Sumpter, J. P. (1994). Estrogenic effects of effluents from sewage treatment works. Chemistry and Ecology, $8(4), 275-285$.

Rabe, B.G. (2002). The subnational role in sustainable development: Lessons from American states and Canadian provinces. In J.M. Gillroy \& J. Bowersox (Eds.), The moral austerity of environmental decision making: Sustainability, democracy, and normative argument in policy and law (pp. 91-114). Durham, NC: Duke University Press.

Radin, B.A., \& Boase, J.P. (2000). Federalism, political structure, and public policy in the United States and Canada. Journal of Comparative Policy Analysis, 2(1), 65-89.

Recycling Council of Ontario [RCO]. (2012, Sept. 17). Extended producer responsibility regulation for the collection of post consumer waste pharmaceuticals and sharps (including syringes) to be made under the Environmental Protection Act. EBR registry number 011-6671. Retrieved from https://www.rco.on.ca/uploads/File/RCO-Submission---EBR-Posting---Sharps-and-Pharmaceutical.pdf

Recycling Council of Ontario [RCO]. (2013, April 15). Guidance document: Phase 2. Retrieved from http://www.mhswphase2.ca/uploads/File/Phase-2-Guidance-Document.pdf

Reddersen, K., Heberer, T., \& Dünnbier, U. (2002). Identification and significance of phenazone drugs and their metabolites in ground- and drinking water. Chemosphere, 49(6), 539-544.

Richardson, M. L., \& Bowron, J. M. (1985). The fate of pharmaceutical chemicals in the aquatic environment. Journal of Pharmacy and Pharmacology, 37, 1-12.

Rogers, I.H., Birtwell, I.K., Kruzynski, G.M. (1986). Organic extractables in municipal wastewater, Vancouver, British Columbia. Water Pollution Research Journal of Canada, 21(2), 187-204. 
Rose, R. (1991). What is lesson drawing. Journal of Public Policy, 11(1), 3-30.

Rose, R. (1993). Lesson-Drawing in public policy: A guide to learning across time and space. Chatham, NJ: Chatham House Publishers, Inc.

Rose, R. (2005). Learning from comparative public policy: A practical guide. New York, NY: Routledge.

Ruhoy, I.S., \& Daughton, C.G. (2007). Types and quantities of leftover drugs entering the environment via disposal to sewage - Revealed by coroner records. The Science of the Total Environment, 388(1-3), 137-148.

Sacher, F., Lange, F.T., Brauch, H.J., \& Blankenhorn, I. (2001). Pharmaceuticals in groundwaters: Analytical methods and results of a monitoring program in BadenWürttemberg, Germany. Journal of Chromatography A, 938(1-2), 199-210.

Scheijgrond, J.W. (2011). Extending producer responsibility up and down the supply chain, challenges and limitation. Waste Management and Research, 29(9), 911-918.

Schramm, W. (1971, Dec.). Notes on case studies of instructional media projects. Working paper for the Academy for Educational Development, Washington, DC.

Sebastine, I.M., \& Wakeman, R.J. (2003). Consumption and environmental hazards of pharmaceutical substances in the UK. Process Safety and Environmental Protection, 81(4), 229-235.

Shoppers Drug Mart. (2012). Environment responsibility. Retrieved from http://corporate. shoppersdrugmart.ca/en-ca/social-responsibility/environment-responsibility

Song, W., Ding, Y., Chiou, C.T., \& Li, H. (2010). Selected veterinary pharmaceuticals in agricultural water and soil from land application of animal manure. Journal of Environmental Quality, 39(4), 1211-1217.

Statistics Canada. (2007). Households and the environment. Catalogue no. 11-526-XIE. Retrieved from http://publications.gc.ca/collections/collection_2007/statcan/11-526X/11-526-XIE2007001.pdf

Statistics Canada. (2009). Survey of drinking water plants 2005 to 2007. Catalogue no.16-403-X. Retrieved from http://www.gov.mb.ca/waterstewardship/licensing/wlb/pdf/water_ statistics /sc_survey_of_drinking_water_plants_2005_2007.pdf

Stewardship Ontario [SO]. (2009a, July 30). Final consolidated municipal hazardous or special waste program plan volume 2: Material-specific plans. Retrieved from 
http://www.stewardshipontario.ca/download/volume-ii-material-category-plans/

Stewardship Ontario [SO]. (2009b, July 30). Final consolidated municipal hazardous or special waste program plan volume 1 . Retrieved from http://www.stewardshipontario.ca/wp-content/uploads/2013/03/Consolidated-MHSWProgram-Plan-Volume-1-July-30-clean.pdf

Stewardship Ontario [SO]. (2009c, July 30). Final consolidated municipal hazardous or special waste (MHSW) program plan - Report on consultation. Retrieved from http://www.stewardshipontario.ca/about-us/performance-accountability/program-plans/ Stewardship Ontario [SO]. (2010a). 2010 Stewardship Ontario annual report. Retrieved from http://www.stewardshipontario.ca/sites/default/files/SO_2010_Annual_Report_ FINAL.pdf

Stewardship Ontario [SO]. (2010b). 2010 EnviroPharm conference - Stewardship Ontario Orange drop program: Pharmaceuticals \& sharps moving forward. Retrieved from http://www.enviroadvisory.com/presentations/2010/Enviropharm\%20Oct\%207\%202010 _TB.pdf

Stone, D. (1999). Learning lessons and transferring policy across time, space and disciplines. Politics, 19(1), 51-59.

Substance Abuse and Mental Health Services Administration. (2012). The DAWN report: Highlights of the 2010 drug abuse warning network (DAWN) findings on drug related emergency department visits. Retrieved from http://www.samhsa.gov/data/2k12/DAWN096/SR096EDHighlights2010.pdf

Tabak, H. H., \& Bunch, R. L. (1970). Steroid hormones as water pollutants I. Metabolism of natural and synthetic ovulation inhibiting hormones by microorganisms of activated sludge and primary settled sewage. Developments in Industrial Microbiology, 11, 367376.

Teixeira, R.M., \& Baum, T. (2001). Tourism education in the UK: Lesson drawing in educational policy. Anatolia, 12(2), 85-109.

Ternes, T.A. (1998). Occurrence of drugs in German sewage treatment plants and rivers. Water Research, 32(11), 3245-3260.

Ternes, T.A., Meisenheimer, M., McDowell, D., Sacher, F., Brauch, H.J., Haist-Gulde, B., . . . Zulei-Seibert, N. (2002). Removal of pharmaceuticals during drinking water treatment. 
Environmental Science and Technology, 36(17), 3855-3863.

Ternes, T.A., Stumpf, M., Mueller, J., Haberer, K., Wilken, R.D., Servos, M. (1999). Behavior and occurrence of estrogens in municipal sewage treatment plants - I. Investigations in Germany, Canada and Brazil. The Science of the Total Environment, 225(1-2), 81-90.

The National Return \& Disposal of Unwanted Medicines Limited. (2011). About us Background. Retrieved from http://www.returnmed.com.au/about-us.php

The National Return \& Disposal of Unwanted Medicines Limited. (n.d.). Collections. Retrieved from http://www.returnmed.com.au/collections.php

Topp, E., Monteiro, S.C., Beck, A., Coelho, B.B., Boxall, A.B.A., Duenk, P.W., .. Metcalfe, C.D. (2008). Runoff of pharmaceuticals and personal care products following application of biosolids to an agricultural field. Science of the Total Environment, 396(1), 52-59.

United States Drug Enforcement Administration [U.S. DEA]. (2013). National take-back initiative. Retrieved from http://www.deadiversion.usdoj.gov/drug_disposal/takeback/

United States Environmental Protection Agency [U.S. EPA]. (2006). Pilot study of pharmaceuticals and personal care products in fish tissue. Retrieved from http://water.epa.gov/scitech/swguidance/ppcp/fish-tissue.cfm

United States Environmental Protection Agency [U.S. EPA]. (2010, Oct. 27). Pharmaceuticals and personal care products (PPCPs) - Frequent questions. Retrieved from http://www.epa.gov/ppcp/faq.html

United States Food and Drug Administration. [U.S. FDA]. (1998, July). Guidance for industry Environmental assessment of human drug and biologics applications. Retrieved from http://www.fda.gov/downloads/Drugs/GuidanceComplianceRegulatoryInformation/Guid ances/ucm070561.pdf

United States Food and Drug Administration. [U.S. FDA]. (2011, April 14). How to dispose of unused medicines. Retrieved from http://www.fda.gov/forconsumers/consumerupdates /ucm101653.htm

United States Food and Drug Administration. [U.S. FDA]. (2013a, Feb. 13). Drugs - Disposal of unused medicines: What you should know. Retrieved from http://www.fda.gov/drugs /resourcesforyou/consumers/buyingusingmedicinesafely/ensuringsafeuseofmedicine/safe disposalofmedicines/ucm186187.htm

United States Food and Drug Administration. [U.S. FDA]. (2013b, April 12). Improperly 
discarded 'sharps' can be dangerous. Retrieved from http://www.fda.gov/forconsumers/ consumerupdates/ucm278763.htm

Valiante, U.A. (2012). In with the old and out with the new: Ontario's environmental protection act offers a new direction for extended producer responsibility. Environews, 22(1), 1-4. Retrieved from http://www.oba.org/en/pdf/sec_news_env_oct12_In_Valiante.pdf

Valiante, U.A. (2013, Mar. 6). Waste, extended producer responsibility and competition. OWMA annual general meeting. Retrieved from http://owma.org/lib/db2file.asp? fileid $=1240$

VanderZwaag, D., \& Duncan, L. (1992). Canada and environmental protection: Confident political faces, uncertain legal hands. In R. Boardman (Ed.), Canadian environmental policy: Ecosystems, politics and process (pp. 3-23). Don Mills, ON: Oxford University Press.

VanNijnatten, D.L. (1999). Participation and environmental policy in Canada and the United States: Trends over time. Policy Studies Journal, 27(2), 267-287.

VanNijnatten, D.L. (2002). The bumpy journey ahead: Provincial environmental policies and national environmental standards. In D.L. VanNijnatten, \& R. Boardman (Eds.), Canadian environmental policy: Context and cases (2nd ed.). (pp. 145-170). Don Mills, ON: Oxford University Press.

VanNijnatten, D.L, \& Boychuck, G.W. (2006). Comparative state and provincial public policy. In C. Dunn (Ed.), Provinces: Canadian provincial politics (2nd ed.). (pp. 487-505). Peterborough, ON: Broadview Press.

Vieno, N.M., Tuhkanen, T., \& Kronberg, L. (2005). Seasonal variation in the occurrence of pharmaceuticals in effluents from a sewage treatment plant and in the recipient water. Environmental Science \& Technology, 39(21), 8220-8226.

Vollmer, G. (2010). Disposal of pharmaceutical waste in households - A European survey. In K. Kümmerer \& M. Hempel (Eds.), Green and sustainable pharmacy (pp. 165-178). Berlin, Germany: Springer.

Waste Diversion Ontario [WDO]. (2012, Nov.). Waste diversion Ontario procedures for industry stewardship plans. Retrieved from http://www.wdo.ca/files/8613/5854/1895/Procedures _for_Industry_Stewardship_Plans_ISPs.pdf

Waste Diversion Ontario [WDO]. (2013). Governance. Retrieved from 
http://www.wdo.ca/about/governance/

Waste Diversion Organization. (2000, Sept. 1). Report to the minister of the environment: Achieving sustainable municipal waste diversion programs in Ontario. Retrieved from http://www.ontla.on.ca/library/repository/mon/ont/ev/2000/sept1full.pdf

Watts, C.D., Crathorne, B., Fielding, M., \& Steel, C.P. (1984). Identification of non-volatile organics in water using field desorption mass spectrometry and high performance liquid chromatography. In G. Angeletti \& A. Bjørseth (Eds.), Analysis of organic micropollutants in water. Proceedings of the third European symposium held in Oslo, Norway, September 19-21, 1983 (pp. 120-131). Dordrecht, Holland: D. Reidel Publishing Company.

Webb, K. (2004). Voluntary codes: Private governance, the public interest and innovation. Ottawa, ON: Carleton Research Unit for Innovation, Science and Environment, Carleton University.

Webb, K. (2007). Voluntary environmental initiatives: The state of play in 2007, and recommendations concerning the Ontario approach. Ottawa, ON: Pollution Probe.

Welsh, M. (2011, March 27). Taxpayers hit with $\$ 18$ million bill to pay for eco-fee fall-out. Toronto Star. Retrieved from http://www.thestar.com/news/canada/article/962062-taxpayers-hit-with-18-million-bill-to-pay-for-eco-fee-fall-out

Wingspread Conference on the Precautionary Principle. (1998). The wingspread consensus statement on the precautionary principle. Retrieved from: http://www.sehn.org/wing.html

Wolman, H. (1992). Understanding cross national policy transfers: The case of Britain and the US. Governance, 5(1), 27-45.

World Health Organization [WHO]. (1999). Guidelines for safe disposal of unwanted pharmaceuticals in and after emergencies. Retrieved from http://www.who.int/ water_sanitation_health/medicalwaste/unwantpharm.pdf

World Health Organization [WHO]. (2011). Pharmaceuticals in drinking-water. Public health and environment - Water, sanitation, hygiene and health. Retrieved from http://www.who.int/water_sanitation_health/publications/2011/pharmaceuticals_2011 0601.pdf

World Health Organization [WHO]. (2012). Pharmaceuticals in drinking-water. Retrieved from http://extranet.who.int/iris/bitstream/10665/44630/1/9789241502085_eng.pdf 
World Health Organization [WHO]. (n.d.). Health impacts of health-care waste. Retrieved from http://www.who.int/water_sanitation_health/medicalwaste/020to030.pdf

Yin, R.K. (2009). Case study research: Design and methods ( $4^{\text {th }}$ ed.). Thousand Oaks, CA: Sage Publications, Inc.

Zuccato, E., Calamari, D., Natangelo, M., \& Fanelli, R. (2000). Presence of therapeutic drugs in the environment. The Lancet, 355(9217), 1789-1790.

Zühlke, S., Dünnbier, U., \& Heberer, T. (2004). Detection and identification of phenazone-type drugs and their microbial metabolites in ground and drinking water applying solid-phase extraction and gas chromatography with mass spectrometric detection. Journal of Chromatography A, 1050(2), 201-209.

\section{Federal Statutes and Regulations}

Canadian Environmental Protection Act, 1999, S.C. 1999, c. 33.

Competition Act, R.S.C. 1985, c. C-34.

Constitution Act, 1867, 30 \& 31 Victoria, c. 3. (U.K.).

Controlled Drugs and Substances Act, S.C. 1996, c. 19.

Criminal Code of Canada, R.S.C. 1985, c. C-46.

Food and Drugs Act, R.S.C. 1985, c. F-27.

New Substances Notification Regulations (Chemicals and Polymers), SOR/2005-247, enacted under the Canadian Environmental Protection Act.

\section{Provincial Statutes and Regulations}

\section{British Columbia}

Environmental Management Act, S.B.C. 2003, c. 53.

Recycling Regulation, B.C. Reg. 449/2004, enacted under the Environmental Management Act. The Post-Consumer Residual Stewardship Program Regulation, B.C. Reg. 111/97, enacted under the Waste Management Act. [NOTE: Repealed by the Recycling Regulation, B.C. Reg. 449/2004]. 


\section{Manitoba}

Household Hazardous Material and Prescribed Material Stewardship, Man. Reg. 16/2010, enacted under The Waste Reduction and Prevention Act.

The Waste Reduction and Prevention Act, C.C.S.M. 1990, c. W40.

\section{Ontario}

Collection of Pharmaceuticals and Sharps - Responsibilities of Producers, O. Reg. 298/12, enacted under the Environmental Protection Act.

Environmental Protection Act, R.S.O. 1990, c. E.19.

Exemption re Section 31 of the Act, O. Reg. 396/10, enacted under the Waste Diversion Act. Industrial, Commercial and Institutional Source Separation Programs, O. Reg. 103/94, enacted under the Environmental Protection Act.

Municipal Hazardous or Special Waste, O. Reg. 542/06, enacted under the Waste Diversion Act, as am. by O. Reg. 11/12.

Packaging audits and packaging reduction work plans, O. Reg. 104/94, enacted under the Environmental Protection Act.

Recycling and Composting of Municipal Waste, O. Reg. 101/94, enacted under the Environmental Protection Act.

Waste Audits and Waste Reduction Work Plans, O. Reg. 102/94, enacted under the Environmental Protection Act.

Waste Diversion Act, S.O. 2002, c. 6.

\section{Municipal By-Laws}

City of Ottawa. By-Law 2003-514. Adopted 2004-01-01, <http://ottawa.ca/en/residents/lawslicenses-and-permits/laws/sewer-use-law-no-2003-514>.

City of Toronto. By-Law 457-2000. Adopted 2000-07-06, <http://www.toronto.ca/legdocs/by laws/2000/law0457.pdf>.

City of Vancouver. By-Law 8417. Adopted 2001-12-13, <http://app.vancouver.ca/bylaw_net/ HttpFind.aspx?\&txtKeywordCons=\%208417\&searchBy=keywordCons $>$.

Metro Vancouver. By-Law 275, 2012. Adopted 2012-10-26, <http://www.metrovancouver.org /boards/bylaws/Bylaws/GVSDD_Bylaw_275.pdf>. 


\section{International Directives, Statutes, Regulations and Treaties}

Alameda County Safe Drug Disposal Ordinance, Ordinance 0-2012-27 (2012) [Alameda Government, California, U.S.A.].

Consolidated Version of the Treaty on the Functioning of the European Union, 2012/C326/01, O.J. C326/47 (2012).

Controlled Substances Act, 21 U.S.C. 801 (1970) [U.S.A.].

European Union Directive 2001/82/EC, The European Parliament and the Council of 6 November 2001 on the Community code relating to veterinary medicinal products, O.J. L311/1 (2001).

European Union Directive 2001/83/EC, The European Parliament and the Council of 6 November 2001 on the Community code relating to medicinal products for human use, O.J. L311/67 (2001).

European Union Directive 2004/27/EC, The European Parliament and the Council of 31 March 2004 amending Directive 2001/83/EC on the Community code relating to medicinal products for human use, O.J. L136/34 (2004).

National Environmental Policy Act, 42 U.S.C. 4321 (1970) [U.S.A.]

Secure and Responsible Drug Disposal Act of 2010, Public Law 111-273, 124 Stat. 2858 (2010) [U.S.A.].

\section{Cases}

114957 Canada Ltée (Spraytech, Société d'arrosage) v. Hudson (Town), 2001 SCC 40, [2001] 2 S.C.R. 241, (2001), 200 D.L.R. (4th) 419.

Croplife Canada v. Toronto (City) (2003), 68 O.R. (3d) 520 (ON S.C.) (Motions Court). Croplife Canada v. Toronto (City) (2005), 75 O.R. (3d) 357, 254 D.L.R. (4th) 40, 198 O.A.C.

35 (Ont. C.A.). Leave to Appeal Dismissed by Supreme Court of Canada, [2005] S.C.C.A. No. 329 (QL).

Spraytech v. Hudson, see 114957 Canada Ltée (Spraytech, Société d'arrosage) v. Hudson (Town). 